\title{
PROGRAMA DE AVALIAÇÃO DA DOR NEONATAL (PAD-NEO): AVALIAÇÃO DE CURSO ONLINE SOB A PERSPECTIVA DE ESPECIALISTAS
}

Versão corrigida da Dissertação apresentada ao Programa de Pós-Graduação em Enfermagem da Escola de Enfermagem da Universidade de São Paulo para obtenção do título de Mestra em Ciências

Área de concentração: Cuidado em Saúde Orientadora: Prof. ${ }^{\text {D }}$ Dra . Mariana Bueno

\section{VERSÃO CORRIGIDA}

A versão original encontra-se disponível na Biblioteca da Escola de Enfermagem da Universidade de São Paulo e na Biblioteca Digital de Teses e Dissertações da Universidade de São Paulo. 
AUTORIZO A REPRODUÇÃO E DIVULGAÇÃO TOTAL OU PARCIAL DESTE TRABALHO, POR QUALQUER MEIO CONVENCIONAL OU ELETRÔNICO, PARA FINS DE ESTUDO E PESQUISA, DESDE QUE CITADA A FONTE.

Assinatura:

Data:

\section{Catalogação na Publicação (CIP) \\ Biblioteca "Wanda de Aguiar Horta" \\ Escola de Enfermagem da Universidade de São Paulo}

Silva, Fernanda Felipe Ferreira da

Programa de avaliação da dor neonatal (PAD-Neo): avaliação de curso online sob a perspectiva de especialistas / Fernanda Felipe Ferreira da Silva. São Paulo, 2017.

$128 \mathrm{p}$.

Dissertação (Mestrado) - Escola de Enfermagem da Universidade de São Paulo.

Orientadora: Prof. ${ }^{\text {a }}$ Dr. ${ }^{\text {a }}$ Mariana Bueno

Área de concentração: Cuidado em Saúde

1. Educação à distância. 2. Enfermagem neonatal. 3. Dor. 4. Tecnologia educacional. 5. Recém-nascido. I. Título. 
Nome: Fernanda Felipe Ferreira da Silva

Título: Programa de Avaliação da Dor Neonatal (PAD-Neo): avaliação de curso online sob a perspectiva de especialistas.

Dissertação apresentada ao Programa de Pós-Graduação em Enfermagem da Escola de Enfermagem da Universidade de São Paulo para obtenção do título de Mestra em Ciências.

Aprovado em:

\section{Banca Examinadora}

Prof. Dr. Instituição:

Julgamento: Assinatura:

Prof. Dr. Instituição:

Julgamento: Assinatura:

Prof. Dr. Instituição:

Julgamento: Assinatura: 


\section{Dedicatória}

Dedico este trabalho aos queridos Felipe e Denize, esta vitória não é só minha.

Ao Rafael pelo exemplo de dedicação e pelo aprendizado e crescimento constantes.

Aos meus familiares e amigos por todo apoio e carinho.

E a todos os pequenos pacientes que se beneficiarão deste estudo no futuro. 


\section{Agradecimenta Especial}

À Prof ${ }^{a}$. Dr . Mariana Bueno, orientadora, mestre, confidente e exemplo de enfermeira, docente e pessoa. Minha gratidão e respeito por todo esforço, comprometimento, profissionalismo, pela luz, pela paciência, por todo aprendizado e por me dar a oportunidade de, ao seu lado, construir o meu caminho. Sem você nada disso seria possível! 


\section{Agradecimentos}

Primeiramente gostaria de agradecer minha amada mãe Denize e meu tio "pai" Felipe, que, desde sempre, fizeram todo o possível para que eu alcançasse meus objetivos, acompanharam meus passos, me incentivaram na busca pela independência e a ser uma pessoa melhor! Amo muito vocês!

Ao querido Rafael, meu grande amigo, parceiro, cúmplice e amado. Obrigada por ter ficado do meu lado durante toda essa jornada e por simplesmente acreditar. Agradeço pelo entusiasmo, pelas palavras de incentivo, por comemorar cada vitória como se fosse sua, por tornar tudo mais leve e pelas risadas nos momentos mais necessários.

Aos meus tios queridos, Zé e Marily, muito obrigada por torcerem sempre por mim e por todo carinho e amor, tenho sorte de tê-los em minha vida.

Aos meus queridos Tatiana, Herika, Heitor, Wagner e Mariana. Muito obrigada pelo apoio, carinho e preocupação durante esta jornada.

Às amigas conquistadas durante o mestrado, em especial minhas "irmãs" que tive a sorte de encontrar, Rosely, Ligyana, Thaís, Gisele, Carol, Mily, Erika, Talita, Danila e Taine. Quanta felicidade poder contar com vocês, obrigada pelas risadas, pela troca de conhecimento e por tanto carinho!

Aos meus grandes e queridos amigos que me acompanham desde a graduação e vibraram comigo desde o primeiro dia de mestrado, Cinthya, Cris, Camila Kaory, Felipe, Erika, Luisa, Sabrina, Uyara, Viviane e Isabela. Muito obrigada por tantos anos de amizade, vocês estarão pra sempre no meu coração!

A quem já não está mais aqui, mas que meus pensamentos carinhosamente trazem de volta. Minha doce "nonna" Graciosa, que, tão amável e delicadamente, cuidou de mim e me ensinou a caminhar. Sua falta é sentida todos os dias. E ao meu pai, obrigada por me tornar mais forte.

Aos meus amores, Keko e Bowie, por me encherem de amor e pela companhia em tantas noites de trabalho. 
Muito obrigada aos membros e colegas do Grupo de Pesquisa Enfermagem e Cuidado Neonatal (GPECNEO), por tantos momentos ricos de trocas de experiência e pela colaboração e crescimento durante esses anos.

Agradeço aos queridos docentes e funcionários do Departamento de Enfermagem Materno-Infantil e Psiquiátrica, em especial à professora Márcia, professora Amélia, professora Maria Alice, professora Emília e Patrícia, por compartilharem suas experiências e conhecimentos e às amáveis e atenciosas Fernanda e Ana Clélia!

Às queridas Professoras Claudia e Heloísa, que tão gentilmente se mostraram disponíveis e preocupadas.

Obrigada também aos queridos colegas da graduação da Escola de Enfermagem da USP, que torceram por mim e me transmitiam muito amor e boas energias.

Obrigada a todos os funcionários da EEUSP, que, indiretamente, auxiliaram na construção desse projeto.

Um agradecimento especial aos profissionais especialistas que participaram deste estudo.

Ao CNPq e à IASP pelo auxílio financeiro para o desenvolvimento e avaliação do Programa de Avaliação da Dor Neonatal.

À agência de fomento CAPES, pela bolsa de estudos. 
"O sofrimenta humana sá é intaleráuel quanda ninguém cuida.

Cicely Saunders (1918 - 2005) Precursora dos Cuidados Paliativos moderno 


\section{RESUMO}

Silva FFF. Programa de Avaliação da Dor Neonatal (PAD-Neo): avaliação de curso online sob a perspectiva de especialistas [dissertação]. São Paulo: Escola de Enfermagem, Universidade de São Paulo; 2017.

Introdução: Atualmente, a literatura evidencia que os profissionais de saúde reconhecem a ocorrência de dor no recém-nascido $(R N)$, embora realizem a avaliação de forma empírica e não sistematizada. Assim, os próprios profissionais apontam a necessidade de treinamento e capacitação em relação à avaliação da dor nesta população. Dessa forma, destaca-se a educação a distância (EAD) como alternativa de organização de novos espaços assíncronos de difusão do conhecimento por oferecer diversas vantagens. O Programa de Avaliação da Dor Neonatal (PAD-Neo) foi desenvolvido com vistas a aprimorar o conhecimento de alunos e profissionais de saúde sobre essa temática. O PAD-Neo está hospedado no Ambiente Virtual de Aprendizagem (AVA) Moodle extensão e é composto por 10 módulos, cujas temáticas incluem definições e conceitos básicos de fisiologia da dor, componentes de avaliação da dor no RN, princípios de mensuração e avaliação da dor neonatal, além de apresentar detalhadamente cinco instrumentos específicos e validados para avaliar a dor em RN. Os módulos são compostos por videoaulas, vídeos, imagens, textos para leitura complementar, fóruns de discussão, exercícios, entre outros. Objetivo: Avaliar a qualidade do curso online PAD-Neo, sob a perspectiva de especialistas. Métodos: Trata-se de um estudo exploratório descritivo, no qual oito especialistas em dor neonatal, oito especialistas em neonatologia e oito especialistas em EAD, que atenderam aos critérios de elegibilidade estabelecidos, foram convidados a avaliar o PAD-Neo, por intermédio do envio de uma carta convite eletrônica. A avaliação do curso online foi realizada utilizando-se um formulário constituído por questões de caracterização dos especialistas e 20 questões relacionadas à avaliação da aparência e do conteúdo do curso. Para cada um dos 20 itens avaliados a pontuação variou de 0 a 1 , sendo que valores médios inferiores a 0,70 foram considerados indicativos para modificações no curso. Resultados: As 24 especialistas participantes do estudo são do gênero feminino, com idade média de 43 anos. Dessas, dezoito (75\%) são graduadas em enfermagem, quatro (16,7\%) psicólogas, uma (4,2\%) fisioterapeuta e uma $(4,2 \%)$ designer instrucional. A maioria das especialistas possui título de Doutora 
$(62,5 \%)$ e são docentes universitárias $(41,6 \%)$. Quanto às médias das respostas das especialistas nos itens avaliados, todos os valores médios ficaram acima de 0,70 , a saber: navegação livre (média 0,92), clareza das informações $(0,97)$, facilidade de localização das informações $(0,89)$, pertinência do conteúdo $(0,96)$, contextualização $(0,94)$, correção de conteúdo $(0,98)$, múltiplas janelas $(0,97)$, facilidade de aprendizagem na interação $(0,96)$, eficiência de utilização $(0,94)$, facilidade de retorno $(0,92)$, ergonomia $(0,94)$, estética $(0,96)$, marcas especiais $(0,93)$, recursos audiovisuais $(0,85)$, referências $(0,93)$, interatividade $(0,82)$, gestão de erros $(0,85)$, ajuda aos usuários $(0,81)$, qualidade das informações $(0,96)$ e portabilidade $(0,97)$. Embora os comentários dos especialistas expressassem satisfação com a organização e apresentação do curso online, houve sugestões para incluir um maior número de artigos para leitura complementar em língua portuguesa, uma maior diversidade de recursos audiovisuais e um fórum de dúvidas para melhorar a interação do aluno com o curso. Estas sugestões foram acatadas. Conclusão: O PAD-Neo foi considerado válido do ponto de vista de aparência e de conteúdo por especialistas das áreas de dor neonatal, neonatologia e EAD. O curso online pode ser compreendido como uma proposta educacional inovadora e válida para o aprendizado sobre avaliação da dor neonatal. Estudos futuros são necessários para que se realize a avaliação do curso online a partir da perspectiva de usuários.

Descritores: Educação a Distância, Enfermagem Neonatal, Dor, Avaliação da Dor, Tecnologia Educacional, Recém-nascido. 


\section{ABSTRACT}

Silva FFF. Neonatal Pain Assessment Program (PAD-Neo): evaluation of an online course from the perspective of experts [dissertation]. São Paulo (SP), Brasil: Escola de Enfermagem, Universidade de São Paulo; 2017.

Introduction: Recently published literature demonstrates that healthcare professionals recognize the occurrence of neonatal pain, however, pain assessment continues to be performed empirically and in a not systematized way. Health care professionals recognize the need for training courses related to neonatal pain assessment. Distance education is an alternative for asynchronous and organized spaces to disseminate knowledge and it presents benefits. The Neonatal Pain Assessment Program (PAD-Neo) was created to enhance students and healthcare professionals' knowledge on this topic. PAD-Neo is hosted by Modular Object-Oriented Dyna- mic Learning Environment (Moodle), a free platform, and consists of 10 modules which contents include definitions and basic concepts on physiology of pain, neonatal pain indicators, principles of neonatal pain assessment and measurement, and training on five specific and validated neonatal pain assessment scales. Modules are composed of video lessons, videos, images, complementary reading texts, discussion forums, exercises, amongst other resources. Objetctive: To evaluate the quality of the PAD-Neo from the perspective of experts. Methods: This is an exploratory descriptive study. Eight specialists on neonatal pain, eight specialists in neonatal care and eight specialists in distance education who met the eligibility criteria were invited to evaluate the PAD-Neo. An invitation letter was sent electronically and the course evaluation was performed by using a form composed by 20 questions related to appearance and content of the course. For each of the 20 items evaluated, scores ranged from 0 to 1 , and average values minor than 0.70 were deem to be modified. Results: The 24 participants in this study are female, with a mean age of 43 years old. 18 (75\%) specialists have a baccalaureate degree in nursing, four (16.7\%) in psychology, one $(4.2 \%)$ in physiotherapy and one (4.2\%) in instructional design. Most of the experts have a doctorate degree (62.5\%) and are university professors (41.6\%). Regarding to specialists answers', all the items' averages were higher than 0.70 , as it follows: free navigation (average 0.92), clarity of information (0.97), ease of information location (0.89), content relevance (0.96), contextualization (0.94), content correction (0.98), 
multiple windows (0.97), ease of learning interaction (0.96), efficiency of usability (0.94), ease of return (0.92) , ergonomics (0.94), aesthetics (0.96), special marks (0.93), audiovisual resources (0.85), references (0.93), interactivity (0.82), bug fixes (0.85), help resource (0.81), quality of information (0.96) and portability (0.97). Although experts' comments expressed satisfaction with the online course organization and presentation, suggestions were made regarding the inclusion of complementary reading resources in Portuguese, increasing the diversity of audiovisual resources, and an enquiry forum in order to improve student's interaction. These suggestions were accepted. Conclusion: Appearance and content of the PADNeo was considered as validated by experts in the fields of neonatal pain, neonatal care and distance education. The online course can be considered as an innovative and validated educational proposal for neonatal pain assessment learning. Future studies are needed to evaluate the course from the perspective of the users.

Descriptors: Education, Distance, Neonatal Nursing, Pain, Pain Assessments, Educational Technology, Infant, Newborn. 


\section{LISTA DE ILUSTRAÇÕES}

Figura 1- Vídeoaula com utilização de avatar de representação digital humana. ..... 45

Figura 2 - Aula interativa desenvolvida com o Software Articulate Storyline ${ }^{\circledR}$. .......... 45

Figura 3 - Síntese das aulas apresentadas em cada módulo no formato PDF........ 46

Figura 4- Vídeo para realização dos exercícios.................................................... 47

Figura 5 - Imagem utilizada nos exercícios de avaliação da dor. ............................48

Figura 6 - Estudo de Caso para avaliação sobre escala EDIN. ............................... 49

Figura 7 - Questões dissertativas de avaliação de conteúdo.................................. 49

Figura 8 - Utilização de recursos de hipertexto nas aulas. ...................................50

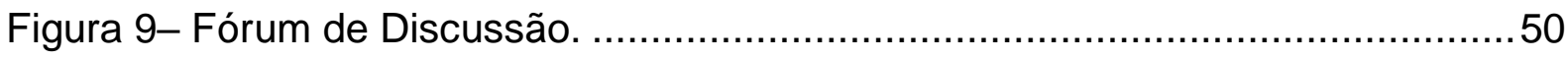

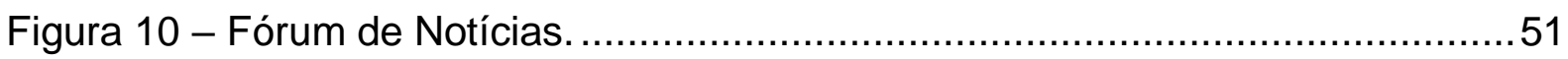

Figura 11- Apresentação de conceito em única janela. .........................................63

Figura 12- Apresentação de menu e de orientações de módulo..............................65

Figura 13 - Orientações para clicar nos botões durante a aula interativa. ................71

Figura 14- Tela da aula interativa do módulo sobre a escala NIPS. ......................74

Figura 15- Tela da aula interativa do módulo sobre a escala EDIN. .......................74

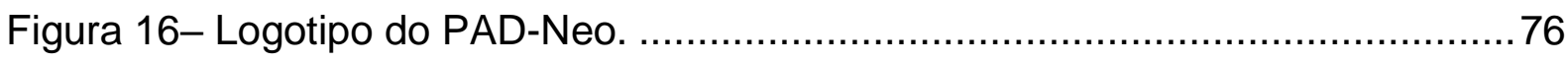

Figura 17- Marcas especiais no módulo sobre a escala BIIP. ................................78 


\section{LISTA DE TABELAS}

Tabela 1 - Respostas da avaliação do item "Navegação Livre" do curso online, de acordo com os especialistas. São Paulo, 2017. ( $n=24)$

Tabela 2 - Respostas da avaliação do item "Clareza das informações" do curso online, de acordo com os especialistas. São Paulo, 2017. ( $n=24)$

Tabela 3 - Respostas da avaliação do item "Facilidade de localização" do curso online, de acordo com os especialistas. São Paulo, 2017. ( $n=24)$ 66

Tabela 4 - Respostas da avaliação do item "Pertinência do conteúdo" do curso online, de acordo com os especialistas. São Paulo, 2017. ( $n=24)$ .67

Tabela 5 - Respostas da avaliação do item "Contextualização" do curso online, de acordo com os especialistas. São Paulo, 2017. ( $n=24)$

Tabela 6 - Respostas da avaliação do item "Correção de conteúdo" do curso online, de acordo com os especialistas. São Paulo, 2017. (n=24)

Tabela 7 - Respostas da avaliação do item "Múltiplas janelas" do curso online, de acordo com os especialistas. São Paulo, 2017. ( $n=24)$ 70

Tabela 8 - Respostas da avaliação do item "Facilidade de aprendizagem na interação" do curso online, de acordo com os especialistas. São Paulo, 2017. ( $n=24)$ .71

Tabela 9- Respostas da avaliação do item "Eficiência na utilização" do curso online, de acordo com os especialistas. São Paulo, 2017. ( $n=24)$

Tabela 10 - Respostas da avaliação do item "Facilidade de retorno" do curso online, de acordo com os especialistas. São Paulo, 2017. (n=24) 73

Tabela 11 - Respostas da avaliação do item "Ergonomia" do curso online, de acordo com os especialistas. São Paulo, 2017. ( $n=24)$ .75

Tabela 12 - Respostas da avaliação do item "Estética" do curso online, de acordo com os especialistas. São Paulo, 2017. ( $n=24)$

Tabela 13 - Respostas da avaliação do item "Marcas especiais" do curso online, de acordo com os especialistas. São Paulo, 2017. ( $n=24)$

Tabela 14 - Respostas da avaliação do item "Recursos audiovisuais" do curso online, de acordo com os especialistas. São Paulo, 2017. ( $n=24)$ 80

Tabela 15 - Respostas da avaliação do item "Referências" do curso online, de acordo com os especialistas. São Paulo, 2017. ( $n=24)$ 
Tabela 16 - Respostas da avaliação do item "Interatividade" do curso online, de acordo com os especialistas. São Paulo, 2017. $(n=24)$

Tabela 17 - Respostas da avaliação do item "Gestão de erros" do curso online, de acordo com os especialistas. São Paulo, 2017. ( $n=24)$

Tabela 18 - Respostas da avaliação do item "Ajuda aos usuários" do curso online, de acordo com os especialistas. São Paulo, 2017. ( $n=24)$

Tabela 19 - Respostas da avaliação do item "Qualidade das informações" do curso online, de acordo com os especialistas. São Paulo, 2017. $(n=24)$ .85

Tabela 20 - Respostas da avaliação do item "Portabilidade" do curso online, de acordo com os especialistas. São Paulo, 2017. (n=24). 


\title{
LISTA DE SIGLAS
}

\author{
AAP American Academy of Pediatrics \\ ADDIE Analysis, Design, Development, Implementation e Evaluation \\ BIIP Behavioral Indicators of Infant Pain \\ BPSN Bernese Pain Scale for Neonates \\ CCEAD Coordenação Central de Educação a Distância \\ CD-ROM Compact Disc Read-Only Memory \\ CNPq Conselho Nacional de Desenvolvimento Científico e Tecnológico \\ CPP Contato Pele a Pele \\ CRIES Crying Requires Oxygen for Saturation Above 95\%, Increased \\ Vital Signs, Expression, Sleepless \\ DAN Douleur Aiguë du Nouveau-Né \\ EAD Ensino A Distância \\ ECR Ensaio Clínico Randomizado \\ EDIN Échelle Douleur Inconfort Nouveau-Né \\ EEG Eletroencefalograma \\ EEUSP Escola de Enfermagem da Universidade de São Paulo \\ FC Frequência Cardíaca
}

FMRI Ressonância Magnética Funcional (Functional Magnetic Ressonance Imaging)

FR Frequência Respiratória

GEPETE Grupo de Estudos e Pesquisas de Tecnologia da Informação nos Processos de Trabalho em Enfermagem

GPECNEO Grupo de Pesquisa Enfermagem e Cuidado Neonatal 


\begin{tabular}{|c|c|}
\hline $\mathrm{HbO}_{2}$ & Oxiemoglobina \\
\hline HCFMUSP & $\begin{array}{l}\text { Hospital das Clínicas da Faculdade de Medicina da Universidade } \\
\text { de São Paulo }\end{array}$ \\
\hline HUUSP & Hospital Universitário da Universidade de São Paulo \\
\hline IASP & International Association for the Study of Pain \\
\hline ICR & Instituto da Criança \\
\hline IG & Idade Gestacional \\
\hline Moodle & Modular Object-Oriented Dynamic Learning Environment \\
\hline NAAN & National Association of Neonatal Nurses \\
\hline NFCS & Neonatal Facial Coding System \\
\hline NIPS & Neonatal Infant Pain Scale \\
\hline NPASS & Neonatal Pain Agitation and Sedation Scale \\
\hline NIRS & $\begin{array}{l}\text { Espectroscopia De Infravermelho Próximo (Near-Infrared } \\
\text { Spectroscopy) }\end{array}$ \\
\hline PA & Pressão Arterial \\
\hline PAD-Neo & Programa de Avaliação da Dor Neonatal \\
\hline PAIN & Pain Assessment in Neonate \\
\hline PDF & Portable Document Format \\
\hline PIC & Pressão Intracraniana \\
\hline PIPP & Premature Infant Pain Profile \\
\hline PIPP-R & Premature Infant Pain Profile - Revised \\
\hline PPGE & Programa de Pós-Graduação em Enfermagem \\
\hline PS & Pronto-Socorro \\
\hline $\mathrm{RCP}$ & Relieving Childrens Pain \\
\hline RN & Recém-Nascido \\
\hline RNPT & Recém-Nascido Pré-Termo \\
\hline $\mathrm{SatO}_{2}$ & Saturação de Oxigênio \\
\hline
\end{tabular}


TIC

UCIN

UMC

UTIN

UTIP
Tecnologias de Informação e Comunicação

Unidade de Cuidados Intermediários Neonatal

Unidade Mãe Canguru

Unidades de Terapia Intensiva Neonatal

Unidades de Terapia Intensiva Pediátrica 


\section{SUMÁRIO}

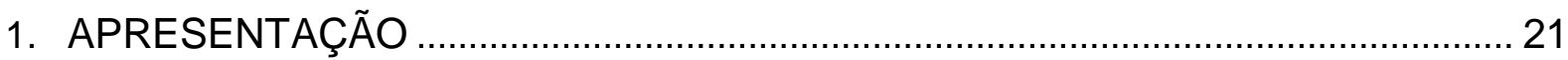

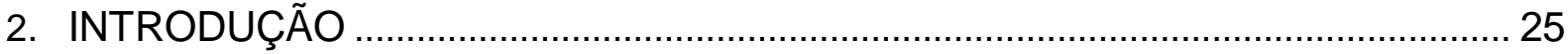

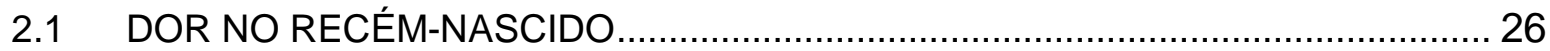

2.2 PERCEPÇÃO DOS PROFISSIONAIS DE SAÚDE SOBRE AVALIAÇÃO DA DOR

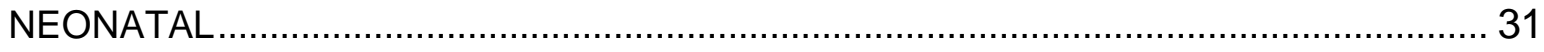

2.3 EDUCAÇÃO A DISTÂNCIA EM ENFERMAGEM …….......................................... 36

2.4 PROGRAMA DE AVALIAÇÃO DA DOR NEONATAL …….................................... 41

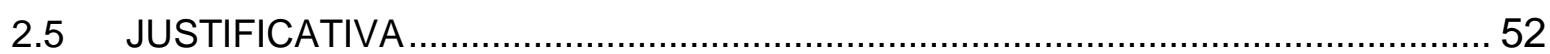

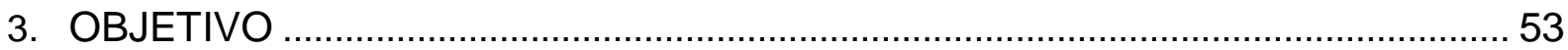

4. MÉTODO

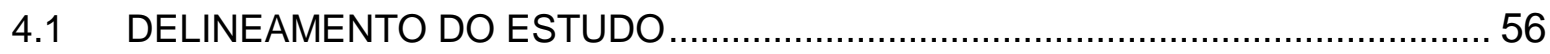

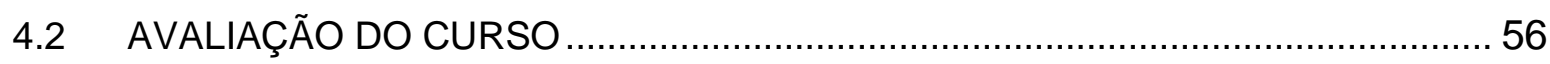

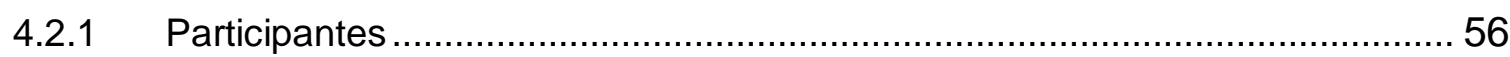

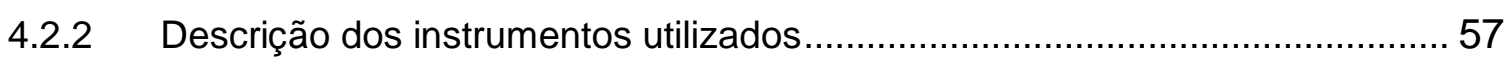

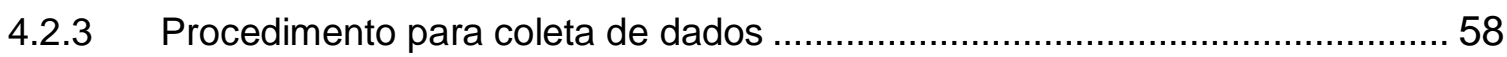

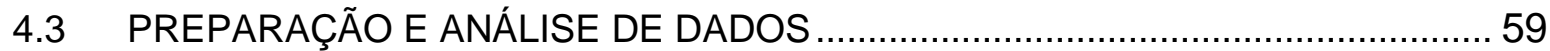

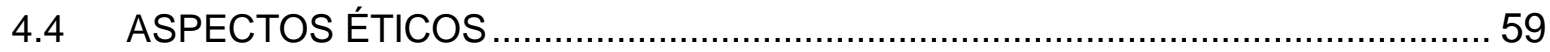

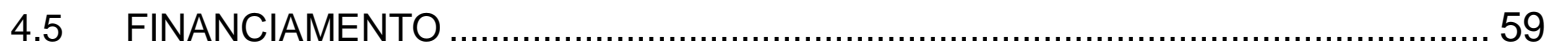

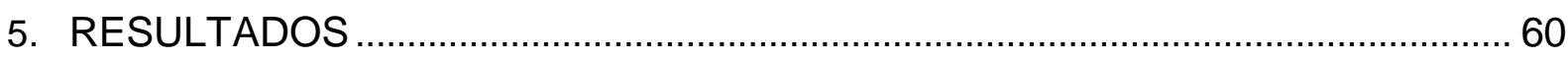

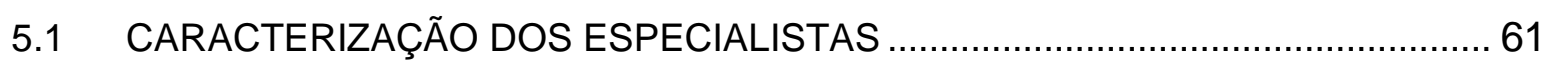

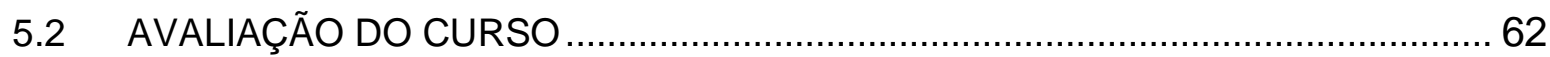

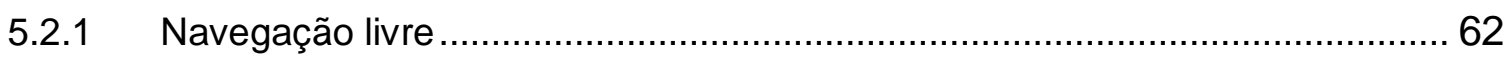

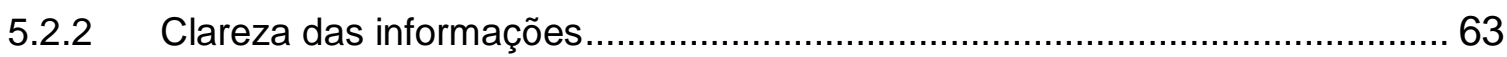

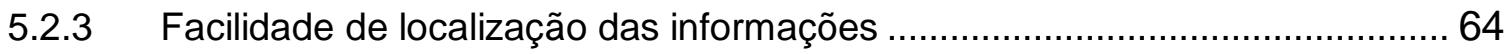

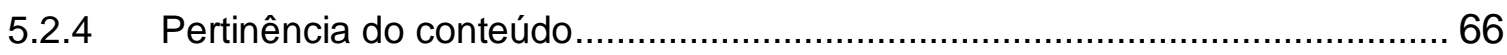

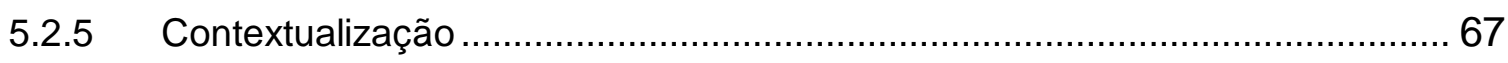

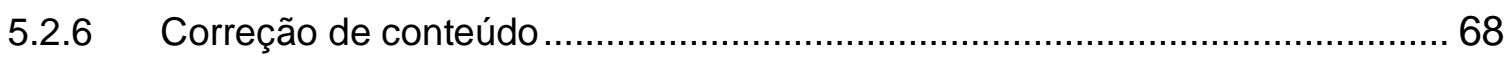

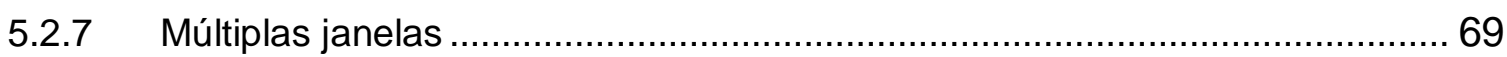

5.2.8 Facilidade de aprendizagem na interação ………………............................. 70

5.2.9 Eficiência de utilização ........................................................................ 71

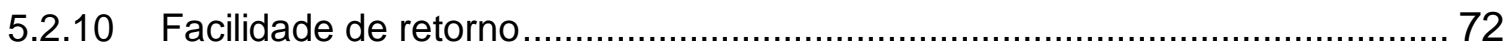

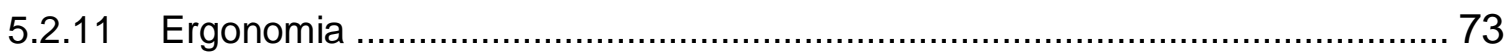

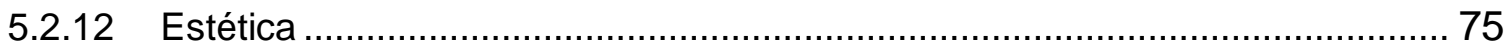

5.2.13 Marcas especiais ................................................................................ 77 


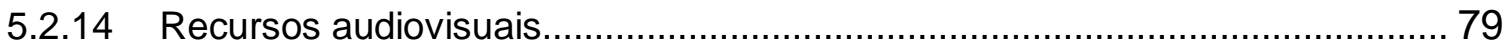

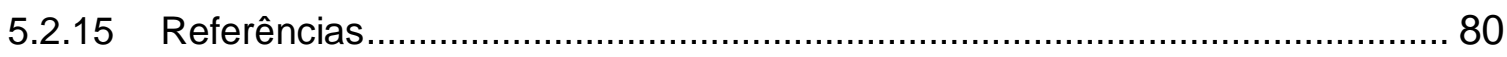

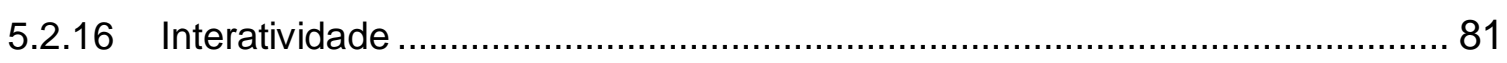

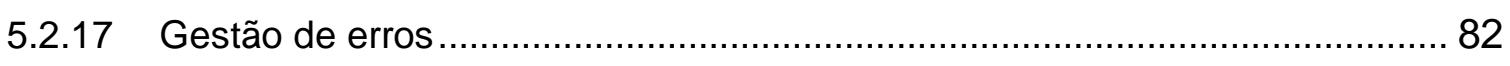

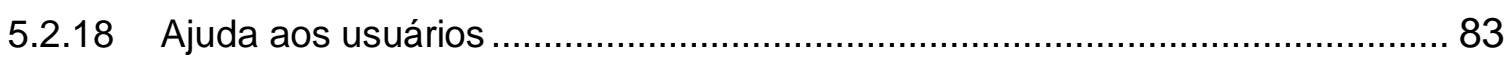

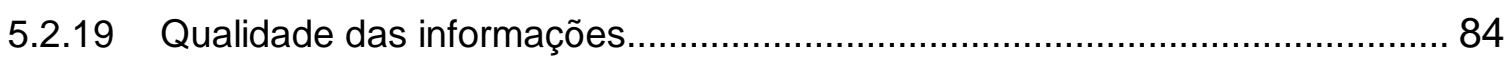

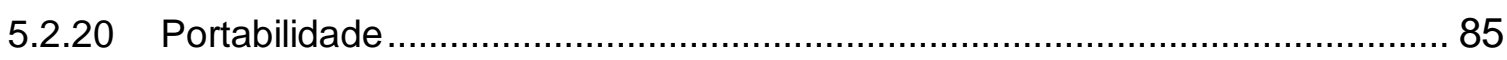

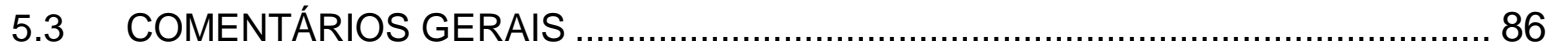

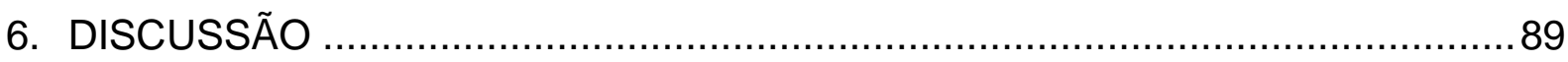

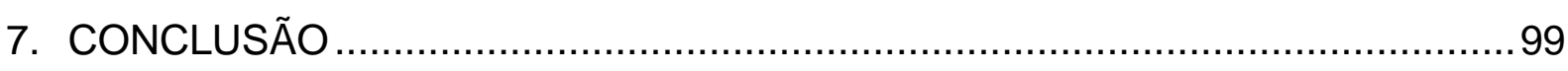

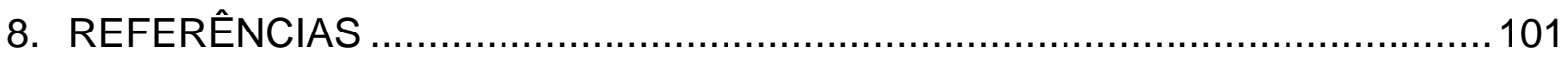

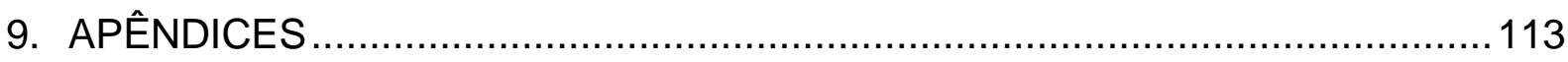

10. ANEXOS 
Apresentaçãa 



\section{APRESENTAÇÃO}

Meu interesse em estudar a temática da dor em recém-nascidos (RN) teve início durante a graduação em Enfermagem, na Escola de Enfermagem da Universidade de São Paulo - EEUSP. Em 2013, tive a oportunidade de pesquisar os cuidados paliativos no neonato em minha iniciação científica e esse tema logo se tornou meu tema de trabalho de conclusão de curso, para obtenção do título de Bacharel em Enfermagem. A partir da leitura de artigos científicos ao longo da iniciação adquiri maior base de conhecimento teórico sobre a dor do neonato, bem como sobre formas de avaliação da dor, métodos analgésicos farmacológicos e não farmacológicos, visto que a dor é muito frequente em doenças terminais.

Ao longo da graduação, realizei estágios no Alojamento Conjunto e no Berçário do Hospital Universitário da Universidade de São Paulo - HU-USP, e na Unidade de Terapia Intensiva Pediátrica do Instituto da Criança do Hospital das Clínicas da Faculdade de Medicina da Universidade de São Paulo - Icr-HCFMUSP. Durante essas experiências a avaliação da dor foi uma das minhas prioridades na realização dos cuidados diários, na qual tive a oportunidade de tentar aplicar meus conhecimentos na prática.

Apesar de não ter experiência como profissional na área, durante os estágios curriculares realizados em minha graduação, pude perceber que a equipe de enfermagem carece de informações sobre as consequências negativas da dor no crescimento e desenvolvimento do RN. Além disso, a falta de conhecimento, a respeito da fisiopatologia da dor e de instrumentos de avaliação da dor no neonato, era frequente. Os profissionais de enfermagem não apresentavam nenhum tipo de treinamento para realizar o gerenciamento da dor dos pacientes que, por sua vez, tinham suas necessidades ignoradas. A equipe de enfermagem priorizava realizar os cuidados de rotina (como banhos, medicação, pesagem, entre outros) colocando sempre a avaliação da dor em segundo plano, mesmo que fossem realizados procedimentos sabidamente dolorosos. Essas experiências foram suficientes para eu perceber que o profissional de enfermagem que atua na área da neonatologia necessita ampliar e consolidar o conhecimento sobre a dor neonatal.

Assim, com meu ingresso no mestrado pelo Programa de Pós-Graduação da Escola de Enfermagem da Universidade de São Paulo - PPGE, pretendi aprofundar 
meus estudos sobre a dor no RN, com enfoque especial à avaliação da dor nessa população, a partir da minha participação no Programa de Avaliação da Dor Neonatal (PAD-Neo). Tive a oportunidade de, junto com a equipe de criação e design do PADNeo, colaborar com o desenvolvimento e avaliação do curso online.

Acredito que a presente pesquisa contribuirá para a conscientização dos profissionais de saúde a respeito da dor neonatal, além de servir como importante ferramenta de aprimoramento do conhecimento desta temática. 
Introduçãa 


\section{INTRODUÇÃO}

\subsection{DOR NO RECÉM-NASCIDO}

Os primeiros estudos acerca do desenvolvimento neurológico do ser humano indicavam que a dor no recém-nascido (RN) era subestimada e, muitas vezes, acreditava-se que era inexistente (Anand, Hall, 2007). No entanto, estudos posteriores comprovaram o surgimento das terminações nervosas na região perioral a partir da $7^{\underline{a}}$ semana de gestação, e na face, palmas das mãos e solas dos pés a partir da $11^{\underline{a}}$ semana; o início da conexão entre o sistema nervoso central (corno dorsal espinal) e o sistema nervoso periférico (neurônios sensoriais) na $12^{\mathrm{a}}$ semana, completando-se na $30^{\mathrm{a}}$ semana de gestação; e a funcionalidade das sinapses nervosas para a

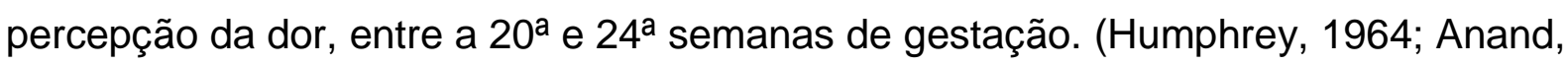
Phil, Hickey, 1987)

Atualmente sabe-se que todas as fases do processamento da dor estão presentes no neonato. A fase de transdução indica que, a partir da detecção de um estímulo externo (químico, mecânico ou térmico), surge o potencial de ação ou impulso nervoso; na transmissão, o impulso é conduzido até o corno posterior da medula espinal por intermédio das fibras nociceptoras (A-delta e $C$ ), que no RN são desorganizadas e geram respostas difusas e inespecíficas; na fase de modulação, os receptores dos interneurônios, ainda imaturos nesta população, ligam-se aos receptores das substâncias químicas excitatórias ou inibitórias, substâncias estas presentes em menor quantidade no neonato; finalmente, a fase de percepção compreende o processamento e reconhecimento do fenômeno doloroso (Fitzgerald, Walker, 2009; Hatfield, Meyers, Messing, 2013).

Cornelissen e colaboradores (2013) identificaram que o reflexo de flexão dos membros ao estímulo doloroso é generalizado e prolongado no neonato, principalmente no neonato pré-termo (<37 semanas) devido à imaturidade das vias de modulação da dor, em contraste com o indivíduo adulto. Isso significa que a modulação da dor no RN é ineficaz, porque sua resposta é prolongada e generalizada. Além disso, o reflexo de flexão não ocorre apenas em situação de estímulo nociceptivo. Os resultados do estudo demonstram que estímulos não dolorosos e 
repetitivos desencadeiam atividade muscular do neonato, que pode acontecer com a mesma intensidade e duração de uma resposta observada a partir de um estímulo doloroso no RN pré-termo (RNPT) (Cornelissen et al., 2013).

Dessa forma, é possível que um evento estressante, mas não doloroso, como a manipulação, cause desconforto ao RNPT da mesma forma que um estímulo doloroso, a partir de um procedimento como a lancetagem de calcâneo, aspiração de vias aéreas e punção venosa e arterial (Carbajal et al., 2008; Rodrigues, Guinsburg, 2013). Tendo em vista a resposta do neonato ao estímulo nociceptivo repetido e prolongado, uma revisão sistemática evidenciou que, durante sua hospitalização, são realizados em média de 7,5 a 17,3 procedimentos dolorosos ou estressantes por dia, sem o uso de intervenções farmacológicas ou não farmacológicas para o alívio da dor neonatal (Cruz, Fernandes, Oliveira, 2015). A dor não tratada no RN pode desencadear respostas exacerbadas a estímulos nociceptivos (hiperalgesia) ou a estímulos não dolorosos (alodínia), gerando consequências desfavoráveis para seu desenvolvimento neurocognitivo, fisiológico e psicocomportamental (Dittz, MalloyDiniz, 2006; Grunau, Holsti, Peters, 2006; Taddio et al., 2009; Valeri, Holsti, Linhares, 2015).

A International Association for the Study of Pain (IASP) descreve o fenômeno doloroso como "uma sensação ou experiência emocional desagradável, associada a um dano tecidual real ou potencial ou descrita em termos de tal dano". A fim de incluir a população incapaz ou impossibilitada de se comunicar verbalmente, como o neonato, a definição acrescentou que essa condição "não impede o indivíduo de vivenciar a dor e de necessitar manejo adequado" (Merskey, Bogduk, 1994). No entanto, o RN apresenta diversos indicadores para expressar a dor, que incluem parâmetros comportamentais, fisiológicos, contextuais, endocrinometabólicos e neurofisiológicos. Tais parâmetros compõem escalas específicas de avaliação da dor nessa população (Van Dijk, Tibboel, 2012; Harrison, Bueno, Reszel, 2015).

Os parâmetros comportamentais são amplamente utilizados em instrumentos de avaliação da dor neonatal (Fitzgerald, Walker, 2009). Destacam-se o choro, a movimentação corporal (flexão e extensão dos membros, punho cerrado ou dedos esticados) e a mímica facial (Stevens et al., 2007). A mímica facial é caracterizada como o indicador comportamental mais confiável e consistente (Cong et al., 2013) e inclui expressões específicas de dor neonatal como fronte saliente, olhos espremidos, 
boca aberta, boca esticada na vertical, boca esticada na horizontal, sulco nasolabial, tremor de queixo, língua tensa e protrusão da língua (Grunau et al., 2007). A mímica facial, indicativa de dor, é observada no feto a partir da $24^{\mathrm{a}}$ semana de gestação e, conforme maturidade gestacional, as expressões tornam-se mais observáveis (Reissland, Francis, Mason, 2013).

Por sua vez, os parâmetros fisiológicos incluem aumento da frequência cardíaca ( $F C$ ), aumento da frequência respiratória (FR), alteração do padrão respiratório, sudorese palmar e aumento da pressão arterial (PA) e pressão intracraniana (PIC), que podem desencadear alterações sistêmicas como a diminuição da saturação de oxigênio (SatO2), do tônus vagal e da perfusão periférica (Cong et al., 2013). No entanto, apesar de os indicadores fisiológicos serem utilizados com frequência em pesquisas para evidenciar a eficácia de intervenções de manejo da dor, ainda são poucos específicos, pois sua alteração pode estar relacionada com o estado clínico do RN, situações estressantes e outros eventos não dolorosos. (Dittz, Malloy-Diniz, 2006; Finer, Leone, 2009; Harrison, Bueno, Reszel, 2015)

A revisão sistemática de Sellam e colaboradores (2011) identificou a influência de indicadores contextuais na percepção e duração da dor. Observou-se que a idade gestacional (IG) foi o fator que mais afetou as respostas do neonato à dor, visto que o $\mathrm{RN}$ a termo apresentou respostas mais consistentes em relação ao RNPT, devido ao desenvolvimento do sistema nervoso. A exposição prévia à dor, o estado clínico do $\mathrm{RN}$, as intervenções terapêuticas e o estado comportamental também foram considerados indicadores contextuais. No entanto, a influência desses fatores na resposta à dor neonatal ainda é inconclusiva (Sellam et al., 2011).

Indicadores endocrinometabólicos da dor neonatal incluem o aumento na secreção de cortisol e catecolamina e a supressão de insulina. Contudo, o uso destes indicadores é limitado na prática clínica devido, especialmente, à longa espera para análise de amostras de material biológico (Guinsburg, Arias, 2010). Os neonatos, principalmente os RNPT, possuem taxas metabólicas mais altas e menos reserva nutricional, assim, os efeitos gerados pela resposta dolorosa são mais deletérios em relação a crianças maiores e indivíduos adultos (Cong et al., 2013). 
Por fim, pesquisadores têm explorado indicadores neurofisiológicos não invasivos, como a espectroscopia de infravermelho próximo (Near-Infrared Spectroscopy - NIRS), a ressonância magnética funcional (Functional Magnetic Ressonance Imaging - FMRI) e o eletroencefalograma (EEG) (Benoit et al., 2017). Um estudo realizado com a NIRS evidenciou que, durante o estímulo doloroso, há ativação bilateral e simétrica no córtex somatossensorial e no córtex motor de neonatos de termo. Tal ativação pode ser detectada pela NIRS, devido ao aumento na concentração de oxiemoglobina $(\mathrm{HbO} 2)$ e à diminuição de deoxiemoglobina $(\mathrm{Hbb})$, presentes no sangue durante a atividade neural, que indicam oxigenação no tecido cerebral, mesmo sem alteração nos parâmetros fisiológicos, estado comportamental e mímica facial. (Bembich et al, 2015; Oliveira et al, 2015)

A complexidade e a subjetividade de formas com que o fenômeno doloroso se manifesta no RN exigem o uso de instrumentos específicos e válidos, que auxiliam na interpretação dos sinais indicativos de dor no RN (Duhn, Medves, 2004). Esses instrumentos são classificados como unidimensionais, por avaliarem somente respostas comportamentais, e multidimensionais, uma vez que avaliam as respostas comportamentais e também fisiológicas. Além disso, os instrumentos multidimensionais compostos incluem parâmetros contextuais (Guinsburg, Cuenca A., 2010; Gibbins et al., 2014). Recomenda-se a utilização de instrumentos multidimensionais ou multidimensionais compostos para acurácia da avaliação da dor do RN (AAP, 2016).

Em revisão sistemática publicada em 2004, foram identificadas 35 escalas de avaliação da dor neonatal, das quais 18 unidimensionais e 17 multidimensionais (Duhn, Medves, 2004). Apesar de inúmeros instrumentos descritos, nenhum deles foi considerado como ideal. A quantidade de instrumentos para avaliação da dor do RN, disponíveis atualmente, pode dificultar a mensuração e o manejo adequado da dor, resultando em uma avaliação pouco específica e, consequentemente, um controle ineficaz da dor. Por essa razão é necessário conhecer as propriedades psicométricas, que garantem a confiabilidade do instrumento, a partir de características como a validade (capacidade do instrumento medir o que se propõe a medir), a precisão (mesmo resultado encontrado em diferentes situações) e a padronização (préestabelecimento dos critérios de aplicação da escala, interpretação dos indicadores 
para a avaliação e da pontuação dos resultados). (Frutuoso, Moraes, 2004; Stevens et al., 2014)

Não há até o momento um instrumento de avaliação da dor que possa ser considerado como padrão ouro no contexto da neonatologia (Melo et al., 2014). No entanto, alguns instrumentos se destacam, como Neonatal Infant Pain Scale (NIPS) (Lawrence et al., 1993), Neonatal Facial Coding System (NFCS) (Grunau, Craig, 1987; Grunau et al., 1998), Behavioral Indicators of Infant Pain (BIIP) (Holsti, Grunau, 2007), Échelle Douleur Inconfort Nouveau-Né (EDIN) (Debillon et al., 2001), Premature Infant Pain Profile (PIPP) (Stevens et al., 1996), Premature Infant Pain Profile - Revised (PIPP-R) (Stevens, et al., 2014), Neonatal Pain Agitation and Sedation Scale (NPASS) (Hummel et al., 2007), Douleur Aiguë du Nouveau-né (DAN) (Carbajal et al. , 1997), Crying Requires oxygen for saturation above 95\%, Increased vital signs, Expression, Sleepless (CRIES) (Krechel, Bildner, 1995), Bernese Pain Scale for Neonates (BPSN) (Cignacco et al., 2004), Pain Assessment in Neonate (PAIN) (Hudson-Barr et al., 2002), entre outros (AAP, 2016).

As escalas de avaliação da dor neonatal podem ser utilizadas à beira leito, porém requerem conhecimento e habilidade do profissional, por serem específicas, devido à variedade de indicadores e de métodos de pontuação dos escores de dor. (Balda et al., 2009; Bueno et al., 2014)

Apesar da crescente produção de evidências científicas relacionadas à importância da prevenção da dor na população neonatal, o RN continua submetido a procedimentos invasivos e dolorosos sem receber adequada analgesia (Simons et al., 2003; Krishnan, 2013; Hall, Anand, 2014). Dessa forma, a avaliação da dor neonatal, acurada e baseada em instrumentos confiáveis e de propriedades psicométricas robustas, é primordial para fomentar o tratamento eficaz e seguro ao RN. (Maxwell, Malavolta, Fraga, 2013) 


\subsection{PERCEPÇÃO DOS PROFISSIONAIS DE SAÚDE SOBRE AVALIAÇÃO DA DOR NEONATAL}

Em função da ausência de queixa verbal e da necessidade de se utilizar métodos indiretos, como instrumentos específicos de avaliação de dor no $\mathrm{RN}$, a atuação de profissionais de saúde como enfermeiros, médicos, fisioterapeutas, entre outros, na identificação da dor neonatal é essencial.

O estudo de Akuma e Jordan (2012), realizado no Reino Unido, incluiu 137 enfermeiros e 62 médicos atuantes em sete Unidades de Terapia Intensiva Neonatal (UTIN) e teve como objetivo verificar o conhecimento desses profissionais acerca da avaliação e manejo da dor neonatal. Os resultados identificaram que $99,5 \%$ dos profissionais reconheceram que o neonato com IG inferior a 28 semanas sente dor. A maioria dos participantes (96,5\%) referiu avaliar a dor do RN por intermédio de comportamento ou alterações nos sinais vitais, sendo que o uso de instrumentos de avaliação foi mencionado por apenas $2,5 \%$ dos profissionais. Contudo, $48,7 \%$ dos participantes referiram que escalas de avaliação da dor neonatal estavam disponíveis nas suas unidades de trabalho, mas somente $25,1 \%$ conheciam essas escalas (Akuma e Jordan, 2012).

Estudo conduzido na Turquia, com 111 enfermeiros, em 15 hospitais universitários, abordou as percepções dos participantes a partir de um questionário. Os resultados apontaram que $36,9 \%$ consideraram que os indicadores fisiológicos da dor do RN incluíam mudança de temperatura, aumento da FC e FR, aumento do tônus muscular, aumento da PIC e da PA e diminuição da SatO2. Por outro lado, 52,3\% dos enfermeiros declararam que choro, mímica facial e movimentação dos membros são respostas comportamentais válidas para avaliar a dor dos RN. Aproximadamente 50\% dos participantes referiu considerar os fatores fisiológicos e comportamentais, de modo combinado, na avaliação da dor do neonato. (Efe et al., 2013).

No contexto brasileiro, estudos confirmam que a avaliação da dor neonatal não é realizada de forma sistematizada e que o embasamento na literatura científica é frágil. 
Em pesquisa qualitativa, Scochi e colaboradores (2006) incluíram três enfermeiros, dois residentes de enfermagem, dois técnicos de enfermagem e 10 auxiliares de enfermagem, atuantes na unidade neonatal de um hospital universitário do estado de SP. Todos os profissionais reconheciam a ocorrência de dor neonatal. A maioria dos profissionais referiu identificar a dor por intermédio de respostas comportamentais, embora a avaliação de parâmetros fisiológicos associados aos parâmetros comportamentais também tenha sido descrita. O choro, a movimentação corporal e a expressão facial foram os indicadores mais referidos pelos profissionais (Scochi et al., 2006).

Crescêndio, Zanelato e Leventhal, em 2009, encontraram resultados similares em um estudo quantitativo realizado com 32 enfermeiros atuantes em uma UTIN de um hospital privado na cidade de São Paulo. O objetivo foi identificar de que forma esses profissionais avaliavam a dor neonatal e quais métodos analgésicos utilizavam. Todos os participantes responderam ao questionário e concordaram que o neonato sente dor. Os indicadores mais utilizados para avaliação do fenômeno doloroso no RN pelos profissionais incluíram: expressão facial $(23,2 \%)$, choro $(23,2 \%)$, alterações dos sinais vitais $(11,6 \%)$, agitação $(10,5 \%)$, movimentação corporal $(7 \%)$, parâmetros referidos na escala NIPS (10,5\%), entre outros. Os enfermeiros indicaram conhecer a escala NIPS $(90,6 \%)$, a Escala de Faces (15,6\%) e a escala verbal numérica (12,5\%), as duas últimas utilizadas para a avaliação da dor de pacientes com capacidade de verbalização (Crescêndio, Zanelato, Leventhal, 2009).

Outro estudo quantitativo, realizado com 15 enfermeiros de UCIN e UTIN em uma maternidade em Maceió - AL, teve como objetivo identificar as percepções e atitudes dos profissionais frente à dor do $\mathrm{RN}$. Somente um profissional referiu fazer uso de escala para avaliar a dor. Dentre os 14 participantes que não utilizavam instrumento de avaliação, 93\% referiram avaliar a dor por intermédio de alterações comportamentais (choro, irritabilidade, hiperextensão dos membros, expressão facial, gemido na manipulação) e 7\% avaliavam a dor pela combinação dos indicadores comportamentais (choro, irritabilidade, hiperextensão dos membros, expressão da face e gemido a manipulação) e fisiológicos (queda de SatO2). De modo geral, os autores concluíram que a avaliação da dor neonatal era realizada de forma empírica e sem a utilização de instrumento apropriado e validado, padronizado pela instituição (Presbytero, Vaz da Costa, Santos, 2010). 
Os 180 profissionais de enfermagem (45 enfermeiros, 74 técnicos e 61 auxiliares) de UTIN de quatro hospitais-escola públicos do CE participaram de um estudo quantitativo, com o objetivo de identificar parâmetros fisiológicos e comportamentais utilizados pelos profissionais para avaliação da dor do RN. Os resultados mostraram que os indicadores fisiológicos mais frequentemente citados pelos profissionais foram alterações cardiovasculares $(28,8 \%)$ e respiratórias $(21,6 \%)$. Dentre os indicadores comportamentais, os mais reconhecidos foram choro $(98,3 \%)$; mímica facial (78,3\%); mudanças comportamentais como agitação, irritabilidade e inquietação (55\%) e movimentação motora (33,8\%). No entanto, o estudo não discutiu a utilização de escalas específicas para a avaliação da dor neonatal (Oliveira et al., 2010).

A partir de um estudo qualitativo, 10 profissionais de enfermagem (cinco enfermeiros e cinco técnicos) de uma UTIN em um hospital público de Feira de Santana-BA, foram entrevistados a fim de identificar parâmetros utilizados para avaliar a dor do RNPT e as técnicas de manejo empregadas. Os profissionais reconheceram a importância da avaliação da dor neonatal, porém, não adotavam nenhum instrumento específico. Adicionalmente, os profissionais referiram não haver nenhuma política institucional para a implementação de escalas, o que levava os enfermeiros a realizar a avaliação da dor de forma não sistematizada e não fundamentada em evidências científicas. Dentre os parâmetros considerados, os profissionais referiram o choro, expressões faciais, agitação e medidas fisiológicas como diminuição da SatO2 e aumento na FC e FR (Santos, Ribeiro, Santana, 2012).

Em 2013, Caetano e colaboradores realizaram estudo quantitativo com 14 enfermeiros, 18 técnicos e 10 auxiliares, todos atuantes em unidades de cuidados ao RN (berçário, UTIN e pediatria), em três hospitais de referência de Alfenas-MG. O objetivo do estudo foi descrever a avaliação e o manejo da dor do neonato, realizados pelos profissionais de enfermagem. Todos os participantes reconheceram que o RN vivencia situações dolorosas, porém, apenas um dos participantes referiu utilizar as escalas de avaliação de dor, enquanto os demais referiram avaliar a dor por intermédio de choro (35\%), mímica facial (26\%), movimentação corporal $(26 \%)$ e respostas fisiológicas (9\%) (Caetano et al., 2013). 
O estudo quantitativo conduzido por Martins e colaboradores (2013), em uma UTIN de um hospital universitário de Vitória-ES, teve como objetivo observar a percepção e atitudes de nove enfermeiros em relação à dor neonatal. Os resultados identificaram que apenas um profissional conhecia a escala NIPS para avaliação da dor no RN, quatro conheciam apenas escalas de avaliação da dor em indivíduos adultos e quatro enfermeiros não conheciam qualquer tipo de escalas. Dessa forma, a avaliação da dor do RN era realizada de forma empírica, com base no estado clínico e por intermédio da observação de indicadores comportamentais como o choro, atividade motora, mimica facial, além de indicadores fisiológicos como aumento da FC e diminuição da SatO2 (Martins, et al., 2013).

Um estudo quantitativo realizado com 57 profissionais de saúde (15 médicos, oito enfermeiros e 34 auxiliares de enfermagem), foi conduzido em uma UTIN, uma Unidade de Cuidados Intermediários Neonatal (UCIN) e uma Unidade Mãe Canguru (UMC) de um hospital localizado no interior do estado de São Paulo. O objetivo foi identificar as percepções e as atitudes dos profissionais de saúde em relação à avaliação e ao manejo da dor aguda neonatal. Os resultados evidenciaram que $98,2 \%$ dos profissionais entrevistados consideraram que o RN sente dor, e $93 \%$ referiu avaliar a dor do RN. O choro foi descrito como parâmetro de avaliação por $89,5 \%$ dos profissionais, a mímica facial por $65 \%$, a movimentação corporal foi citada por $63,2 \%$ e os parâmetros fisiológicos por $26,3 \%$. No entanto, nenhum profissional conhecia escalas de avaliação da dor neonatal (Capellini et al., 2014).

Araújo e colaboradores (2015) realizaram em estudo quantitativo na UTIN de um hospital de Feira de Santana-BA. O objetivo do estudo foi descrever a avaliação e o manejo da dor neonatal realizada pelos 62 profissionais de enfermagem (enfermeiros, auxiliares e técnicos de enfermagem). A partir dos dados de um questionário, os profissionais referiram utilizar a observação de parâmetros comportamentais (choro, movimentação corporal, alterações do sono, mímica facial e alterações no padrão alimentar) e fisiológicos (aumento de FC e FR e queda de SatO2) para avaliação da dor. Além disso, os profissionais afirmaram utilizar alterações de temperatura corporal como indicador de dor. Apenas 39,3\% referiram conhecer as escalas, entretanto, nenhum as adotava na prática clínica para avaliação da dor do RN (Araújo et al., 2015). 
Neste sentido, observa-se um acréscimo significativo de estudos na temática de avaliação da dor neonatal nos últimos anos. No entanto, existe ainda uma lacuna entre a produção do conhecimento e sua utilização na prática clínica. Evidências científicas são pouco utilizadas pelos profissionais de saúde durante o cuidado com o paciente, o que dificulta ainda mais em como a assistência ao RN com dor deve ser prestada (AAP, 2016).

Um estudo com 70 profissionais (23 médicos, 13 enfermeiros, cinco fisioterapeutas e 29 técnicos e auxiliares de enfermagem) realizado em um Hospital de Recife-PE teve como objetivo conhecer a percepção de profissionais de UTIN sobre avaliação e manejo da dor neonatal antes e após a implementação de estratégia educativa presencial. $O$ estudo foi constituído de três etapas: na primeira fase foi aplicado um questionário para identificar como os profissionais avaliavam e realizavam o manejo da dor neonatal; na segunda fase, por intermédio de grupos focais, os profissionais realizaram discussões a fim de identificar práticas que influenciavam positiva ou negativamente a avaliação e o manejo da dor na UTIN, e, a partir de buscas de evidências científicas, procuraram soluções para melhorar a assistência; e, por fim, a terceira fase se constituiu na reaplicação do questionário para avaliar as percepções dos profissionais após a intervenção. Assim, os resultados do pós-teste demonstraram que houve diferença significativa em relação ao conhecimento dos profissionais sobre utilização de instrumentos de avaliação de dor e de estratégias de analgesia. (Aymar et al., 2014)

Ainda neste sentido, Oliveira e colaboradores (2010) ressaltam a importância do treinamento no uso de escalas de avaliação de dor neonatal, a fim de aprimorar a prática assistencial ao RN com dor. Santos, Ribeiro e Santana (2012) verificaram a necessidade de organizar curso de capacitação aos profissionais para melhor controle da dor dos pacientes. Akuma e Jordan (2012) apontam que os próprios enfermeiros e médicos atuantes em UTINs sugerem treinamento da equipe em avaliação e manejo da dor neonatal.

De modo geral, os estudos apontam que os profissionais de saúde, predominantemente aqueles da equipe de enfermagem, reconhecem a ocorrência de dor neonatal e conhecem parâmetros comportamentais e fisiológicos relacionados à dor no RN. Apesar de a mímica facial ter sido destacada em grande parte dos estudos, o choro é o indicador comportamental predominantemente citado pelos profissionais. 
Destaca-se, entretanto que, embora o choro esteja relacionado à ocorrência de dor no RN, não é específico o suficiente para ser utilizado de modo isolado na avaliação. Ressalta-se ainda que os parâmetros fisiológicos, citados com muita frequência pelos profissionais envolvidos nos estudos, são pouco específicos quando empregados isoladamente para a avaliação da dor neonatal. Ademais, os instrumentos de avaliação da dor neonatal são pouco conhecidos, pouco utilizados e, por conseguinte, a avaliação sistemática da dor neonatal, baseada em protocolos institucionais, é pouco frequente nos serviços investigados.

Assim, observa-se que o treinamento e a capacitação profissional em relação à avaliação e ao manejo da dor são necessidades apontadas pelas equipes de saúde participantes dos estudos descritos acima.

\subsection{EDUCAÇÃO A DISTÂNCIA EM ENFERMAGEM}

Atualmente, a tecnologia faz parte de todos os domínios da sociedade, logo, está presente também no uso de ferramentas didáticas e métodos instrucionais (Rodrigues, Peres, 2008). As tecnologias de informação e comunicação, denominadas TICs, são estratégias que criam oportunidades ao processo educacional, e permitem a articulação de teoria, prática e pesquisa (Gonçalves et al., 2010). As TICs possibilitam a interação entre alunos e professores, separados pelo tempo e/ou espaço e o compartilhamento de informações pertinentes para a técnica de disseminação de informações. (Prado, 2012; Alavarce, 2014)

Nesse sentindo, a educação a distância (EAD), uma modalidade das TICs, surgiu como alternativa útil de organização de novos espaços assíncronos de construção e difusão do conhecimento (Padalino, Peres, 2007). A EAD possibilita a utilização de recursos audiovisuais, com a finalidade de aperfeiçoar a experiência do usuário com o curso online (Alvarez, Dal Sasso, 2011; Moore, Dickson-Deane, Galyen, 2011). Os recursos audiovisuais servem de apoio educacional e possibilitam 
a interação e estimulam o usuário a explorar o curso online. Esses recursos podem ser utilizados em diversos formatos como: textos, sons, imagens, animações, vídeos, entre outros. (Cook et al., 2010)

Um ensaio clínico randomizado (ECR), conduzido por Alemán e colaboradores (2011) e realizado com estudantes de graduação do segundo ano de enfermagem, buscou comparar o conhecimento e a retenção do conhecimento após a EAD e ensino tradicional na temática "enfermagem médico-cirúrgica". Os alunos foram divididos em grupo controle, que participaram de aulas teóricas com slides e textos, e grupo experimental, que incluiu a utilização do curso via computador. O curso online foi composto por recursos audiovisuais como vídeos, áudios, textos, imagens e endereço para websites úteis. Os resultados demonstraram que os alunos que participaram da EAD obtiveram ganhos significativos logo após a intervenção. No entanto, tanto o grupo que realizou o EAD quanto o grupo que participou do ensino tradicional obtiveram os mesmos resultados em relação à retenção do conhecimento. Dessa forma, os autores descrevem que a EAD e o ensino tradicional são igualmente eficazes no aprimoramento de conhecimentos e formação de profissionais de saúde (Alemán et al, 2011).

Além disso, a EAD apresenta vantagens como flexibilidade temporal, por permitir o acesso no local e horário mais adequado à rotina do indivíduo; possibilita o estudo auto direcionado e centrado no usuário, no qual o aluno pode respeitar suas dificuldades; desenvolvimento de competências e conhecimentos, a partir de experiências de aprendizagem ativa; facilidade de comunicação entre os cursistas e professores/tutores; permite a busca rápida por informações; desenvolvimento de autonomia e autoconfiança em relação ao aprendizado, sendo que o próprio aluno pode fazer sua rotina de estudos; e, pode ser facilmente atualizado com novas evidências científicas (Huckstadt, Hayes, 2008; Dy et al., 2008; Puljak, Sapuna, 2011).

Assim, a EAD tem sido cada vez mais explorada no Brasil como uma alternativa eficiente em cursos de graduação, licenciatura, pós-graduação e educação continuada (Camacho, 2009). Neste sentido, o emprego da EAD é favorável para a formação e atualização de profissionais da área da saúde, possibilitando o desenvolvimento de uma postura crítico-reflexiva (Buxton, De Muth, 2013). No ensino de enfermagem, a EAD pode promover embasamento para prestação de assistência 
adequada, eficaz e de forma humanizada (Fonseca et al, 2011; Rochman, Sheehan, Kulich, 2013).

A revisão sistemática de Du e colaboradores (2013) incluiu nove ECR para identificar a eficácia do uso de EAD, ou aprendizado por meio de tecnologias, na prática clínica de profissionais de enfermagem. Seis estudos fizeram um comparativo da EAD com as metodologias tradicionais de ensino para avaliar o impacto no conhecimento do usuário, e revelaram que o ensino online produziu efeitos superiores ou semelhantes aos identificados em usuários que participaram do ensino tradicional. Com base nos resultados apresentados em quatro estudos, a EAD também apresentou benefícios quanto ao aprimoramento de habilidades e competências. A maioria dos estudos analisados reportou que os usuários ficaram satisfeitos com a modalidade de aprendizado online e dois estudos demonstraram que o ensino online tem melhor desempenho no aperfeiçoamento do conhecimento e habilidades (Du et al., 2013).

Em 2014, a revisão sistemática conduzida por Lahti, Hatonen e Valimaki teve como objetivo avaliar o impacto da EAD no conhecimento, nas habilidades e na satisfação de enfermeiros e estudantes de enfermagem e incluiu 11 estudos. Os achados indicaram que o aproveitamento do aluno foi mais elevado no uso da EAD do que no ensino tradicional, porém não houve significância estatística. Em relação ao impacto nas habilidades, também não há diferença considerável entre o uso da EAD e educação tradicional. Por fim, os estudos analisados identificam que os usuários mostram-se satisfeitos com ambas as modalidades de ensino descritas na revisão. $O$ estudo concluiu que a EAD não se categoriza como uma estratégia educativa melhor, porém, complementar ao ensino presencial (Lahti, Hatonen, Valimaki, 2014).

Com relação à dor neonatal especificamente, Gibbins e colaboradores (2007) realizaram um estudo quantitativo com o objetivo de descrever a implementação e satisfação com um curso online sobre a escala de dor neonatal PIPP. O conteúdo foi desenvolvido em ambiente virtual de aprendizagem (AVA) por pesquisadores e profissionais de saúde e, posteriormente, revisado por especialistas em dor neonatal. O conteúdo abordado incluiu objetivos do módulo, definições e fisiopatologia da dor neonatal, avaliação e manejo da dor, indicadores fisiológicos e comportamentais de dor no RN, 
os componentes da escala PIPP e perguntas frequentes sobre a PIPP. Os recursos utilizados foram vídeos, fotos, áudios, questões de múltipla escolha e estudos de caso para aplicação da escala PIPP. Após a intervenção, foi avaliada a satisfação dos usuários e aplicabilidade do programa a partir de um instrumento com questões tipo escala Likert (1-5) que considerava características como: tempo, instruções, aceitabilidade, formato do módulo, conteúdo, navegabilidade, clareza das informações e pertinência de recursos instrucionais. Participaram do estudo 68 profissionais de saúde de uma UTIN. De modo geral, os participantes relataram que o curso é mais acessível e flexível e eficaz para a disseminação de informações. Os usuários mostraram-se satisfeitos com o programa (95\%), relataram que as instruções são fáceis de entender (90\%) e que a linguagem é clara e objetiva (90\%). Noventa por cento dos participantes ficou satisfeito com o formato, 100\% aprovou as fotos e vídeos. Alguns dos benefícios apontados foram confiança, desenvolvimento de autonomia, estudo auto direcionado e motivador e aprimoramento do conhecimento por parte dos usuários (Gibbins et al., 2007).

Um estudo quantitativo teve como objetivo descrever e avaliar a aplicabilidade da estratégia denominada Relieving Children's Pain (RCP), sobre avaliação e manejo da dor pediátrica. O RCP foi hospedado online, utilizou recursos como: fotos, vídeos, áudios e gráficos. O conteúdo abordou temas como uso de opióides, efeitos da dor não tratada e validade do auto relato da criança. Foram convidados para participar do estudo 30 enfermeiros, dos quais 24 finalizaram o curso, sendo que um enfermeiro escolheu não participar, três enfermeiros completaram apenas o pré-teste e dois profissionais não conseguiram acessar o conteúdo pelo computador pessoal. Após o curso, foi aplicado um questionário de avaliação para os usuários sobre os seguintes aspectos: aceitabilidade do programa, crenças e práticas em relação à dor pediátrica e registro. Além disso, o curso incluiu pré-teste e pós-teste para avaliação do conhecimento. A maioria dos participantes relatou que o RCP foi fácil de utilizar e de entender e que o programa era engajador e organizado. Houve relato de aumento do conhecimento sobre manejo da dor e que o RCP seria bem recebido por outros colegas. Apenas um participante relatou ter dificuldades em navegar no curso. Houve diferença significativa entre os resultados do pré-teste e pós-teste relacionadas à dor e seu tratamento na criança. Ademais, a média de acertos dos profissionais na avaliação da dor pediátrica aumentou significativamente no pós-teste (média pré- 
teste=5.13; média no pós-teste=7.96). No entanto, não houve diferença significante entre as médias do pré-teste e pós-teste em relação ao pico e duração de opióides mais utilizados. Os testes realizados com estudo de caso também não mostraram diferença significativa em relação à avaliação da dor e uma diferença menor em relação a administração das drogas. Pela análise dos prontuários dos pacientes, notou-se diminuição no escore de dor referida pelas crianças e melhora na administração de analgésicos (Vincent, Wilkie, Wang 2011).

O estudo qualitativo de Habich e Letizia (2015), conduzido em um ProntoSocorro (PS) de um hospital em Chicago, teve como objetivo descrever o desenvolvimento, a implementação e a avaliação do programa educacional e do protocolo de avaliação da dor pediátrica. O curso foi reproduzido por intermédio de um software eletrônico e abordou temas sobre avaliação da dor em crianças, manejo da dor, barreiras para o adequado tratamento, instrumentos de avaliação e educação da família e do paciente. Os recursos audiovisuais utilizados incluíram apresentação narrada do módulo e questionário de avaliação do curso. Foram aplicados pré-teste e pós-teste, que consistiram em um questionário com 20 itens múltipla-escolha sobre o conteúdo abordado, e um questionário de avaliação do curso, que integrou perguntas tipo escala Likert (1-4). Participaram do curso online 78 enfermeiros. A pontuação do teste final foi $12,6 \%$ maior que o pré-teste. A maioria dos participantes acreditou que o curso atingiu os objetivos; $54 \%$ dos enfermeiros mostrou-se confiante na avaliação da dor, $88 \%$ referiu que o curso foi eficaz para transmitir o conteúdo, $96 \%$ apontou que o conteúdo abordado foi relevante para a prática, $78 \%$ espera mudar as práticas. Durante a assistência de 60 pacientes pediátricos no PS, pôde-se observar que $87 \%$ prontuários possuíam registro da avaliação da dor, sendo que $65 \%$ desses pacientes possuíram escore de dor maior ou igual a um. Contudo, apenas $32 \%$ dos pacientes recebeu intervenção farmacológica ou não farmacológica para a dor, onde apenas seis pacientes foram medicados com analgésicos. Isto significa que, apesar da utilização correta das escalas para avaliação da dor pediátrica durante a triagem no PSI, houve falha na documentação e pouca medicação de analgésicos (Habich, Letizia, 2015).

Contudo, apesar do crescimento da EAD voltada para profissionais e estudantes da saúde, no contexto da neonatologia essa modalidade de ensino ainda é pouco explorada. Ademais, observa-se a necessidade de descrever não somente o 
desenvolvimento como também a avaliação dos cursos, com vistas a garantir confiabilidade e qualidade do ensino. Além disso, as avaliações de qualidade de conteúdo e aparência são primordiais para a satisfação do usuário do EAD (Carvalho Neto, 2009).

\subsection{PROGRAMA DE AVALIAÇÃO DA DOR NEONATAL}

A fim de contribuir com a minimização das lacunas existentes entre a prática clínica e as evidências no contexto da avaliação da dor no RN, o Programa de Avaliação da Dor Neonatal (PAD-Neo) foi criado em 2010.

O PAD-Neo é um curso online que teve como objetivo educacional aprimorar os conhecimentos de profissionais e alunos da área da saúde sobre a dor neonatal, bem como sua avaliação e mensuração. Além disso, o PAD-Neo possibilita aprimorar as habilidades de reconhecimento da dor neonatal de profissionais que atuam com essa população e, por fim, capacitar os profissionais na escolha e utilização de instrumentos de avaliação da dor neonatal pertinentes a cada neonato.

O curso foi desenvolvido com base no modelo Analysis, Design, Development, Implementation e Evaluation (ADDIE), amplamente utilizado no planejamento e desenvolvimento de estratégias educacionais por ser uma abordagem sistemática do design instrucional (Filatro, 2003; Molenda, 2003). A fase um ou análise compreendeu na identificação do problema educacional, que foi a avaliação da dor neonatal como uma atividade complexa, que requer o uso de instrumentos válidos e confiáveis, e conhecimento e habilidades específicas do avaliador (Bueno et al., 2014). As fases de design e de desenvolvimento constituíram a definição de estratégias de ensino utilizadas, levantamento bibliográfico, o estabelecimento dos conteúdos teórico e prático, a definição do meio virtual a ser utilizado, e o planejamento e desenvolvimento dos objetivos do programa e das ferramentas de avaliação do curso (Bueno et al., 2014). A quarta fase foi a implementação da primeira versão do PAD-Neo, cuja plataforma de escolha foi o Moodle (Modular Object-Oriented Dynamic Learning Environment), um software livre, gratuito e aberto que possibilita maior participação e interação dos alunos com o ambiente (Prado et al., 2012). A quinta etapa 
compreendeu a avaliação do design e funcionalidade do programa sob a perspectiva dos usuários e incluiu a participação de dez profissionais e estudantes de graduação e pós-graduação da área da saúde (Bueno et al., 2014).

Em sua versão inicial, o PAD-Neo foi organizado em módulos. O módulo um apresentava orientações gerais sobre o curso, bem como um cronograma. Os módulos dois a quatro abordaram tópicos de anatomia e fisiologia da dor neonatal, indicadores de dor no RN e aspectos gerais sobre instrumentos de avaliação da dor neonatal. Os módulos cinco a oito apresentavam quatro escalas específicas para a avaliação da dor neonatal, a saber: NFCS, NIPS, PIPP e CRIES (Bueno et al., 2014). A primeira versão do curso online apresentava pré-teste e pós-teste imediato, com vistas a avaliar a aquisição de conhecimento pelo usuário, e formulário de avaliação de satisfação do usuário com o curso. Além disso, o PAD-Neo incluiu recursos audiovisuais tais como videoaulas, exercícios de avaliação, textos para leitura complementar e fóruns de discussão.

Esta versão do PAD-Neo foi testada por dez usuários que se mostraram satisfeitos ou muito satisfeitos com a carga horária (43,4\% e 56,6\%, respectivamente), com a organização do conteúdo (22,5\% e $75 \%)$, com o curso online (20\% e $76 \%)$, com a aplicabilidade do conteúdo (33,3\% e 66,7\%), e, finalmente, com os recursos audiovisuais (32,5\% e 62,5\%). Os usuários realizaram um pré-teste, composto por 20 questões de múltipla escolha, obtendo número médio de acertos de $13( \pm 1,88)$ e um pós-teste, no qual a média de acertos foi $16( \pm 2,41)$, com uma diferença significativa entre o número de acertos ( $p=0,006)$ (Bueno et al., 2014).

Recentemente, identificou-se a necessidade de atualização do conteúdo do PAD-Neo. Dessa forma, considerando-se a avaliação inicial do curso, bem como o conhecimento técnico-científico de uma equipe composta por pesquisadores da Escola de Enfermagem da Universidade de São Paulo, Escola de Enfermagem da Universidade Federal de Minas Gerais e Faculdade de Enfermagem de Goiás, assessorada por pesquisadores da Universidade de Toronto e Universidade de Ottawa, optou-se por atualizar o conteúdo e produzir uma nova versão do PAD-Neo.

O curso manteve-se hospedado na plataforma Moodle em formato modular. O primeiro módulo, assim como na versão original, apresenta uma visão geral sobre o curso, os recursos audiovisuais disponíveis e a plataforma. Esse módulo ainda inclui pré-teste, composto por 30 questões de múltipla escolha, com a finalidade de avaliar 
o conhecimento prévio dos usuários acerca da temática. Os módulos dois a quatro mantiveram-se como na versão original e discorrem sobre aspectos de anatomia e fisiologia da dor no neonato, indicadores da dor neonatal e as características gerais de instrumentos de avaliação da dor neonatal, embora todo seu conteúdo tenha sido revisado e atualizado.

Os módulos cinco a nove do curso PAD-Neo apresentam instrumentos específicos de avaliação da dor neonatal, adequadamente validados e traduzidos para a língua portuguesa, adotada no Brasil. Foram mantidos dois instrumentos apresentados na versão inicial do curso, o NFCS, validado por Pereira e colaboradores (1999) como Sistema de Codificação da Atividade Facial Neonatal (Pereira et al., 1999), e o NIPS, traduzido como Escala de Dor no Recém-Nascido (Motta, Shardosim, Cunha, 2015). Já o módulo sobre a escala PIPP foi substituído por conteúdo relacionado à versão atualizada do instrumento, o Premature Infant Pain Profile - Revised (PIPP-R) (Stevens et al., 2014), traduzido como "Perfil de Dor no Recém-Nascido Pré-Termo - Revisado" (Bueno et al., 2015). Houve também a necessidade de substituir a escala CRIES (Krechel, Bildner, 1995) pela Behavioral Indicators of Infant Pain (BIIP) (Holsti, Grunau, 2007), validada para o português como "Indicadores Comportamentais de Dor no Recém-Nascido" (Bueno et al., 2013), visto que a CRIES avalia apenas a dor neonatal no pós-operatório, e os demais instrumentos podem ser utilizados para este fim. Finalmente, observou-se a necessidade de incluir um instrumento de avaliação da dor prolongada no RN, assim optou-se pela escala Échelle Douleur Inconfort Nouveau-Né - EDIN (Escala de Dor e Desconforto do Recém-Nascido) (Dias, Marba, 2014). Isso porque todos os instrumentos anteriormente citados são específicos para avaliação da dor aguda resultante, predominantemente, de procedimentos invasivos e cirúrgicos.

Por fim, o módulo 10 do PAD-Neo compreende o pós-teste composto de 30 questões de múltipla escolha para se verificar a aquisição de conhecimento do usuário, além do formulário de satisfação do curso online. O formulário de satisfação é composto por questões do tipo Likert, relacionadas à carga horária, à qualidade e utilidade das instruções, conteúdo e recursos utilizados, à aparência e qualidade do ambiente virtual, à aplicabilidade do conteúdo, aos recursos audiovisuais e aos aspectos relacionados à própria participação do aluno e interação com o tutor. Uma questão final aberta consta no instrumento, para que o usuário comente sobre 
aspectos que considera merecedores de ênfase ou maior detalhamento. Este instrumento foi desenvolvido com base no instrumento proposto por Fonseca (Fonseca, 2007).

O conteúdo de cada módulo do PAD-Neo foi desenvolvido para ser finalizado ao longo de uma semana, sugerindo-se aproximadamente uma hora de atividade diária e cinco horas semanais. Dessa forma, a carga horária total é de 50 horas.

Além disso, a fim de melhorar a interação do usuário com o curso online e aprimorar a experiência pedagógica do mesmo, o PAD-Neo contará com dois tutores. O papel do tutor é participar de forma ativa do processo ensino-aprendizagem, por meio de avaliações e feedback, esclarecimento de dúvidas do aluno quanto ao curso online e/ou conteúdo e integração durante a apresentação do curso e atividades. (Brasil, 2007; Mattar, 2012)

Com relação aos recursos audiovisuais utilizados, a versão atualizada do PADNeo inclui:

- Aulas: recurso dinâmico utilizado para apresentar e reforçar temas e conceitos importantes; aborda o conteúdo teórico relacionado à anatomia, fisiologia e fisiopatologia da dor no RN, avaliação da dor neonatal, indicadores de dor no RN e instrumentos de avaliação. Os módulos 2 a 4 incluem aulas de vídeo com áudio e representação do professor por meio de avatar (forma digital de representação) (Figura 1). Nas demais unidades, as aulas foram desenvolvidas no software Articulate Storyline ${ }^{\circledR}$, que permite a produção de conteúdo interativo, facilitando o processo de aprendizado do usuário (Alavarce, 2014) (Figura 2). Além disso, em todas as unidades, são disponibilizados textos de síntese de conteúdo, no formato Portable Document Format (PDF) (Figura 3). 
Figura 1- Vídeoaula com utilização de avatar de representação digital humana.

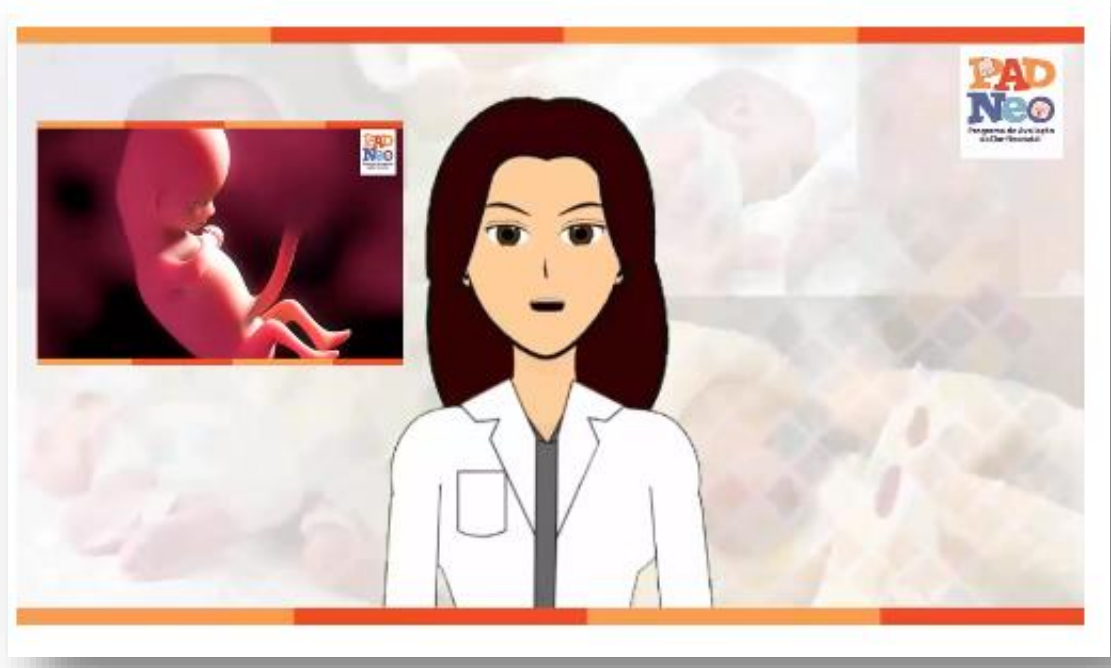

Fonte: Programa de Avaliação da Dor Neonatal (Pad-Neo), 2017.

Figura 2 - Aula interativa desenvolvida com o Software Articulate Storyline®.

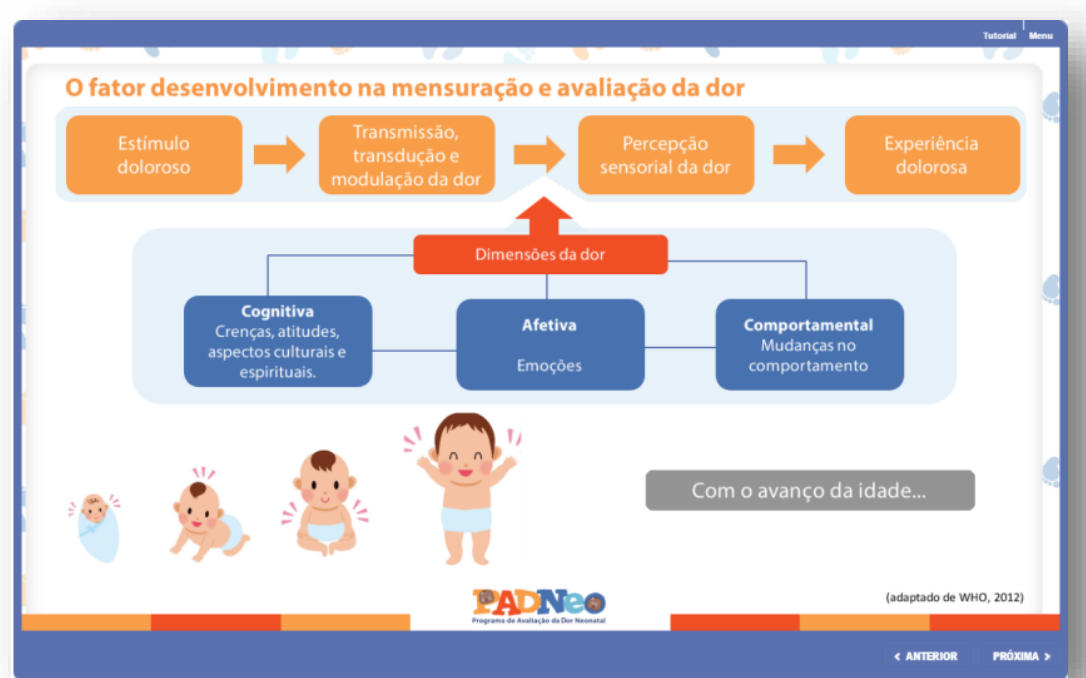

Fonte: Programa de Avaliação da Dor Neonatal (Pad-Neo), 2017. 
Figura 3 - Síntese das aulas apresentadas em cada módulo no formato PDF.

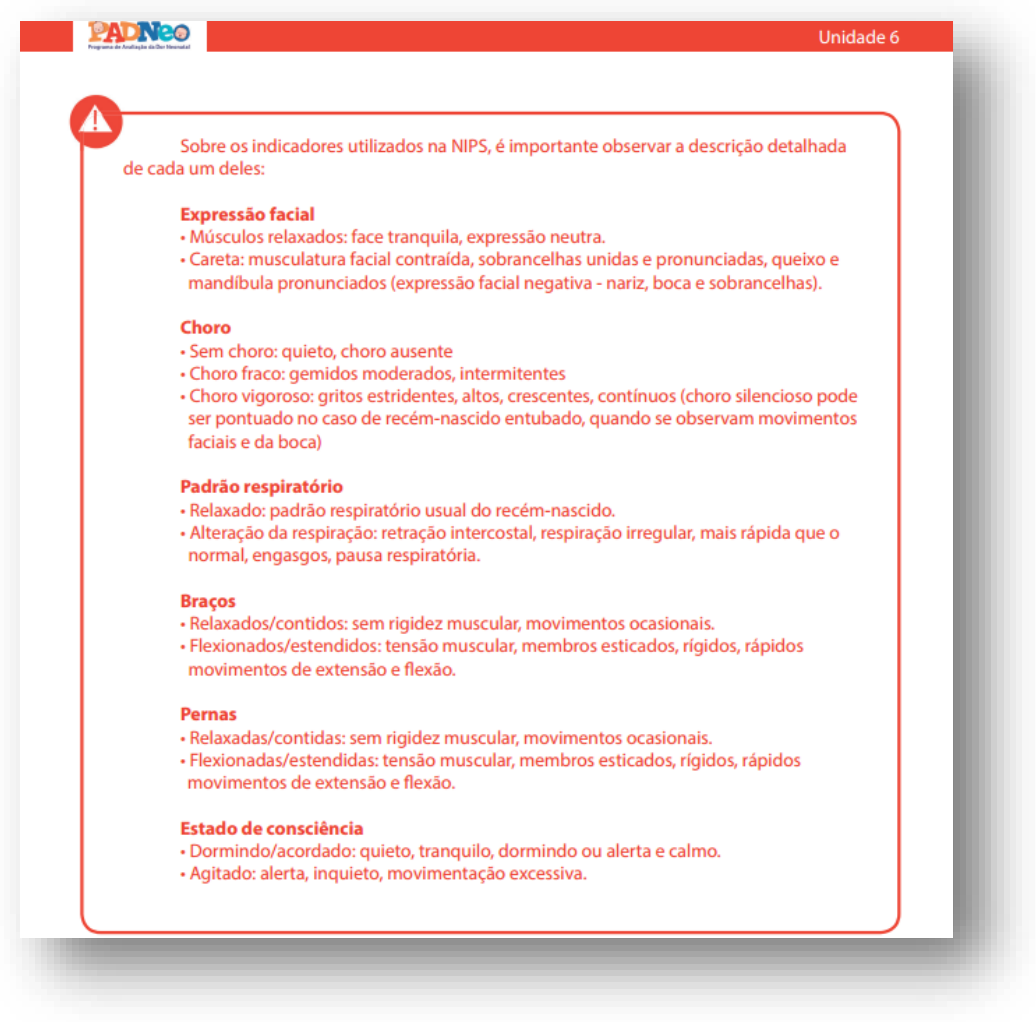

Fonte: Programa de Avaliação da Dor Neonatal (Pad-Neo), 2017.

- Vídeos: são apresentadas imagens de RN submetidos a procedimentos dolorosos de rotina, como imunização e punção de calcâneo. Os vídeos foram gravados em um Hospital Universitário do Estado de São Paulo, mediante aprovação ética e autorização dos pais, e disponibilizados exclusivamente para fins educativos (Figura 4). As imagens são usadas para que os cursistas identifiquem os indicadores de dor e apliquem as escalas de avaliação da dor neonatal abordadas no curso. Esse recurso é utilizado nos módulos cinco a oito. 
Figura 4- Vídeo para realização dos exercícios.

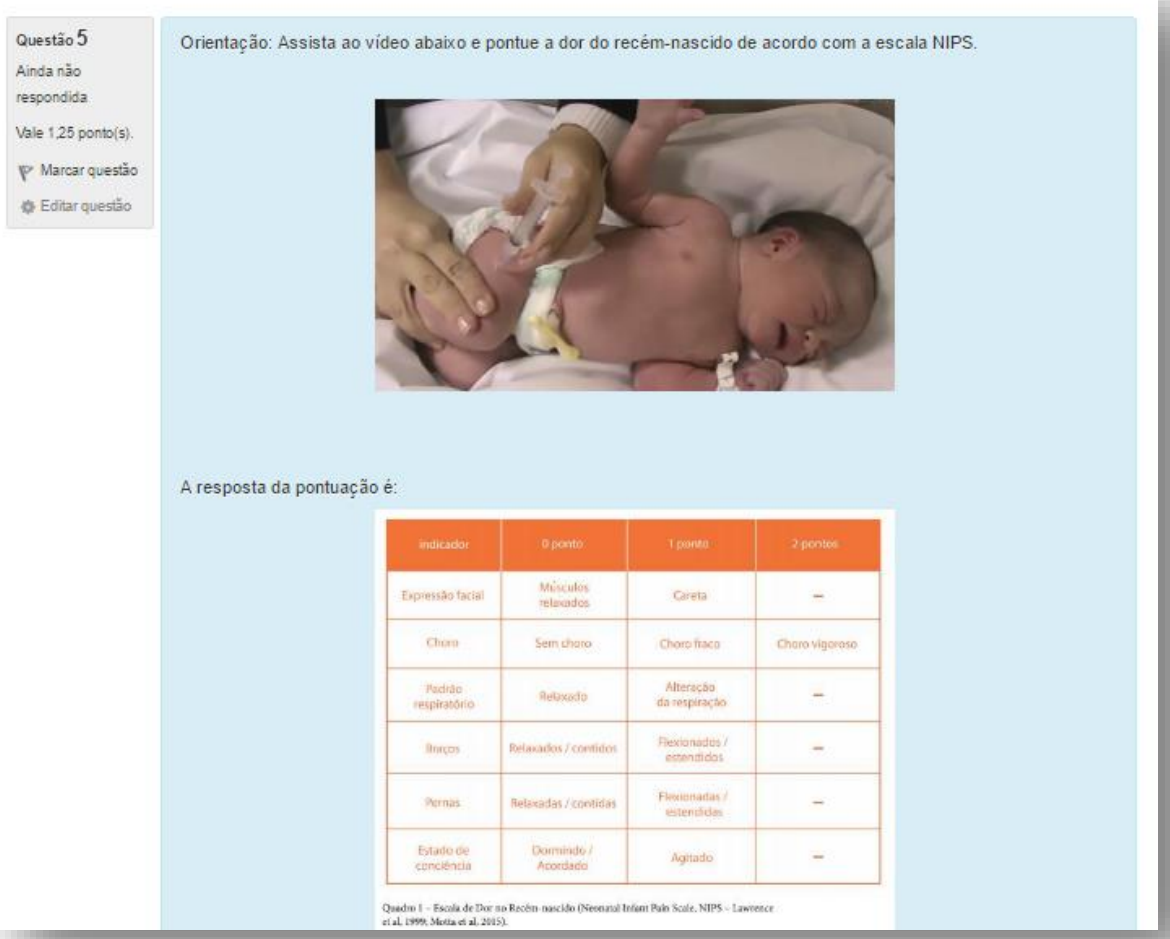

Fonte: Programa de Avaliação da Dor Neonatal (Pad-Neo), 2017.

- Imagens: são utilizadas fotos de RN para que os cursistas identifiquem alterações na mímica facial que compõem os instrumentos de avaliação da dor neonatal (Figura 5). As imagens fazem parte do acervo do curso e são utilizadas nos módulos cinco a nove. 
Figura 5 - Imagem utilizada nos exercícios de avaliação da dor.

Colocando em prática: NFCS $\odot$

Visualizar Editar Relatónios Avaliar dissertaçöes

Você consegue identificar movimentos da mimica facial relacionados à dor que compõem a NFCS nesta imagem?
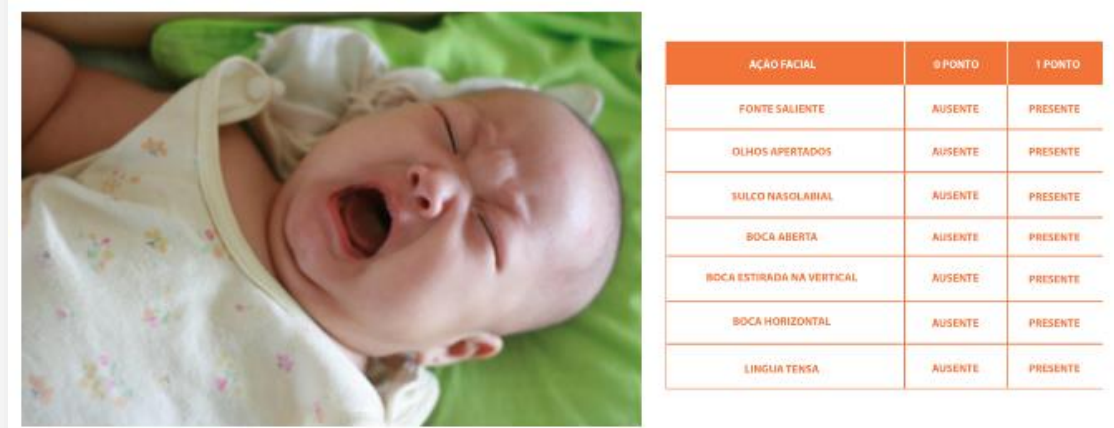

Fonte: Programa de Avaliação da Dor Neonatal (Pad-Neo), 2017.

- Exercícios: a partir do conteúdo teórico exposto durante cada módulo, foram elaborados exercícios para fixação do conteúdo abordado, com vistas a auxiliar a autoavaliação do aluno. Após a realização dos exercícios o aluno recebe um feedback do professor ou tutor do curso. Os exercícios foram disponibilizados em formatos como estudos de caso, questões de múltiplaescolha, questões de verdadeiro ou falso e questões dissertativas (Figura 6, Figura 7). 
Figura 6 - Estudo de Caso para avaliação sobre escala EDIN.

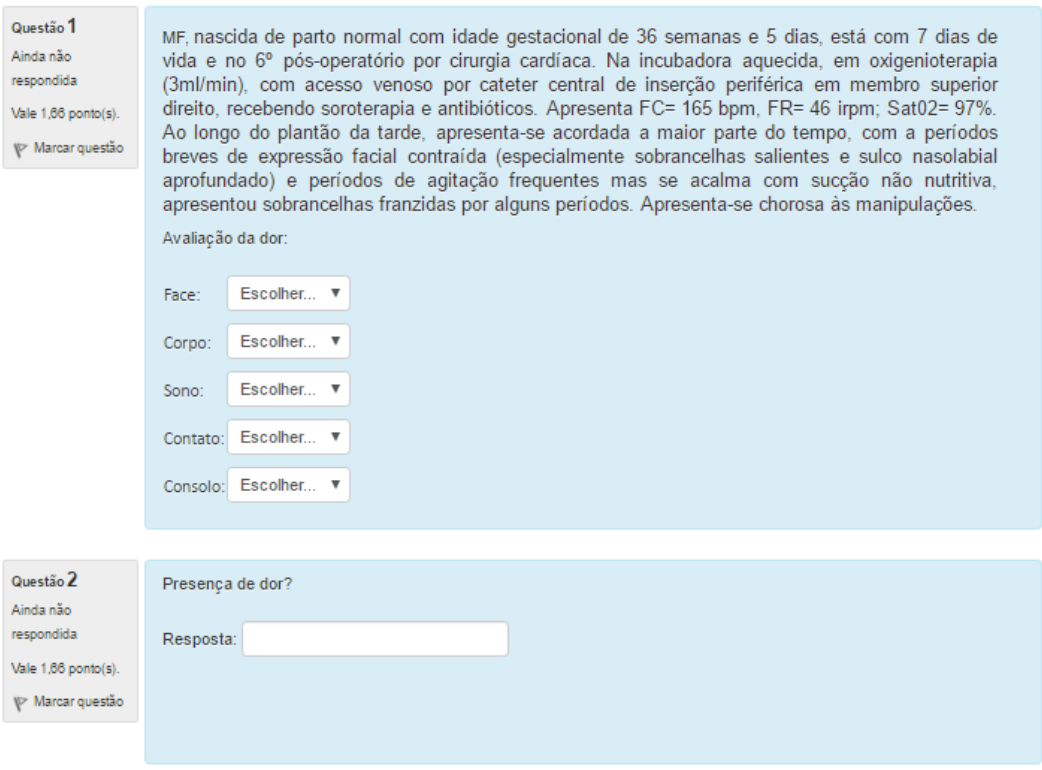

Fonte: Programa de Avaliação da Dor Neonatal (Pad-Neo), 2017.

Figura 7 - Questões dissertativas de avaliação de conteúdo.

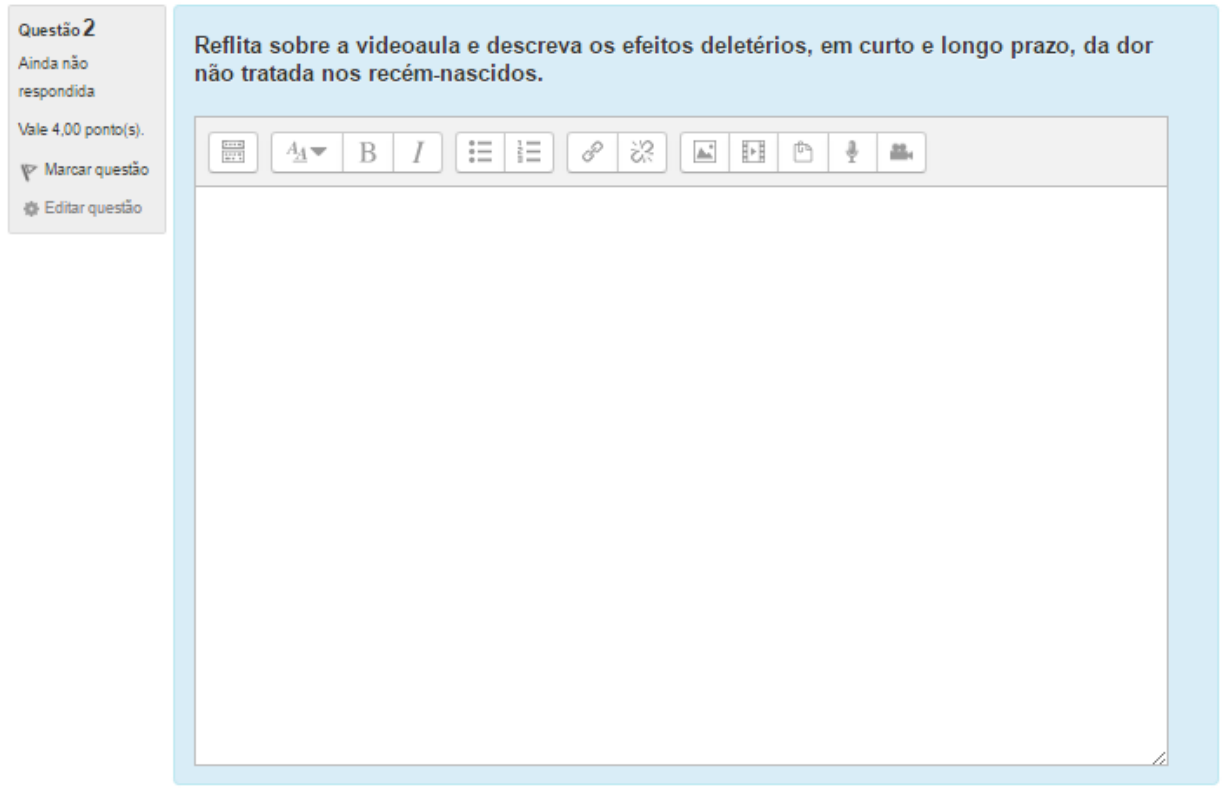

Fonte: Programa de Avaliação da Dor Neonatal (Pad-Neo), 2017. 
- Hipertexto: recurso utilizado para interligar informações de forma a permitir a não linearidade do texto e a interação do usuário com o curso online (Figura 8).

Figura 8 - Utilização de recursos de hipertexto nas aulas.

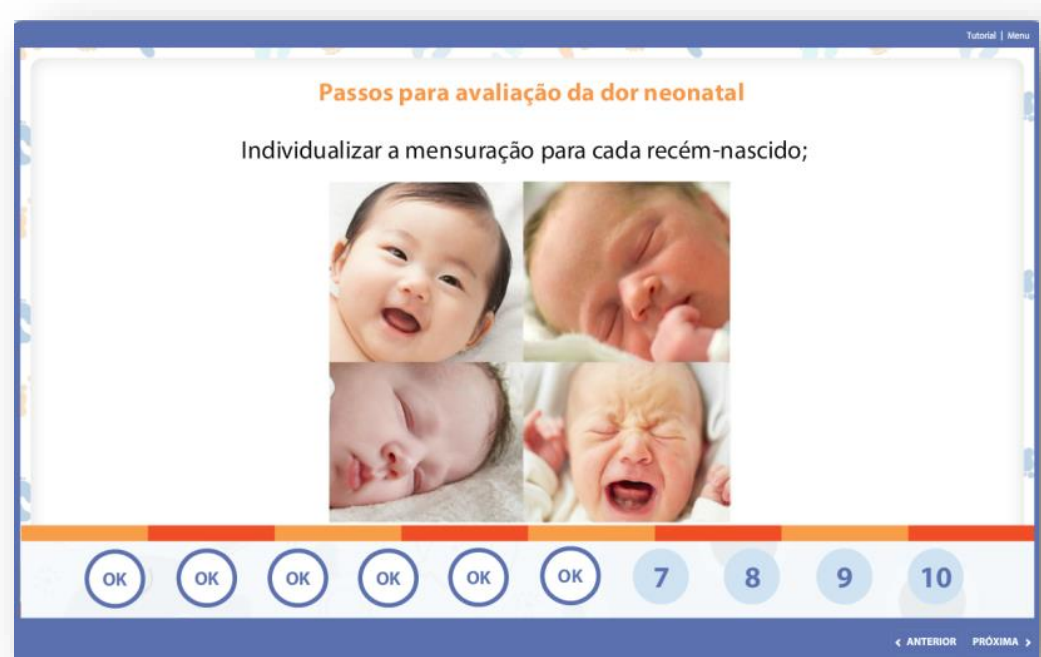

Fonte: Programa de Avaliação da Dor Neonatal (Pad-Neo), 2017.

- Fórum de discussão: espaço interativo de discussão, assíncrono, em que o cursista compartilha de suas experiências, troca conhecimentos e esclarece dúvidas. Disponível em todos os módulos (Figura 9).

Figura 9- Fórum de Discussão.

\section{Fórum de Discussão 7}

O que você considera como principais facilitadores e dificultadores para o uso do Perfil de Dor no Recém-Nascido Pré-Termo Revisado na prática clínica?

Procure elaborar uma reflexão de 4 a 7 linhas sobre o assunto. Após a sua participação procure, ler as postagens dos colegas e faça pelo menos 2 comentários. 
- Fórum de notícias: área em que o aluno pode solicitar informações e orientações sobre o curso online (Figura 10).

Figura 10 - Fórum de Notícias.

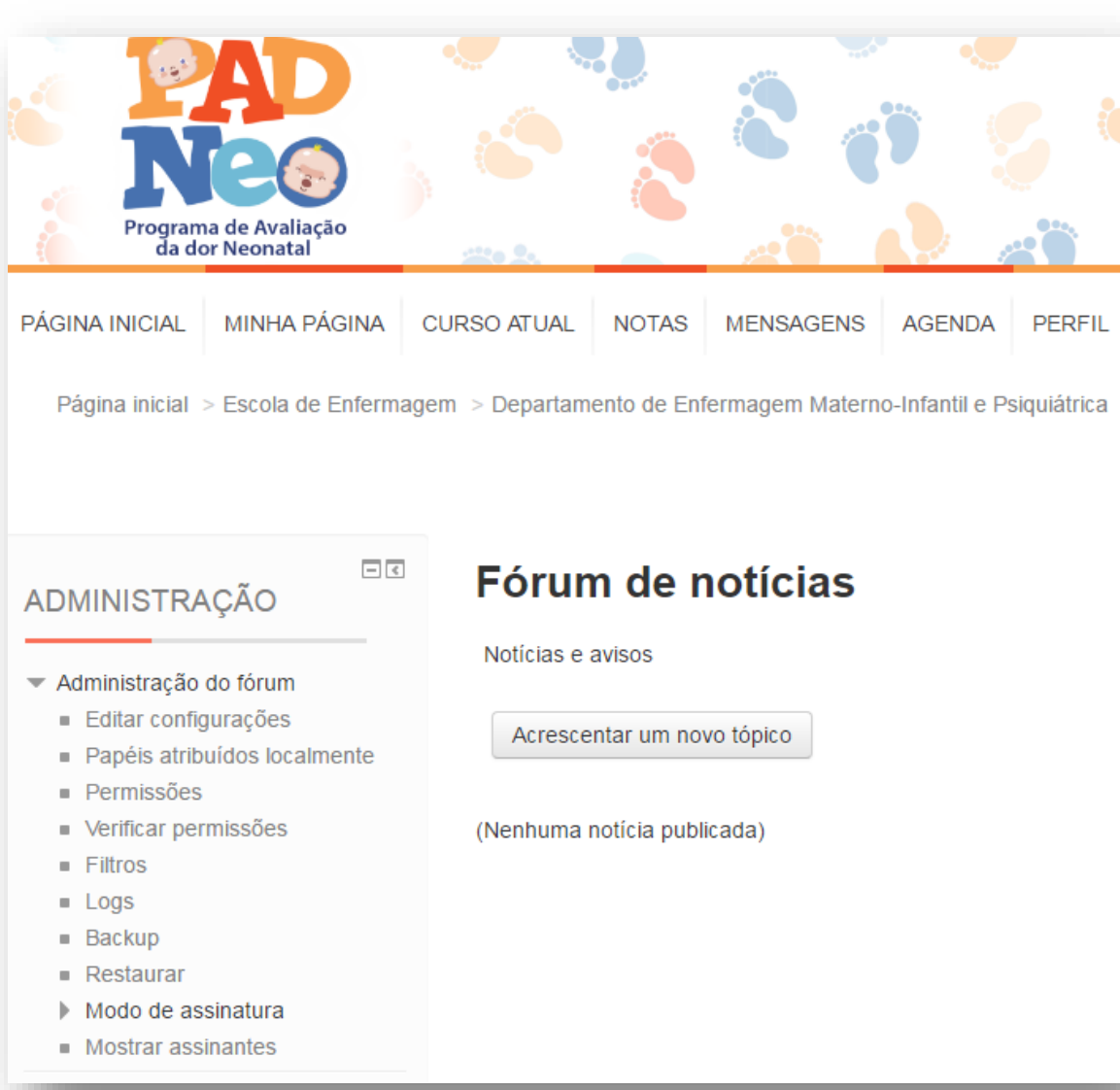

Fonte: Programa de Avaliação da Dor Neonatal (Pad-Neo), 2017. 


\subsection{JUSTIFICATIVA}

A partir da necessidade de aprimorar a utilização das TICs na educação em saúde, com intuito de minimizar a lacuna entre o conhecimento e a prática clínica, faz-se essencial a avaliação de aparência e conteúdo de cursos online desenvolvidos. A avaliação será conduzida por especialistas em áreas de interesse, a fim de garantir o uso de evidências científicas e recursos audiovisuais interativos. O intuito da avaliação é promover a qualidade do ensino-aprendizado. Dessa forma, acredita-se que avaliação é o passo inicial para contribuir com a assistência ao neonato, principalmente em relação à avaliação da dor neonatal. 
Objetiva 


\section{OBJETIVO}

Avaliar a qualidade do curso online Programa de Avaliação da Dor Neonatal (PAD-Neo), sob a perspectiva de especialistas das áreas de dor neonatal, neonatologia e educação a distância. 
Métada 


\section{MÉTODO}

\subsection{DELINEAMENTO DO ESTUDO}

Trata-se de um estudo exploratório descritivo. Esse tipo de desenho permite analisar de forma descritiva determinado fenômeno (Gil, 2008). Portanto, este estudo pretendeu descrever a etapa de avaliação de qualidade do Programa de Avaliação da Dor Neonatal, realizada entre julho a dezembro de 2016.

\subsection{AVALIAÇÃO DO CURSO}

\subsubsection{Participantes}

O presente estudo considerou a participação de oito profissionais de saúde com experiência na temática dor neonatal, oito profissionais de saúde atuantes na assistência neonatal e oito profissionais com experiência em EAD. Foram considerados os critérios estabelecidos pelas Normas de Qualidade dos Produtos de Software ABNT/ISO/IEC 9126-1 (2003) e ABNT/ISO/IEC 14589-6 (2004), que definem ao menos oito indivíduos para cada categoria avaliada.

A escolha dos profissionais para a composição do comitê de especialistas se deve ao fato dos profissionais com experiência em neonatologia e estudos sobre dor neonatal estarem familiarizados com a temática pesquisada. Por sua vez, os especialistas em EAD foram eleitos pois o foco da avaliação do PAD-Neo foi garantir a qualidade dos recursos e métodos educacionais utilizados.

Os critérios de inclusão para a participação no estudo como especialistas em dor neonatal foram ter título de Doutor e possuir projetos de pesquisa e/ou orientações de Mestrado ou Doutorado na área específica. Os profissionais de saúde foram incluídos caso atuassem em assistência neonatal por tempo maior ou equivalente a três anos, ou possuíssem título de Mestre ou Doutor na área específica. Finalmente, 
os especialistas em EAD foram incluídos caso tivessem formação de nível superior na área, ou possuíssem título de Doutor na área ou possuíssem projetos de pesquisa e/ou orientações de Mestrado ou Doutorado na área específica.

A amostragem foi não probabilística de conveniência, selecionada de forma não aleatória, portanto, intencional (Heimann, 2012; Hulley et al., 2015), mediante contatos e parcerias já existentes com líderes e membros do Grupo de Pesquisa Enfermagem e Cuidado Neonatal e Grupo de Estudos e Pesquisas de Tecnologia da Informação nos Processos de Trabalho em Enfermagem, ambos cadastrados no diretório dos Grupos de Pesquisa do CNPq e vinculados à Escola de Enfermagem da Universidade de São Paulo.

\subsubsection{Descrição dos instrumentos utilizados}

O instrumento empregado para a avaliação dos especialistas foi composto por duas partes. A primeira referiu-se à caracterização do perfil do avaliador, considerando os seguintes dados: gênero, idade, formação profissional, titulação, cargo e função atual.

Já, a segunda etapa do instrumento abordou os critérios específicos para a avaliação do curso online e foi desenvolvida com base no instrumento proposto pela Coordenação Central de Educação a Distância - CCEAD - PUCRIO (Campos, Martins, Nunes, 2008) e adaptado por Tobase (2016). Os aspectos avaliados foram: navegação livre, clareza das informações, facilidade de localização das informações, pertinência do conteúdo, contextualização, correção do conteúdo, múltiplas-janelas, facilidade de aprendizagem na interação, eficiência de utilização, facilidade de retorno, ergonomia, estética, marcas especiais, recursos audiovisuais, referências, interatividade, gestão de erros, ajuda aos usuários, qualidade das informações e portabilidade.

Para cada item foram apresentadas seis opções de pontuação $(0 ; 0,25 ; 0,5$; 0,75; 1 e não se aplica), sendo que a pontuação 0 representa a pior avaliação do item e 1, a avaliação mais positiva. Mediante a avaliação dos especialistas, os valores das médias foram calculados, descartando as respostas Não Se Aplica, visto que essa 
opção foi utilizada caso os especialistas não conseguissem avaliar o aspecto. Assim, foi determinado que os itens que apresentassem média final inferior a 0,70 seriam modificados pela equipe de pesquisa para correções e ajustes no curso online, conforme sugestões e necessidade. Deste modo, de acordo com o proposto pelas normas de qualidade ISO/IEC 14598-6, a média final considerada aceitável foi $\geq 0,70$. Ainda, mesmo com relação aos itens avaliados com notas positivas, sugestões e comentários dos especialistas serão considerados, a fim de aprimorar o curso online.

Adicionalmente, todos os itens apresentavam um campo para que o avaliador pudesse expressar de modo descritivo sugestões para melhoria dos critérios apresentados, observações e justificativa de pontuações menores que 0,5.

O formulário foi elaborado e apresentado no aplicativo Google Docs $\AA_{\text {. }}$

\subsubsection{Procedimento para coleta de dados}

Inicialmente, foram listados os nomes de 12 especialistas por área. A seguir, foi enviada uma carta convite, por meio eletrônico, aos primeiros oito profissionais elencados em cada área para a composição do comitê de especialistas (Apêndices $A$, $\mathrm{B} \mathrm{e} C$ ). Na carta, foi oferecida breve descrição do curso online, bem como os objetivos do estudo; também foram incluídas informações sobre a estrutura do formulário de avaliação e os prazos para a participação. Ressaltou-se a confidencialidade quanto aos dados de caracterização e a participação de caráter voluntário.

Mediante 0 aceite de cada especialista, foi enviada nova mensagem eletrônica contendo endereço eletrônico do curso (http://cursosextensao.usp.br/enrol/index.php?id=269), instruções para acesso ao curso como visitante e senha, além de link para o preenchimento do formulário de avaliação online (Apêndice D).

No caso de especialistas impossibilitados de participar do estudo ou na ausência de resposta, mesmo após contatos eletrônicos, foram acionados outros profissionais, de acordo com as áreas de conhecimento e atuação, para composição do comitê. O preenchimento do formulário de avaliação foi monitorado diariamente até a obtenção das respostas dos 24 especialistas, sendo oito especialistas por área. 


\subsection{PREPARAÇÃO E ANÁLISE DE DADOS}

Os dados de caracterização e de avaliação do software foram preenchidos diretamente no Google Docs $\AA$, recurso que permite a visualização dos dados em planilha compatível com o programa Microsoft Excel for Windows. Mediante a obtenção das respostas de todos os especialistas, os dados foram analisados e apresentados de forma descritiva.

\subsection{ASPECTOS ÉTICOS}

O projeto de pesquisa foi apreciado e aprovado pelo Comitê de Ética em Pesquisa da Escola de Enfermagem da Universidade de São Paulo, CAAE 41048915.8.0000.5392 (Anexo 1).

\subsection{FINANCIAMENTO}

Este estudo foi financiado pelo Conselho Nacional de Desenvolvimento Científico e Tecnológico (CNPq), na modalidade Apoio a Projetos de Pesquisa/MCTI/CNPQ/Universal 14/2014, Faixa A, número de processo \#449774/2014-7 e pela International Association for the Study of Pain (IASP), Developing Countries Project: Initiative for Improving Pain Education, 2015-2016. 
Resultados 


\section{RESULTADOS}

O PAD-Neo foi avaliado por 24 especialistas. A princípio foram convidados oito avaliadores de cada área, porém três profissionais com experiência na temática dor neonatal, quatro profissionais atuantes na assistência neonatal e quatro profissionais com experiência em EAD, não responderam ao convite inicial. Dessa forma, foram substituídos por outros profissionais que atenderam aos critérios de inclusão estabelecidos. A seguir, serão apresentados os dados de caracterização dos especialistas e da avaliação do curso online.

\subsection{CARACTERIZAÇÃO DOS ESPECIALISTAS}

O questionário de caracterização foi respondido por todas as participantes, que eram do gênero feminino. A idade média foi de 43 anos, sendo 47 anos a média de idade das especialistas em dor, 38 anos para as participantes com experiência em assistência neonatal e para as avaliadoras com experiência em EAD, 47 anos. A maioria das participantes era graduada em enfermagem (18 - 75\%). Dessas, quatro eram especialistas em dor neonatal, sete atuavam na assistência neonatal e sete, especialistas em EAD. Integraram ainda o comitê de especialistas quatro psicólogas, todas especialistas em dor neonatal, uma fisioterapeuta atuante na assistência ao RN e uma participante graduada em design instrucional, na categoria de especialista em EAD.

Quanto à titulação, duas especialistas eram Pós-Doutoras (8,3\%), quinze especialistas possuíam doutorado (62,5\%), seis possuíam título de Mestre $(25 \%)$ e uma das avaliadoras era especialista em design instrucional $(4,2 \%)$.

Quanto ao cargo e função atual dez avaliadoras eram docentes universitárias $(41,6 \%)$, sendo seis especialistas em dor, três especialistas em EAD e uma de assistência neonatal. Quatro (16,7\%) especialistas em assistência ao RN e uma $(4,2 \%)$ especialista em dor neonatal atuavam em unidades de assistência neonatal ou alojamento conjunto. Duas avaliadoras eram pós-doutorandas (8,3\%), uma especialista em dor neonatal e uma em EAD. Uma especialista em EAD era designer 
instrucional (4,2\%), uma era diretora técnica de educação continuada $(4,2 \%)$, uma era enfermeira de gestão em pessoas $(4,2 \%)$ e uma educadora (4,2\%). Uma avaliadora da área de neonatologia atuava como chefe de unidade de gerenciamento das atividades da graduação e ensino técnico $(4,2 \%)$, uma como supervisora de setor hospitalar do serviço de fisioterapia $(4,2 \%)$ e uma era enfermeira especialista de laboratório em universidade pública (4,2\%).

\subsection{AVALIAÇÃO DO CURSO}

A análise dos dados da avaliação do curso online é apresentada a seguir, considerando-se cada item avaliado pelos especialistas.

\subsubsection{Navegação livre}

Este item é descrito como "permite a navegação livre, isto é, permite o controle da sequência de uso durante a utilização do software. Favorece a autonomia do usuário no uso dos comandos" (Campos, Martins, Nunes, 2008; Tobase, 2016). A maioria dos participantes $(79,2 \%)$ avaliou este item com nota máxima $(1,0)$, sendo a média geral 0,92. A média resultante da avaliação dos especialistas em educação foi 0,81 . Dessa forma, não foram realizadas modificações relacionadas à navegação livre.

Dois avaliadores $(8,3 \%)$ sugeriram o acesso aberto ao conteúdo de todas as unidades desde a primeira semana de curso.

“... esta configuração é linear e dificulta a livre navegação do cursista." 
Tabela 1 - Respostas da avaliação do item "Navegação Livre" do curso online, de acordo com os especialistas. São Paulo, 2017. $(n=24)$

\begin{tabular}{c|cccccc|c}
\hline ESPECIALISTAS & 0 & 0,25 & 0,5 & 0,75 & 1,0 & NA & MÉDIA \\
\hline Todas & $\begin{array}{c}0 \\
(0 \%)\end{array}$ & $\begin{array}{c}1 \\
(4,2 \%)\end{array}$ & $\begin{array}{c}1 \\
(4,2 \%)\end{array}$ & $\begin{array}{c}3 \\
(12,5 \%)\end{array}$ & $\begin{array}{c}19 \\
(79,2 \%)\end{array}$ & $\begin{array}{c}0 \\
(0 \%)\end{array}$ & 0,92 \\
\hline Dor & 0 & 0 & 0 & 2 & 6 & 0 & 0,94 \\
\hline Neonatologia & 0 & 0 & 0 & 0 & 8 & 0 & 1,0 \\
\hline Educação & 0 & 1 & 1 & 1 & 5 & 0 & 0,81 \\
\hline
\end{tabular}

\subsubsection{Clareza das informações}

O item clareza das informações salienta que cada conceito deve ser definido individualmente, conforme ilustrado na Figura 11. Ainda, descreve que "é interessante que cada conceito seja abordado de maneira clara, facilitando o entendimento das informações" (Campos, Martins, Nunes, 2008; Tobase, 2016). De modo geral, 22 especialistas $(91,7 \%)$ avaliaram positivamente a organização e a apresentação das informações. Sendo assim, não foram feitas modificações relacionadas ao item "clareza das informações" na versão atualizada do PAD-Neo.

Figura 11- Apresentação de conceito em única janela.

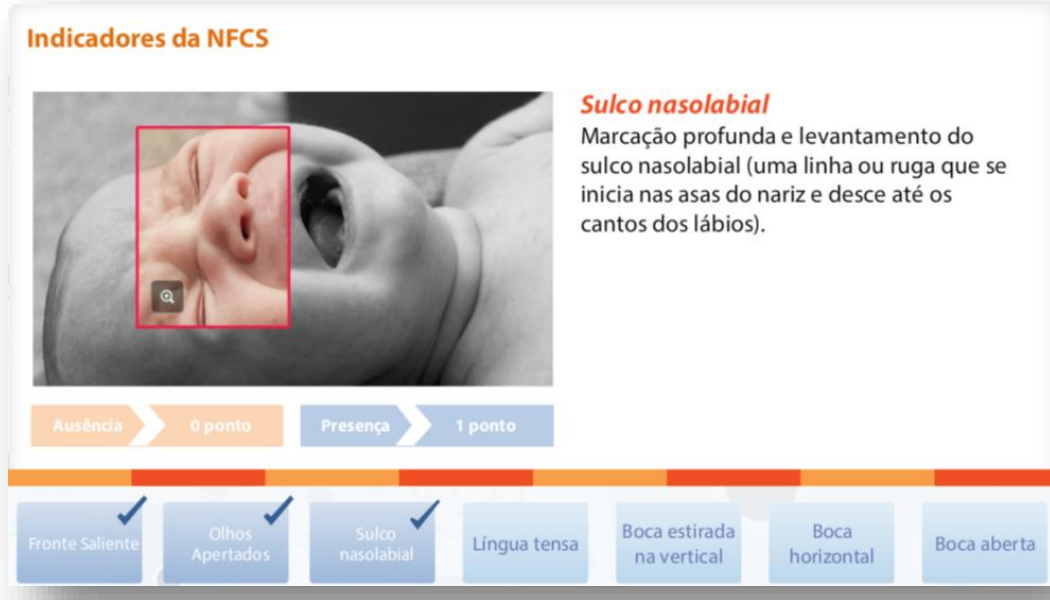

Fonte: Programa de Avaliação da Dor Neonatal (Pad-Neo), 2017. 
Cinco comentários foram realizados, ressaltando a utilização e apresentação dos conceitos e as sugestões apontadas pelos especialistas incluíram a revisão e destaque de conceitos principais.

"Os conceitos e demais explicações são apresentadas brevemente, mas contém as informações necessárias, facilitando a aprendizagem do tema."

"Não foi possível observar o destaque do conceito em uma única janela, no entanto, todos os conceitos estavam claros e explicados com uma abordagem objetiva."

Tabela 2 - Respostas da avaliação do item "Clareza das informações" do curso online, de acordo com os especialistas. São Paulo, 2017. $(n=24)$

\begin{tabular}{c|cccccc|c}
\hline ESPECIALISTAS & 0 & 0,25 & 0,5 & 0,75 & 1,0 & NA & MÉDIA \\
\hline Todas & 0 & 0 & 1 & 1 & 22 & 0 & 0,97 \\
\hline Dor & 0 & 0 & 0 & 1 & 7 & 0 & 0,97 \\
\hline Neonatologia & 0 & 0 & 0 & 0 & 8 & 0 & 1,0 \\
\hline Educação & 0 & 0 & 1 & 0 & 7 & 0 & 0,94 \\
\hline
\end{tabular}

\subsubsection{Facilidade de localização das informações}

A facilidade de localização das informações considera se o curso "possui mecanismos que facilitam a localização da informação. É importante que o usuário tenha informação sobre o que existe no curso e como ele está organizado. Para isto é preciso que existam mecanismos que apresentem formas de localização tais como mapas globais, rota de aprendizagem, menu, glossário e outras guias" (Campos, Martins, Nunes, 2008; Tobase, 2016). A figura 12 exibe a apresentação do conteúdo programático, objetivos e orientações para atividades de um módulo do curso. 
Figura 12- Apresentação de menu e de orientações de módulo.

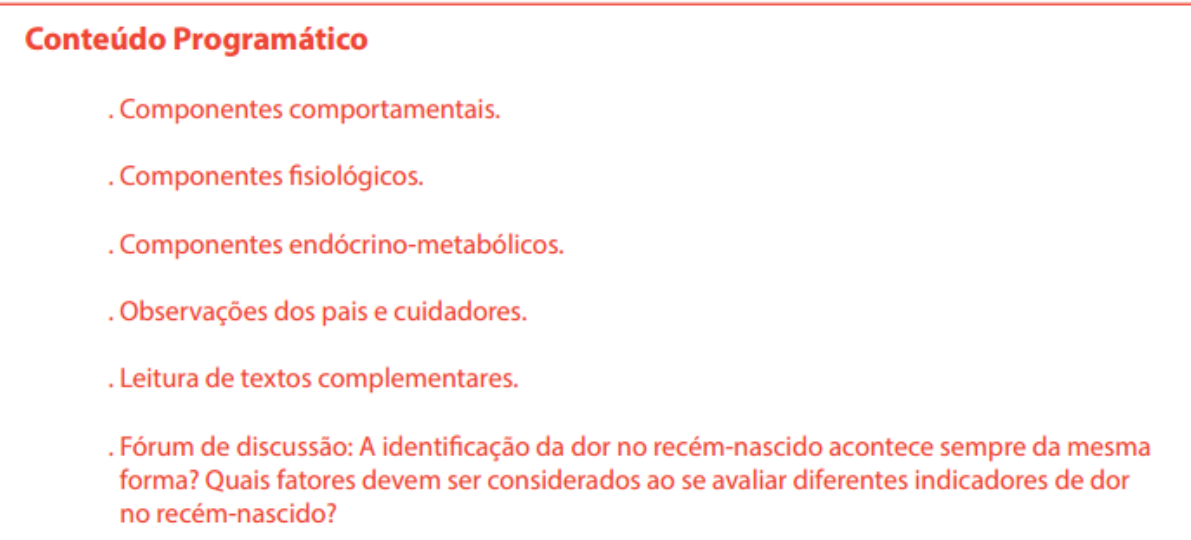

Objetivos

Esperamos que você, ao final desta unidade, seja capaz de:

. Identificar os componentes de dor em recém-nascidos

. Diferenciar os tipos de componentes de dor em recém-nascidos

.Identificar fatores que podem influenciar na percepção da dor em recém-nascidos

Fonte: Programa de Avaliação da Dor Neonatal (Pad-Neo), 2017.

Dessa forma, 18 (75\%) especialistas avaliaram com nota máxima a facilidade de localização das informações. Apenas um especialista em educação avaliou o item com nota zero. No entanto, nenhuma justificativa foi realizada para explicar tal avaliação. Um avaliador sugeriu acrescentar um índice para apresentar o usuário aos temas que serão abordados no curso. Dois participantes indicaram que as instruções do curso foram claras e úteis para o direcionamento pelo AVA. 
Tabela 3 - Respostas da avaliação do item "Facilidade de localização" do curso online, de acordo com os especialistas. São Paulo, 2017. $(n=24)$

\begin{tabular}{c|cccccc|c}
\hline ESPECIALISTAS & 0 & 0,25 & 0,5 & 0,75 & 1,0 & NA & MÉDIA \\
\hline Todas & $\begin{array}{c}1 \\
(4,2 \%)\end{array}$ & $\begin{array}{c}0 \\
(0 \%)\end{array}$ & $\begin{array}{c}1 \\
(4,2 \%)\end{array}$ & $\begin{array}{c}4 \\
(16,7 \%)\end{array}$ & $\begin{array}{c}18 \\
(75 \%)\end{array}$ & $\begin{array}{c}0 \\
(0 \%)\end{array}$ & 0,89 \\
\hline Dor & 0 & 0 & 1 & 1 & 6 & 0 & 0,91 \\
\hline Neonatologia & 0 & 0 & 0 & 1 & 7 & 0 & 0,97 \\
\hline Educação & 1 & 0 & 0 & 2 & 5 & 0 & 0,81 \\
\hline
\end{tabular}

\subsubsection{Pertinência do conteúdo}

Este item avalia se "o conteúdo é apresentado de forma lógica. As formas de interação e navegação são rapidamente compreendidas" (Campos, Martins, Nunes, 2008; Tobase, 2016). Vinte e um (87,5\%) especialistas atribuíram nota máxima, sendo a nota média da avaliação geral 0,96. Assim, não foram realizadas mudanças significativas com relação ao conteúdo teórico abordado no curso.

Três avaliadores apontaram a apresentação do conteúdo como um aspecto positivo, porém um participante afirmou que as informações contidas no curso não foram compreendidas rapidamente.

“... organização facilita muito a compreensão e a fácil navegação."

“... a informação 'clique no botão', quando aparece pela primeira vez, não está em destaque o suficiente para que seja dada continuidade ao conteúdo da forma desejada." 
Tabela 4 - Respostas da avaliação do item "Pertinência do conteúdo" do curso online, de acordo com os especialistas. São Paulo, 2017. $(n=24)$

\begin{tabular}{c|cccccc|c}
\hline ESPECIALISTAS & 0 & 0,25 & 0,5 & 0,75 & 1,0 & NA & MÉDIA \\
\hline Todas & 0 & 0 & 1 & 2 & 21 & 0 & 0,96 \\
$(0 \%)$ & $(0 \%)$ & $(4,2 \%)$ & $(8,3 \%)$ & $(87,5 \%)$ & $(0 \%)$ & 0,94 \\
\hline Dor & 0 & 0 & 0 & 2 & 6 & 0 & 0 \\
\hline Neonatologia & 0 & 0 & 0 & 0 & 8 & 0 & 0,94 \\
\hline Educação & 0 & 0 & 1 & 0 & 7 & 0 & 0 \\
\hline
\end{tabular}

\subsubsection{Contextualização}

A contextualização permite julgar se "o conteúdo está adequado e coerente com a área e o nível de ensinos propostos" (Campos, Martins, Nunes, 2008; Tobase, 2016). O item foi avaliado com nota máxima por 18 (75\%) avaliadores. Um avaliador de educação assinalou "Não se aplica" e justificou que não possuía conhecimento em dor neonatal para avaliar o item.

A principal justificativa oferecida pelos especialistas em dor neonatal para a avaliação (média 0,87) foi a carência de referências em língua portuguesa nas sugestões de leitura complementar. Outra questão levantada foi a necessidade de adequar a linguagem aos profissionais de nível médio, como técnicos de enfermagem, principalmente em relação aos tópicos sobre fisiologia da dor e propriedades psicométricas.

“... a definição de construto, por se tratar de um conceito difícil para quem não o conhece, não está muito claro mesmo para profissionais de nível superior."

Mediante nova busca na literatura, alguns recursos em língua portuguesa foram selecionados e incluídos no curso. Contudo, optou-se por manter a linguagem adotada 
inicialmente, visto que o público-alvo do PAD-Neo são estudantes de ensino superior e profissionais de saúde.

Tabela 5 - Respostas da avaliação do item "Contextualização" do curso online, de acordo com os especialistas. São Paulo, 2017. $(n=24)$

\begin{tabular}{c|cccccc|c}
\hline ESPECIALISTAS & 0 & 0,25 & 0,5 & 0,75 & 1,0 & NA & MÉDIA \\
\hline Todas & 0 & 0 & 0 & 5 & 18 & 1 & 0,94 \\
& $(0 \%)$ & $(0 \%)$ & $(0 \%)$ & $(20,8 \%)$ & $(75 \%)$ & $(4,2 \%)$ & 0,87 \\
\hline Dor & 0 & 0 & 0 & 4 & 4 & 0 & 0 \\
\hline Neonatologia & 0 & 0 & 0 & 0 & 8 & 0 & 1,0 \\
\hline Educação & 0 & 0 & 0 & 1 & 6 & 1 & 0,96 \\
\hline
\end{tabular}

\subsubsection{Correção de conteúdo}

Este item aprecia o "rigor cientifico dos conhecimentos transmitidos" (Campos, Martins, Nunes, 2008; Tobase, 2016). Assim, 20 (83,3\%) especialistas atribuíram nota máxima à "correção de conteúdo". As médias de avaliação pelos especialistas, de modo geral $(0,98)$, e de cada categoria de avaliadores, foram bastante elevadas.

No entanto, os avaliadores indicaram a presença de alguns erros ortográficos e de digitação, que foram revisados. 
Tabela 6 - Respostas da avaliação do item "Correção de conteúdo" do curso online, de acordo com os especialistas. São Paulo, 2017. ( $n=24)$

\begin{tabular}{c|cccccc|c}
\hline ESPECIALISTAS & 0 & 0,25 & 0,5 & 0,75 & 1,0 & NA & MÉDIA \\
\hline Todas & 0 & 0 & 0 & 2 & 20 & 2 & 0,98 \\
$(0 \%)$ & $(0 \%)$ & $(0 \%)$ & $(8,3 \%)$ & $(83,3 \%)$ & $(8,3 \%)$ & \\
\hline Dor & 0 & 0 & 0 & 1 & 7 & 0 & 0,97 \\
\hline Neonatologia & 0 & 0 & 0 & 0 & 8 & 0 & 1,0 \\
\hline Educação & 0 & 0 & 0 & 1 & 5 & 2 & 0,96 \\
\hline
\end{tabular}

\subsubsection{Múltiplas janelas}

Este item avalia se o curso "abre várias janelas simultaneamente, se necessário. Isto não é uma regra, pois a abertura de múltiplas janelas sobrepostas também pode confundir o leitor. Contudo, em certas situações torna-se interessante apresentar informações parcialmente sobrepostas" (Campos, Martins, Nunes, 2008; Tobase, 2016).

Vinte e um avaliadores (87,5\%) atribuíram nota máxima a este item, sendo a média geral 0,97 . No entanto, um avaliador considerou que essa opção depende da preferência pessoal do cursista, visto que a abertura de várias janelas pode confundir o usuário ou facilitar o retorno ao AVA.

“... entendo que pode confundir. No entanto, acredito que se fosse em uma mesma janela o usuário iria ficar com muita dificuldade para acessar novamente $o$ ambiente virtual de aprendizagem."

Este aspecto, portanto, não sofreu modificações mediante a avaliação dos especialistas. 
Tabela 7 - Respostas da avaliação do item "Múltiplas janelas" do curso online, de acordo com os especialistas. São Paulo, 2017. $(n=24)$

\begin{tabular}{c|cccccc|c}
\hline ESPECIALISTAS & 0 & 0,25 & 0,5 & 0,75 & 1,0 & NA & MÉDIA \\
\hline Todas & 0 & 0 & 0 & 3 & 21 & 0 & 0,97 \\
$(0 \%)$ & $(0 \%)$ & $(0 \%)$ & $(12,5 \%)$ & $(87,5 \%)$ & $(0 \%)$ & 0,97 \\
\hline Dor & 0 & 0 & 0 & 1 & 7 & 0 & 0,97 \\
\hline Eeonatologia & 0 & 0 & 0 & 1 & 7 & 0 & 0,97 \\
\hline
\end{tabular}

\subsubsection{Facilidade de aprendizagem na interação}

A facilidade de aprendizagem na interação "permite compreender rapidamente a interação no software. A estrutura, o software e sua navegação devem ser de fácil entendimento pelo usuário" (Campos, Martins, Nunes, 2008; Tobase, 2016).

Vinte e dois avaliadores (91,7\%) atribuíram nota máxima ao item. A média geral foi de 0,96 . No entanto, a média de avaliação dos especialistas em educação foi 0,87, porém nenhuma justificativa foi oferecida para explicar as notas atribuídas. 
Tabela 8 - Respostas da avaliação do item "Facilidade de aprendizagem na interação" do curso online, de acordo com os especialistas. São Paulo, 2017. ( $n=24)$

\begin{tabular}{c|cccccc|c}
\hline ESPECIALISTAS & 0 & 0,25 & 0,5 & 0,75 & 1,0 & NA & MÉDIA \\
\hline Todas & 0 & 1 & 0 & 1 & 22 & 0 & 0,96 \\
& $(0 \%)$ & $(4,2 \%)$ & $(0 \%)$ & $(4,2 \%)$ & $(91,7 \%)$ & $(0 \%)$ & \\
\hline Dor & 0 & 0 & 0 & 0 & 8 & 0 & 1,0 \\
\hline Neonatologia & 0 & 0 & 0 & 0 & 8 & 0 & 1,0 \\
\hline Educação & 0 & 1 & 0 & 1 & 6 & 0 & 0,87 \\
\hline
\end{tabular}

\subsubsection{Eficiência de utilização}

A eficiência de utilização sugere que "todas as informações e comandos apresentados são necessários para a utilização no curso" (Campos, Martins, Nunes, 2008; Tobase, 2016). A figura 13 ilustra os comandos de orientação para a utilização das aulas interativas.

Figura 13 - Orientações para clicar nos botões durante a aula interativa.

\section{Pontuação do PIPP-R}

A pontuação total é o valor da soma da pontuação sub-total, pontuação da idade gestacional e pontuação do estado comportamental. Varia de 0 a 21 para recém-nascidos pré-termo e entre 0 e 18 pontos para neonatos a termo.

จ 0 : ausência de dor 1 a 6:dor mínima

7 a 12: dor moderada

$\checkmark 12$ : dor intensa 
Vinte participantes $(83,3 \%)$ avaliaram este item com nota máxima. Um especialista em educação atribuiu nota 0,25 ao item. No entanto, nenhuma justificativa foi oferecida. Visto que a média geral da avaliação dos especialistas foi 0,94 , não foram propostas correções relacionadas à eficiência de utilização.

Tabela 9- Respostas da avaliação do item "Eficiência na utilização" do curso online, de acordo com os especialistas. São Paulo, 2017. $(n=24)$

\begin{tabular}{c|cccccc|c}
\hline ESPECIALISTAS & 0 & 0,25 & 0,5 & 0,75 & 1,0 & NA & MÉDIA \\
\hline Todas & 0 & 1 & 0 & 3 & 20 & 0 & 0,94 \\
\hline Dor & 0 & 0 & 0 & 2 & 6 & 0 & 0,94 \\
\hline Neonatologia & 0 & 0 & 0 & 1 & 7 & 0 & 0,97 \\
\hline Educação & 0 & 1 & 0 & 0 & 7 & 0 & 0,91 \\
\hline
\end{tabular}

\subsubsection{Facilidade de retorno}

Este item avalia o "retorno fácil a localizações anteriores. Muitas vezes, durante a navegação pode ocorrer o caso em que o leitor decide seguir ligações que o conduzam a informações inesperadas e/ou indesejadas. Neste caso, o software deve possibilitar o retorno fácil" (Campos, Martins, Nunes, 2008; Tobase, 2016).

Dezenove avaliadores conferiram nota 1,0 a este item, sendo a média das respostas é de 0,92. Em contra partida, um (4,2\%) especialista em educação atribuiu nota mínima $(0,0)$ ao item, sem justificativa para a avaliação negativa. Assim, a média de avaliação dos especialistas em EAD 0,81. Duas especialistas (8,3\%) afirmaram que tiveram sucesso ao retornar para a página inicial.

Mediante avaliação positiva dos especialistas, nenhuma mudança foi realizada a fim de facilitar o retorno a localizações anteriores. 
"Este quesito chamou a atenção, pois diversas vezes decidi fazer ligações com outras aulas e textos, e a navegação para essa atividade estava acessível."

Tabela 10 - Respostas da avaliação do item "Facilidade de retorno" do curso online, de acordo com os especialistas. São Paulo, 2017. $(n=24)$

\begin{tabular}{c|cccccc|c}
\hline ESPECIALISTAS & 0 & 0,25 & 0,5 & 0,75 & 1,0 & NA & MÉDIA \\
\hline Todas & $\begin{array}{c}1 \\
(4,2 \%)\end{array}$ & $\begin{array}{c}0 \\
(0 \%)\end{array}$ & $\begin{array}{c}0 \\
(0 \%)\end{array}$ & $\begin{array}{c}4 \\
(16,7 \%)\end{array}$ & $\begin{array}{c}19 \\
(79,2 \%)\end{array}$ & $\begin{array}{c}0 \\
(0 \%)\end{array}$ & 0,92 \\
\hline Dor & 0 & 0 & 0 & 2 & 6 & 0 & 0,94 \\
\hline Neonatologia & 0 & 0 & 0 & 0 & 8 & 0 & 1,0 \\
\hline Educação & 1 & 0 & 0 & 2 & 5 & 0 & 0,81 \\
\hline
\end{tabular}

\subsubsection{Ergonomia}

A ergonomia considera a "manutenção da interação e da apresentação de forma uniforme em todas as telas. A uniformidade dos recursos utilizados na navegação (ex.: botões e ícones localizados sempre na mesma posição) permite ao usuário uma familiarização de forma mais eficiente" (Campos, Martins, Nunes, 2008; Tobase, 2016). Assim, como ilustrado nas figuras 14 e 15, os módulos apresentam uniformidade com relação ao uso de botões, fotos, cores e informações similares a respeito de diferentes conteúdos. 
Figura 14 - Tela da aula interativa do módulo sobre a escala NIPS.

\section{Sobre a NIPS}

A escala NIPS pode ser usada em recém-nascidos de qualquer idade gestacional?

\section{SIM}

Sim.

A escala NIPS é indicada e validada para avaliar a dor em recém-nascidos pré-termo e termo.

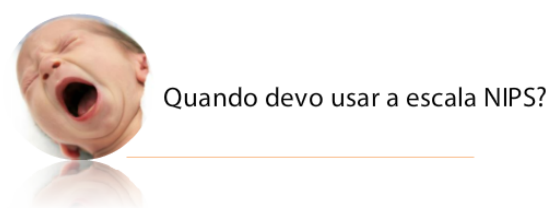

- Em horários preestabelecidos no plano assistencial, em geral, concomitante à aferição de dados vitais.

- No período pós-operatório, conforme estabelecido no plano assistencial.

v Antes, durante e após procedimentos dolorosos ou estressantes.

- Sempre que houver suspeita de ocorrência de dor.

Fonte: Programa de Avaliação da Dor Neonatal (Pad-Neo), 2017.

Figura 15 - Tela da aula interativa do módulo sobre a escala EDIN.

\section{Perguntas sobre a EDIN?}

A escala EDIN pode ser usada em recém-nascidos de qualquer idade gestacional?

\section{SIM}

Sim.

A escala EDIN é indicada e validada para avaliar a dor prolongada em recém-nascidos pré termo e termo.

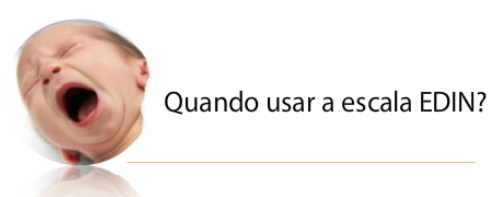

- A escala pode ser aplicada em horários estabelecidos no plano assistencial com intervalos mínimos de três horas.

- Recomenda-se sua aplicação, minimamente, de uma a duas vezes ao dia por profissionais que mantenham contato prolongado com o recémnascido. 
Em relação a este item, vinte $(83,3 \%)$ especialistas avaliaram com nota máxima, assim a média de avaliação geral é 0,94. Pode-se atribuir a avaliação positiva desse item à padronização que foi seguida, não somente quanto à localização de botões e ícones, mas também quanto ao padrão das informações mantidas nas videoaulas, por exemplo. Um avaliador $(4,2 \%)$ sugeriu acrescentar som para identificar a seleção dos ícones, ao clicar com o mouse.

Tabela 11 - Respostas da avaliação do item "Ergonomia" do curso online, de acordo com os especialistas. São Paulo, 2017. ( $n=24)$

\begin{tabular}{c|cccccc|c}
\hline ESPECIALISTAS & 0 & 0,25 & 0,5 & 0,75 & 1,0 & NA & MÉDIA \\
\hline Todas & 0 & 1 & 0 & 3 & 20 & 0 & 0,94 \\
& $(0 \%)$ & $(4,2 \%)$ & $(0 \%)$ & $(12,5 \%)$ & $(83,3 \%)$ & $(0 \%)$ & \\
\hline Dor & 0 & 0 & 0 & 1 & 7 & 0 & 0,97 \\
\hline Neonatologia & 0 & 0 & 0 & 2 & 6 & 0 & 0,94 \\
\hline Educação & 0 & 1 & 0 & 0 & 7 & 0 & 0,91 \\
\hline
\end{tabular}

\subsubsection{Estética}

Este item avaliou se "o objeto possui padrões de interface adequados ao conteúdo" (Campos, Martins, Nunes, 2008; Tobase, 2016). Assim, 22 (91,7\%) avaliadores atribuíram nota máxima à estética do curso online, conferindo média geral de avaliação 0,96.

Os avaliadores consideraram a escolha das cores, animações, ícones, fontes e outros objetos de aprendizagem digitais, agradáveis e chamativos (Figura 16). Ressalta-se que todos esses elementos foram desenvolvidos especificamente para 0 PAD-Neo e exaustivamente avaliados, aprimorados e testados pela equipe responsável pelo curso. 
Figura 16- Logotipo do PAD-Neo.

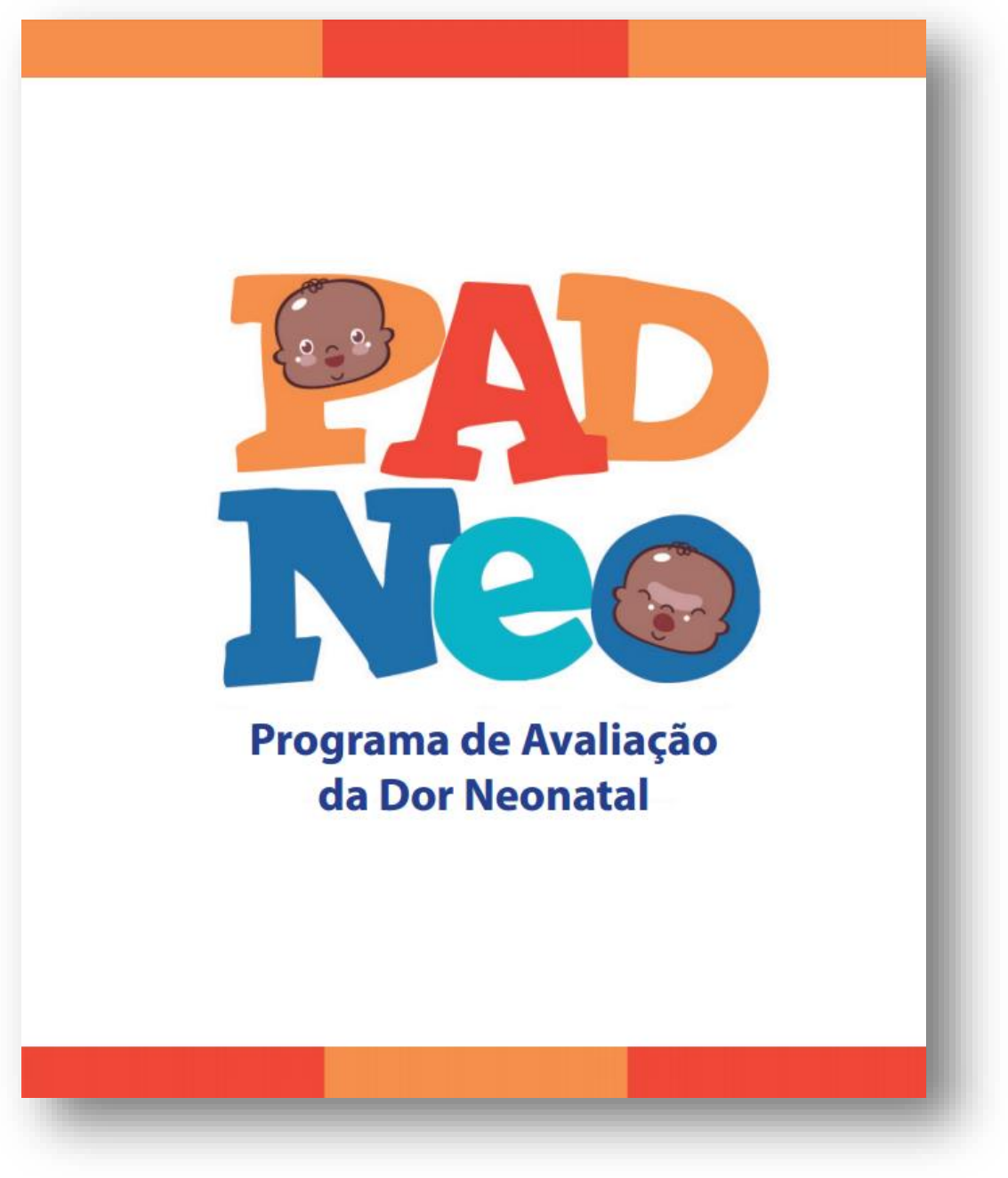

Fonte: Programa de Avaliação da Dor Neonatal (Pad-Neo), 2017.

“... as fontes utilizadas favorecem a legibilidade e leiturabilidade."

Assim, a avaliação positiva deste item dispensou a necessidade de revisões. 
Tabela 12 - Respostas da avaliação do item "Estética" do curso online, de acordo com os especialistas. São Paulo, 2017. $(n=24)$

\begin{tabular}{c|cccccc|c}
\hline ESPECIALISTAS & 0 & 0,25 & 0,5 & 0,75 & 1,0 & NA & MÉDIA \\
\hline Todas & 0 & 1 & 0 & 1 & 22 & 0 & 0,96 \\
\hline Dor & 0 & 0 & 0 & 0 & 8 & 0 & 1,0 \\
\hline Neonatologia & 0 & 0 & 0 & 1 & 7 & 0 & 0,97 \\
\hline Educação & 0 & 1 & 0 & 0 & 7 & 0 & 0,91 \\
\hline
\end{tabular}

\subsubsection{Marcas especiais}

Este item aprecia a "utilização de marcas especiais como cores, molduras e outras para facilitar o reconhecimento do contexto em que se encontra. É interessante que, ao mudar de contexto durante a navegação pelo curso, o leitor receba indicações visuais a respeito do ponto em que se encontra, facilitando a sua orientação" (Campos, Martins, Nunes, 2008; Tobase, 2016). A figura 17 ilustra o logotipo e as marcas desenvolvidos especificamente para o PAD-Neo e utilizado em todos os materiais do curso. 
Figura 17- Marcas especiais no módulo sobre a escala BIIP.

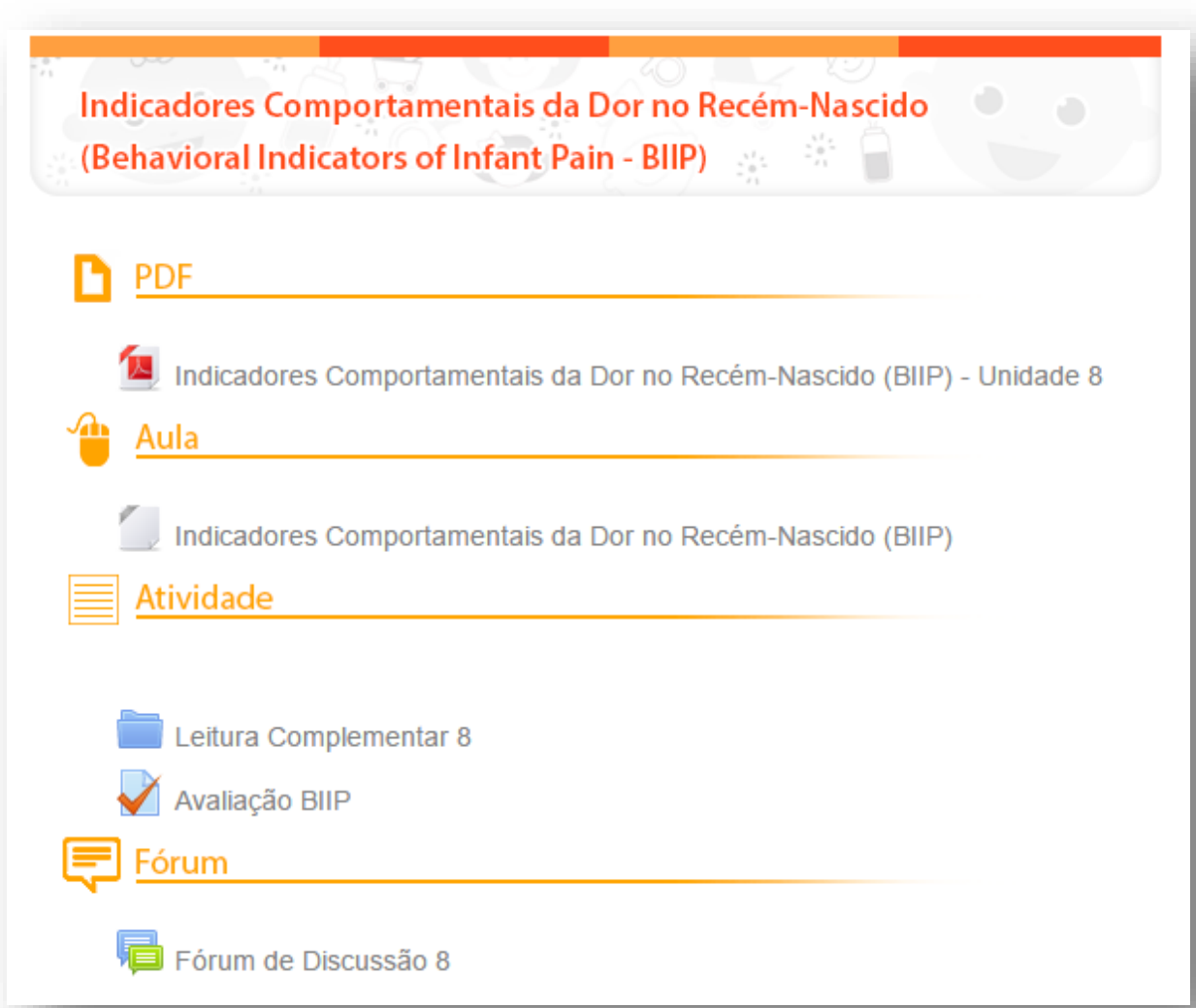

Fonte: Programa de Avaliação da Dor Neonatal (Pad-Neo), 2017.

Vinte $(83,3 \%)$ avaliadores atribuíram nota máxima ao item uso de marcas especiais, sendo a média geral 0,93 . Uma pessoa $(4,2 \%)$ sugeriu utilizar ícones para identificar o avanço entre as unidades do programa.

"Existe indicação de progressão dentro de um mesmo modulo, mas não no avanço entre os módulos ao longo do curso". 
Tabela 13 - Respostas da avaliação do item "Marcas especiais" do curso online, de acordo com os especialistas. São Paulo, 2017. $(n=24)$

\begin{tabular}{c|cccccc|c}
\hline ESPECIALISTAS & 0 & 0,25 & 0,5 & 0,75 & 1,0 & NA & MÉDIA \\
\hline Todas & 0 & 1 & 1 & 2 & 20 & 0 & 0,93 \\
& $(0 \%)$ & $(4,2 \%)$ & $(4,2 \%)$ & $(8,3 \%)$ & $(83,3 \%)$ & $(0 \%)$ & 0,97 \\
\hline Dor & 0 & 0 & 0 & 1 & 7 & 0 & 0,91 \\
\hline Neonatologia & 0 & 0 & 1 & 1 & 6 & 0 & 0,91 \\
\hline
\end{tabular}

\subsubsection{Recursos audiovisuais}

Este item avalia se o curso "apresentou recursos audiovisuais de forma adequada" (Campos, Martins, Nunes, 2008; Tobase, 2016). Catorze (58,3\%) especialistas atribuíram nota máxima ao uso de recursos audiovisuais. A média geral da avaliação dos especialistas foi 0,85 .

Os especialistas consideram que os recursos audiovisuais utilizados nas unidades de quatro a nove são menos interessantes em relação às unidades dois e três, que apresentam videoaulas com uso de áudio e avatar de representação do professor. No entanto, as aulas apresentadas a partir da unidade quatro são interativas, apresentam animações, hipertextos e botões clicáveis. Os exercícios das unidades de quatro a nove possuem recursos audiovisuais tais como estudos de caso, vídeos e imagens para a avaliação da dor neonatal por intermédio dos instrumentos de avaliação.

A escassez na variedade de recursos de multimídia foi considerada um fator negativo na avaliação deste critério. Os recursos multimídia sugeridos pelos especialistas incluíram uso de vídeos mais curtos e legendados em português e áudios durante as aulas interativas, das unidades quatro a nove. 
Tabela 14 - Respostas da avaliação do item "Recursos audiovisuais" do curso online, de acordo com os especialistas. São Paulo, 2017. $(n=24)$

\begin{tabular}{c|cccccc|c}
\hline ESPECIALISTAS & 0 & 0,25 & 0,5 & 0,75 & 1,0 & NA & MÉDIA \\
\hline Todas & 0 & 0 & 4 & 6 & 14 & 0 & 0,85 \\
\hline Dor & 0 & 0 & 0 & 4 & 4 & 0 & 0,87 \\
\hline Neonatologia & 0 & 0 & 0 & 0 & 8 & 0 & 1,0 \\
\hline Educação & 0 & 0 & 4 & 2 & 2 & 0 & 0,69 \\
\hline
\end{tabular}

\subsubsection{Referências}

A utilização de referências compreende a "apresentação das fontes de seu conteúdo e das informações de seu autor" (Campos, Martins, Nunes, 2008; Tobase, 2016). Este item teve média geral 0,93, devido à avaliação com nota máxima por 19 $(79,2 \%)$ especialistas.

O uso de evidências cientificas válidas e atualizadas foi avaliado positivamente por grande parte dos especialistas. A escassez de artigos na língua portuguesa foi novamente considerada como um aspecto negativo pelos avaliadores nesta categoria.

“... a maioria dos artigos de leitura complementar está em inglês, como o curso deve incluir enfermeiros e estudantes de todas as localidades do Brasil, considero ter equilíbrio dos artigos em inglês/português." 
Tabela 15 - Respostas da avaliação do item "Referências" do curso online, de acordo com os especialistas. São Paulo, 2017. $(n=24)$

\begin{tabular}{c|cccccc|c}
\hline ESPECIALISTAS & 0 & 0,25 & 0,5 & 0,75 & 1,0 & NA & MÉDIA \\
\hline Todas & 0 & 1 & 0 & 4 & 19 & 0 & 0,93 \\
& $(0 \%)$ & $(4,2 \%)$ & $(0 \%)$ & $(16,7 \%)$ & $(79,2 \%)$ & $(0 \%)$ & 0,94 \\
\hline Dor & 0 & 0 & 0 & 2 & 6 & 0 & 0 \\
\hline Neonatologia & 0 & 0 & 0 & 0 & 8 & 0 & 0,84 \\
\hline Educação & 0 & 1 & 0 & 2 & 5 & 0 & 0 \\
\hline
\end{tabular}

\subsubsection{Interatividade}

A interatividade tem como objetivo avaliar a "interação do usuário com o software. Há evidências de que o aluno aprende mais quando participa ativamente do processo de aprendizado ao invés de apenas receber informações" (Campos, Martins, Nunes, 2008; Tobase, 2016).

Treze $(54,2 \%)$ participantes avaliaram a interatividade com nota máxima. Alguns avaliadores, entretanto, consideraram que a sequência linear do Moodle, as aulas expositivas e a escassez de recursos de multimídia não permitem a participação ativa do aluno. Os especialistas apontaram o fórum de discussão como ferramenta que facilita e estimula a interação do aluno.

"... com o fórum de discussão, os textos que eles terão que produzir e os exercícios ao final de cada unidade, eles se sintam bem estimulados." 
Tabela 16 - Respostas da avaliação do item "Interatividade" do curso online, de acordo com os especialistas. São Paulo, 2017. $(n=24)$

\begin{tabular}{c|cccccc|c}
\hline ESPECIALISTAS & 0 & 0,25 & 0,5 & 0,75 & 1,0 & NA & MÉDIA \\
\hline Todas & 0 & 2 & 2 & 7 & 13 & 0 & 0,82 \\
$(0 \%)$ & $(8,3 \%)$ & $(8,3 \%)$ & $\begin{array}{c}(29,2 \%) \\
(54,2 \%)\end{array}$ & $(0 \%)$ & 0,84 \\
\hline Dor & 0 & 0 & 1 & 3 & 4 & 0 & 0,97 \\
\hline Neonatologia & 0 & 0 & 0 & 1 & 7 & 0 & 0,66 \\
\hline
\end{tabular}

\subsubsection{Gestão de erros}

A gestão de erros avalia "mecanismos que permitem evitar ou reduzir a ocorrência de erros, e quando eles ocorrem, estes mecanismos devem favorecer a sua correção. Inclui proteção contra erros, qualidade das mensagens de erro e correção dos erros e reversão fácil das ações" (Campos, Martins, Nunes, 2008; Tobase, 2016).

Nove $(37,5 \%)$ especialistas avaliaram a gestão de erros com nota máxima. Sete avaliadores consideraram que foi um aspecto impossível de avaliar, visto que não identificaram erros ou mensagens e informações. Assim, o item recebeu média de respostas 0,85 . 
Tabela 17 - Respostas da avaliação do item "Gestão de erros" do curso online, de acordo com os especialistas. São Paulo, 2017. $(n=24)$

\begin{tabular}{c|cccccc|c}
\hline ESPECIALISTAS & 0 & 0,25 & 0,5 & 0,75 & 1,0 & NA & MÉDIA \\
\hline Todas & 0 & 1 & 0 & 7 & 9 & 7 & 0,85 \\
\hline Dor & 0 & 0 & 0 & 1 & 3 & 4 & 0,94 \\
\hline Neonatologia & 0 & 0 & 0 & 3 & 3 & 2 & 0,87 \\
\hline Educação & 0 & 1 & 0 & 3 & 3 & 1 & 0,69 \\
\hline
\end{tabular}

\subsubsection{Ajuda aos usuários}

Este item considera a "disponibilidade de recursos de auxílio ao usuário" (Campos, Martins, Nunes, 2008; Tobase, 2016).

Dez $(41,7 \%)$ especialistas avaliaram com nota máxima, sendo a média geral 0,81 . Cinco participantes não avaliaram o item, referindo que a ajuda não foi necessária para a navegação no curso online.

Uma especialista afirmou que, apesar de o recurso encontrar-se disponível, não foi possível acessa-lo. Em contra partida, uma especialista não localizou a ajuda aos usuários e sugeriu incluir um fórum de dúvidas para facilitar a comunicação do usuário com os tutores e/ou professores do curso, no caso de dificuldades em relação à navegação ou conteúdo do curso. Essa sugestão foi acatada. 
Tabela 18 - Respostas da avaliação do item "Ajuda aos usuários" do curso online, de acordo com os especialistas. São Paulo, 2017. $(n=24)$

\begin{tabular}{c|cccccc|c}
\hline ESPECIALISTAS & 0 & 0,25 & 0,5 & 0,75 & 1,0 & NA & MÉDIA \\
\hline Todas & 0 & 2 & 1 & 6 & 10 & 5 & 0,81 \\
& $(0 \%)$ & $(8,3 \%)$ & $(4,2 \%)$ & $(25 \%)$ & $(41,7 \%)$ & $(20,8 \%)$ & 0,90 \\
\hline Dor & 0 & 0 & 0 & 2 & 3 & 3 & 1 \\
\hline Neonatologia & 0 & 0 & 0 & 3 & 4 & 1 & 0,89 \\
\hline Educação & 0 & 2 & 1 & 1 & 3 & & 1 \\
\hline
\end{tabular}

\subsubsection{Qualidade das informações}

A qualidade de informações avalia "conteúdos corretos, fontes fidedignas, vocabulário adequado ao público, carga informacional (quantidade de informação) compatível" (Campos, Martins, Nunes, 2008; Tobase, 2016).

Vinte e um $(87,5 \%)$ especialistas avaliaram com nota máxima, sendo que a média geral atribuída foi 0,96 . Apenas um avaliador especialista em EAD assinalou "Não se aplica", pois refere que não tem conhecimento para avaliar o conteúdo e as evidências utilizadas.

Quatro (16,7\%) especialistas realizaram comentários que incluíram avaliações positivas em relação ao uso de evidências válidas, atuais e de autores e estudiosos com grande expertise na temática.

“... considerei o vocabulário adequado e a carga informacional compatível com o tempo de dedicação aos estudos informados."

“... as informações fornecidas são retiradas de fontes confiáveis evidências científicas de autores que realmente estudam a temática." 
Tabela 19 - Respostas da avaliação do item "Qualidade das informações" do curso online, de acordo com os especialistas. São Paulo, 2017. $(\mathrm{n}=24)$

\begin{tabular}{c|cccccc|c}
\hline ESPECIALISTAS & 0 & 0,25 & 0,5 & 0,75 & 1,0 & NA & MÉDIA \\
\hline Todas & 0 & 1 & 0 & 1 & 21 & 1 & 0,96 \\
& $(0 \%)$ & $(4,2 \%)$ & $(0 \%)$ & $(4,2 \%)$ & $(87,5 \%)$ & $(4,2 \%)$ & 0 \\
\hline Dor & 0 & 0 & 0 & 0 & 8 & 0 & 1,0 \\
\hline Neonatologia & 0 & 0 & 0 & 0 & 8 & 0 & 1,0 \\
\hline Educação & 0 & 1 & 0 & 1 & 5 & 1 & 0,86 \\
\hline
\end{tabular}

\subsubsection{Portabilidade}

A portabilidade avalia o "funcionamento adequado em diferentes browsers" (Campos, Martins, Nunes, 2008; Tobase, 2016). Dessa forma, 18 (75\%) especialistas avaliaram com pontuação máxima e quatro pessoas não avaliaram visto que não realizaram testes em outros dispositivos e navegadores de busca. Assim, a média geral das respostas dos especialistas neste item foi de 0,97 .

Dois $(8,3 \%)$ especialistas testaram nos navegadores da web "Google Chrome", "Mozilla Firefox" e "Safari", e referiram que o curso abriu sem complicações. Um (4,2\%) avaliador refere que teve dificuldades em acessar a página por meio de dispositivos móveis (celulares ou tablets). 
Tabela 20 - Respostas da avaliação do item "Portabilidade" do curso online, de acordo com os especialistas. São Paulo, 2017. $(n=24)$

\begin{tabular}{c|cccccc|c}
\hline ESPECIALISTAS & 0 & 0,25 & 0,5 & 0,75 & 1,0 & NA & MÉDIA \\
\hline Todas & 0 & 0 & 0 & 2 & 18 & 4 & 0,97 \\
$(0 \%)$ & $(0 \%)$ & $(0 \%)$ & $(8,3 \%)$ & $(75 \%)$ & $(16,7 \%)$ & 0,96 \\
\hline Dor & 0 & 0 & 0 & 1 & 6 & 1 & 1 \\
\hline Neonatologia & 0 & 0 & 0 & 0 & 7 & 2 & 0,96 \\
\hline Educação & 0 & 0 & 0 & 1 & 5 & 2 & 1,0 \\
\hline
\end{tabular}

\subsection{COMENTÁRIOS GERAIS}

O formulário de avaliação de aparência e conteúdo do curso online incluiu um espaço aberto para observações e sugestões dos avaliadores. Dessa forma, 17 comentários foram realizados, desses, cinco comentários realizados por avaliadores da área de neonatologia, seis de especialistas em dor neonatal e seis de especialistas em EAD.

De forma geral, os especialistas expressaram satisfação com a apresentação e organização do curso online.

“... objetivo, preciso, agradável, conteúdo claro, pertinente, de fácil exploração.";

“... diversidade de recursos e ferramentas utilizadas no curso como vídeos, aulas e disponibilização de artigos."

“... o curso está extremamente organizado, coerente em todos os sentidos.”

“... gostei muito do layout do curso bem como navegar por ele.” 
No entanto, os especialistas sugeriram acrescentar definições sobre a consequência da dor neonatal no desenvolvimento infantil, adequar a linguagem do curso e melhorar recursos como vídeos, mapas de navegação e fóruns de discussão.

“... incluir brevemente algo sobre o impacto da dor no desenvolvimento da criança. Este aspecto é importante para reforçar a importância de avaliar a dor para prevenir e tratar."

“... falta mapa de navegação para usuários, falta mapa instrucional, o objetivo de cada módulo (falta), as imagens nas aulas não contêm referências, necessário colocar para não apresentar problemas com direitos autorais, os vídeos estão muito pesados (precisam ficar mais leves), não consegui abrir os fóruns."

“... descrever a configurações mínimas do computador, softwares necessários para acessar o Programa."

“... senti falta apenas do uso de uma linguagem mais dialógica, desejável mesmo em cursos de autoaprendizagem, pois favorece a criação do sentimento de pertencimento ao curso, colaborando inclusive para redução da evasão."

Além disso, os especialistas referiram que o curso online permite vantagens para o aprendizado do usuário e ressaltaram que o PAD-Neo trará benefícios para a prática clínica e assistência ao neonato.

“... vai colaborar muito para o aprendizado de enfermeiros e por consequência, promover melhorias no cuidado aos neonatos."

“... estas últimas aulas dão certa autonomia ao usuário, o que pode ser avaliado muito positivamente."

“... bem completo, de fácil entendimento e utiliza de materiais com conteúdo consistente e embasado em literatura atualizada. Com certeza terá uma bela contribuição na prática da assistência em neonatologia."

"O curso apresenta de forma dinâmica a avaliação da dor neonatal, favorecendo o aprendizado." 
Os demais comentários realizados incluíram apontamentos em relação a erros de digitação e de definição de conteúdo, bem como agradecimentos e elogios à aparência e organização do curso online. 
89

Discussãa 


\section{DISCUSSÃO}

Este estudo teve como objetivo avaliar a qualidade do curso online PAD-Neo sob a perspectiva de especialistas. Estudos nessa temática são essenciais para conferir validade e qualidade a propostas educativas. Esta avaliação oferece subsídios para desenvolver e aprimorar o processo de ensino-aprendizagem no meio virtual (Romiszowski, 2004). Deste modo, o PAD-Neo foi avaliado por especialistas em dor neonatal, especialistas em neonatologia e especialistas em educação a distância, áreas que apresentam interface em relação à temática abordada.

A navegação livre foi positivamente avaliada pelos especialistas, de modo geral. Em virtude da média geral atribuída, não foram realizadas modificações no curso online. Contudo, semelhante aos resultados apresentados no estudo de Tobase (2016), alguns dos avaliadores apontaram o formato linear do curso como uma desvantagem ou limitação para a navegação livre do usuário.

A navegação livre do usuário é caracterizada pelo formato não linear, ou seja, não sequencial e mostra-se como um aspecto importante na $E A D$, pois permite o desenvolvimento de autonomia e promove efeitos positivos no processo de ensinoaprendizado (Naumann, Salmerón, 2016).

No entanto, estudo de Martin (2008), teve como objetivo comparar os efeitos de curso online no formato linear e curso online no formato não linear, nas atitudes, no conhecimento e nas práticas de alunos de graduação em computação. Ambos os cursos abordavam temáticas relativas à informática. Os resultados evidenciaram que não houve diferenças significativas no aprendizado, atitudes e nem com relação ao tempo de conclusão dos cursos entre os alunos que utilizaram ambas as estruturas de navegação (Martin, 2008).

Embora os módulos um a quatro tratem de temas básicos para o curso e a linearidade do aprendizado seja considerada necessária nessa etapa, este formato foi avaliado como desfavorável no curso como um todo, em especial para os especialistas na área da educação. A equipe responsável pelo PAD-Neo considerou, entretanto, importante manter a linearidade dos módulos um (Introdução ao Programa de Avaliação da Dor Neonatal), dois (Dor: definições e conceitos básicos de fisiologia), 
três (Componentes de avaliação da dor no recém-nascido) e quatro (Princípios de mensuração e avaliação da dor no recém-nascido). Por outro lado, considerando-se a avaliação dos especialistas, os módulos cinco a nove, referentes às escalas, serão abertos para que o cursista desenvolva suas atividades conforme suas preferências e, portanto, de modo não linear.

Com relação à linguagem utilizada em um curso online esta deve ser clara, objetiva e acessível, a fim de promover a compreensão e o processo de aprendizado do usuário de EAD (Xelegati, Évora, 2011). Nesse sentido, quanto ao item clareza de informações, os especialistas consideraram a linguagem utilizada no curso online como clara e objetiva.

Resultados similares foram encontrados no estudo de Gibbins e colaboradores, após a avaliação de um curso online por especialistas, sendo o item "clareza de informação" avaliado com nota positiva (escore 4,38 de 5,0 pontos) e a maioria dos avaliadores considerou a linguagem clara e de fácil compreensão (Gibbins et al., 2007). Analogamente ao estudo de Fonseca e colaboradores (2013), o item clareza do texto foi criteriosamente avaliado pelos especialistas, que consideraram que este aspecto deveria passar por alterações para facilitar a compreensão das informações pelo aluno.

Além disso, o item clareza de informações avalia a apresentação de um conceito por vez em uma única janela. Para Tobase (2016), evidenciar uma única informação pode facilitar a compreensão do usuário sobre determinado tema. Salienta-se que no presente estudo, os conceitos principais para compreensão do aluno estão destacados nas videoaulas e aulas interativas, reforçando assim a importância das informações transmitidas.

Quanto à facilidade de localização nas informações, a avaliação geral foi positiva. Embora a introdução do curso online apresente um quadro exibindo os temas tratados ao longo do PAD-Neo e cada unidade inclua um índice do conteúdo programático e objetivos propostos, um especialista sugeriu acrescentar um menu na página inicial, indicando quais conteúdos seriam abordados no curso. Além disso, cada aula interativa apresenta um tutorial com orientações de navegação. 
O curso online permite o aprendizado centrado no próprio aluno e isso possibilita uma navegação independente com desenvolvimento de autonomia. Dessa forma, o uso de recursos para localização de informações é fundamental para o usuário compreender o funcionamento do curso a partir dos tutoriais e se localizar, por intermédio dos menus (Tobase, 2016).

Com relação à pertinência, os especialistas avaliaram o curso de modo bastante positivo. A pertinência facilita o alcance dos objetivos de aprendizado propostos pelo curso, devido à apresentação lógica e clara das informações (Rangel, 2009). Assim, a pertinência é importante para o curso online, pois o conteúdo deve ser relevante e apresentado de uma forma lógica que facilite a compreensão do usuário e, consequentemente, possibilite o alcance dos objetivos propostos. Em suas avaliações, três participantes referiram que o curso foi organizado de forma a facilitar a compreensão pelo usuário.

A pertinência ainda considera que a navegação e a interação dos recursos instrucionais devem ser compreendidas rapidamente (Campos, Martins, Nunes, 2008; Tobase, 2016). Segundo Carvalho Neto (2009), um curso online deve ser intuitivo para facilitar a utilização e aprendizado do usuário (Carvalho Neto, 2009). Contudo, um especialista identificou que a utilização dos botões clicáveis não é clara e sua função não foi prontamente entendida. Em função da avaliação positiva oferecida pelos especialistas, não foram feitas correções significativas neste item.

A contextualização também foi avaliada positivamente pelos especialistas. A adequação e a coerência no conteúdo são aspectos fundamentais e, por esse motivo, especialistas em neonatologia e dor neonatal foram selecionados para participarem da avaliação do curso online.

Neste item, a carência de artigos em língua portuguesa nas sugestões de leitura complementar foi uma observação recorrente feita pelos especialistas, principalmente das áreas de neonatologia e dor. Uma das premissas do uso da EAD é tornar a informação e aprendizado acessíveis (Gava et al., 2014). Dessa forma, incluir recursos em língua portuguesa pode beneficiar usuários que possuem pouco ou nenhum domínio de outros idiomas e favorecer a consulta de material complementar. Destaca-se, entretanto, a escassez de artigos científicos pertinentes à temática do curso publicados em língua portuguesa. Contudo, esforços foram feitos para incluir mais recursos na língua portuguesa. 
A correção de conteúdo se refere ao rigor científico dos conhecimentos transmitidos pelo curso. Desde sua primeira versão, o PAD-Neo apresenta conteúdo pertinente e com base em evidências científicas de alta qualidade (Bueno et al., 2014). Para a versão atual, o material foi revisado por uma equipe de pesquisadores atuantes na área de neonatologia e dor neonatal, que trabalhou exaustivamente na inserção de novos conteúdos e referências atualizadas, o que se reflete na avaliação positiva feita pelos especialistas.

A escassez de conteúdos relacionados ao manejo da dor, incluindo a população neonatal, na grade curricular de cursos de graduação, especialização e residências (Carr et al., 2016) reforçam a importância do PAD-Neo e a necessidade de se oferecer conteúdo adequado e pertinente. Destaca-se que, em uma revisão sistemática da literatura com o objetivo de identificar estratégias de educação mediadas por tecnologia que tratassem da temática dor, não foram identificados outros cursos ou estratégias educacionais específicas para o ensino do tema 'avaliação da dor neonatal', exceto pela versão inicial do PAD-Neo (Silva et al., 2016).

O item que apreciou a abertura de múltiplas janelas simultaneamente foi avaliado positivamente, destacando-se a avaliação de dois especialistas que consideraram que este recurso facilitou a visualização e a compreensão do conteúdo. No entanto, um especialista afirmou que a utilização de múltiplas janelas pode levar a confusão do cursista.

A utilização de múltiplas janelas pode ser considerada como de preferência individual de cada usuário. A exemplo do estudo de Granito (2008), onde a utilização de recursos sem a necessidade de abertura de múltiplas janelas, foi um fator positivo para os alunos de graduação do curso de administração. No entanto, uma das vantagens identificadas na literatura com o uso de múltiplas janelas foi o acesso a diferentes meios de informações em um único momento, destacado no estudo de Xelegati e Évora (2011).

Atribui-se a avaliação positiva do item facilidade de aprendizagem na interação, à utilização da plataforma Moodle para hospedar o curso online. O Moodle é uma estrutura livre, gratuita, aberta e amplamente utilizada, pois contribui para o uso das TICs na educação, ofertando vantagens tais como a flexibilidade e baixo custo para 
desenvolvimento e permite a configuração e a aplicação de recursos audiovisuais interativos (Prado, Vaz, Almeida, 2011).

O Moodle ainda possibilita uma maior participação e interação dos usuários com o ambiente virtual de aprendizagem (Prado et al., 2012). O aluno tem a autonomia e liberdade para organizar seu próprio aprendizado, de acordo com o seu interesse e suas necessidades (Alvarez, 2009). No presente estudo, os especialistas consideraram a estrutura, o software e a navegação do curso como de fácil entendimento, o que possivelmente contribuirá para o aprendizado do usuário. Dessa forma, considerando a avaliação positiva deste item, nenhuma mudança foi realizada no PAD-Neo.

O item eficiência de utilização refere-se à facilidade de navegação e foi avaliado positivamente pelos especialistas. Alavarce (2014) descreve que a navegação simples é essencial na educação online de profissionais de saúde, especialmente em função da rotina de trabalho, que pode dificultar a disponibilidade do indivíduo para o aprendizado de novas evidências.

Quanto à facilidade de retorno, a avaliação dos especialistas confirmou a adequação do item e dispensou a necessidade de ajustes. Um especialista sugeriu que a opção de retornar à página inicial do curso deve estar presente em todas as atividades como leitura complementar, vídeos e exercícios. Contudo, o Moodle mantém aparente uma barra de navegação que permite o retorno à página inicial do PAD-Neo.

A ergonomia avalia a uniformidade na apresentação do conteúdo e recursos do curso online. No presente estudo, foi avaliada positivamente pelos especialistas. Góes e colaboradores (2010) afirmam que avaliar critérios de usabilidade pautados nos critérios de ergonomia é fundamental para aprimorar aspectos técnicos que envolvem o processo ensino-aprendizagem. Dessa forma, adequar o curso online a critérios de ergonomia favorece a compreensão e a utilização pelo usuário (Castro el al., 2015).

De acordo com questionário ErgoList, desenvolvido por equipe de especialistas em tecnologia e informática, seguindo as normas ISO 9241, a avaliação ergonômica inclui apreciação de aspectos como: presteza, que observa se o curso fornece orientações e direciona o usuário durante a navegação; agrupamento, que avalia a uniformidade da organização, do posicionamento e do formato e tamanho dos itens 
contidos no curso; legibilidade, relacionada à apresentação do texto que pode facilitar a leitura pelo usuário de acordo com a fonte, tamanho e cores utilizadas, por exemplo; controle do usuário, que avalia se o aluno pode controlar a navegação de acordo com suas necessidades; proteção e correção contra erros, que verificam se o curso fornece apoio para minimizar e solucionar erros; consistência que permite observar se é mantida a uniformidade das telas, códigos e demais recursos; entre outros aspectos considerados. (ErgoList, 2011)

Assim, no presente estudo, os especialistas, de modo geral, apontaram que o curso apresenta uma organização favorável ao entendimento do usuário, configuração das fontes que facilitam a legibilidade e que os ícones, telas e recursos são apresentados de forma uniforme. Deste modo, uma vez que os critérios de ergonomia obtiveram avaliações positivas dos especialistas, não foi necessário realizar alterações.

Os avaliadores consideraram a qualidade dos recursos audiovisuais e do design do curso bastante positiva. Os comentários foram direcionados a cores, fontes, marcas especiais e fotos, sendo que a escolha das cores facilitou a apresentação e legibilidade do conteúdo, segundo os especialistas.

Quanto à utilização de marcas especiais, não foram necessárias modificações no curso em função da avaliação positiva por parte dos especialistas. Fonseca e colaboradores (2012) consideram que a informação visual dos cursos online influencia o aprendizado do usuário, visto que a organização da interface pode tanto incentivar o indivíduo, favorecendo o ensino, ou ser um recurso distrativo.

A utilização de recursos audiovisuais também foi positiva. Alguns especialistas afirmaram que a variedade de recursos oferecidos é limitada. Observou-se que os especialistas em EAD atribuíram notas mais baixas ao item. Os recursos audiovisuais utilizados em estratégias de EAD são um dos principais responsáveis pela interação do usuário com o meio virtual $e$, por isso, podem definir a aceitabilidade de uma estratégia educativa (Liu et al., 2009). Fonseca e colaboradores (2013) observaram que os usuários das estratégias de EAD consideram que a utilização de recursos audiovisuais beneficia o aprendizado do aluno, tornando o processo mais interessante e prazeroso (Fonseca et al, 2013). 
O curso online dispõe de fóruns de discussão, fórum de notícias, videoaulas, sínteses das videoaulas em PDF, artigos para leitura complementar, links para websites úteis, hipertexto, exercícios com questões de múltipla-escolha, fotos e vídeos. Dessa forma, considera-se suficiente a variedade e a quantidade de recursos audiovisuais disponíveis no PAD-Neo.

Com relação à utilização de referências, a avaliação dos especialistas também foi positiva. De modo geral, as evidências utilizadas na construção do conteúdo foram consideradas adequadas e pertinentes com a temática estudada e os objetivos propostos pelo curso. Este item recebeu especial atenção por parte da equipe de pesquisa que desenvolveu o curso, na etapa de revisão de literatura e atualização do conteúdo.

Assim como no critério que avaliou a contextualização, os especialistas sugeriram a inclusão de referências na língua portuguesa. Um avaliador afirmou que algumas citações antigas foram utilizadas como evidências, porém tratam-se de referências clássicas e atemporais para a temática estudada. Um especialista sugeriu especificar os artigos indicados para a leitura complementar nos arquivos em PDF disponíveis em cada módulo, entretanto o intuito do curso é apresentar evidências válidas, que podem ser incluídas posteriormente conforme atualizações. Dessa forma, alguns artigos em português foram incluídos, conforme sugestão descrita anteriormente. Ressalta-se que os artigos e demais referências disponibilizadas para download no curso online constituem-se de material de livre acesso.

Quanto à interatividade, os especialistas consideraram o conteúdo como predominantemente expositivo, com poucos recursos audiovisuais que incentivassem a aprendizagem ativa do aluno e pouca possibilidade de interação do usuário com o curso online, e até mesmo com os professores e seus pares.

Considera-se que a interatividade no EAD, por meio de recursos audiovisuais, caracteriza-se como uma importante ferramenta para a participação dos usuários no processo de ensino-aprendizagem (Maldonado, Reichert, 2010). No PAD-Neo, por exemplo, alguns recursos são considerados interativos pelos especialistas, a saber: 
o fórum de discussão, por permitir a aprendizagem ativa e a interação do cursista com seus pares; exercícios com vídeos, pois podem representar uma situação da realidade; e, a participação de tutores por meio de feedbacks das atividades, que poderão favorecer a comunicação dos alunos com professores e tutores.

Com relação à gestão de erros os especialistas avaliaram positivamente, assim, nenhuma alteração com relação a este item foi necessária. É importante avaliar a gestão de erros de um curso online, a fim de evitar que estes ocorram ou que sejam solucionados de forma simples, caso houver necessidade para garantir a funcionalidade e viabilidade do curso (Fonseca et al., 2012). Assim como no estudo de Tobase (2016), ao longo do curso, o usuário foi guiado por orientações que indicavam as etapas seguintes, para minimizar os erros de navegação.

Em relação à ajuda aos usuários, os avaliadores informaram que não tiveram acesso a nenhum recurso de ajuda. Dessa forma, foi sugerida a criação de um fórum de ajuda aos usuários. Após a avaliação das sugestões e alterações no curso online, o fórum de ajuda foi incluído junto ao fórum de notícias na página principal do curso.

Quanto à qualidade das informações, os especialistas avaliaram o item de modo bastante positivo. As referências utilizadas para o desenvolvimento do conteúdo teórico foram bem avaliadas pelos especialistas, bem como a carga horária para o cumprimento das atividades propostas. O vocabulário utilizado foi considerado apropriado ao público-alvo pretendido.

Por fim, em relação à portabilidade, o curso online foi testado pelos avaliadores em diversos dispositivos eletrônicos e navegadores de internet. Os participantes referiram que obtiveram sucesso ao carregar o curso nos três navegadores utilizados no teste (Safari, Mozilla Firefox e Google Chrome). Entretanto, dificuldades foram encontradas no carregamento das aulas com slides em um computador específico e em dispositivos móveis como tablets e celulares.

Visto que as propostas educativas, em sua maioria, são executadas sem avaliação de qualidade, a avaliação por especialistas é determinante a usabilidade adequada e validade ao curso online (Romiszowski, 2004). Ressalta-se que avaliação deve ser realizada por especialistas com competências específicas, com intuito de questionar aspectos relacionados à aplicabilidade e qualidade de conteúdo do curso online (Granito, 2008; Roque, Silva, 2011). 
Assim, considerando a avaliação positiva por parte dos especialistas e as sugestões, o curso online apresentado se configura como uma estratégia útil e pertinente para aprimorar o conhecimento de profissionais de saúde, especialmente aqueles que atuam na assistência ao RN.

A despeito das vantagens no uso de tecnologias na educação, ainda se observa uma escassez de estudos sobre desenvolvimento e avaliação de cursos online na assistência neonatal, inclusive em relação à dor (Freire et al., 2015).

Assim, espera-se disponibilizar o curso online como uma estratégia de EAD para alunos de curso de graduação da área da saúde, por meio de cursos de extensão, e a disponibilização do curso para o aprimoramento e treinamento profissional na educação continuada e permanente, com vistas a disseminar conhecimento sobre a dor neonatal. 
99

Conclusãa 


\section{CONCLUSÃO}

Mediante avaliação de qualidade do curso online PAD-Neo sob a perspectiva de especialistas, conclui-se que o objetivo do presente estudo foi alcançado. Os resultados contemplam a satisfação dos avaliadores, principalmente em relação aos aspectos como clareza de informações, pertinência do conteúdo, correção do conteúdo, utilização de múltiplas janelas, facilidade de aprendizagem na interação, estética, qualidade das informações e portabilidade.

Dessa forma, as avaliações contribuíram na identificação de falhas e questões que implicariam em mau funcionamento do curso online ou que poderiam influenciar negativamente a experiência dos usuários. Ressalta-se que as sugestões dos avaliadores foram consideradas e ajustes foram realizados, sobretudo nos itens como facilidade de localização, recursos audiovisuais, interatividade, gestão de erros e ajuda aos usuários. No entanto, como não foram atribuídas médias abaixo de 0,70 a nenhum dos itens avaliados, não foram feitas mudanças significativas no conteúdo ou na aparência do curso online.

Como limitação deste estudo, consideramos que algumas das notas atribuídas abaixo de 0,50 não foram adequadamente justificadas pelos especialistas, conforme orientações. Assim, dificultou a avaliação acurada da qualidade do curso e impediu que a equipe realizasse melhorias de forma a adequar os itens aos critérios propostos. Observa-se ainda que o instrumento utilizado no presente estudo pode ter contribuído para a falha e/ou dificuldade de interpretação de alguns itens, gerando assim ambiguidade de sentido das descrições.

Por fim, conclui-se que o PAD-Neo foi considerado válido do ponto de vista de aparência e de conteúdo. O curso online pode ser compreendido como uma proposta educacional inovadora e eficaz para o aprendizado sobre a avaliação da dor neonatal. Salienta-se que o curso online possivelmente será pertinente como estratégia no ensino de graduação, pós-graduação e educação continuada e permanente de profissionais da área da saúde que prestam assistência ao neonato. 
Referências 


\section{REFERÊNCIAS}

Akuma AO, Jordan S. Pain management in neonates: a survey of nurses and doctors. J Adv Nurs. 2012;68(6):1288-1301.

Alavarce DC. Desenvolvimento e avaliação da reação, aprendizagem e impacto de treinamento on-line para profissionais da saúde [tese]. São Paulo. Escola de Enfermagem da Universidade de São Paulo. 2014.

Alemán JLF, Carrillo de Gea JM, Mondéjar JJR. Effects of competitive computerassisted learning versus conventional teaching methods on the acquisition and retention of knowledge in medical surgical nursing students. Nurse Educ Today. 2011;31:866-871.

Alvarez AG. Objeto virtual de aprendizagem simulada em enfermagem para a avaliação da dor aguda em adultos [dissertação]. Florianópolis. Universidade Federal de Santa Catarina. 2009.

Alvarez AG, Dal Sasso GTM. Objetos virtuais de aprendizagem: contribuições para o processo de aprendizagem em saúde e enfermagem. Acta paul. enferm. 2011;24(5):707-11.

American Academy of Pediatrics, Committee on Fetus and Newborn and Section on Anesthesiology and Pain Medicine. Prevention and management of procedural pain in the neonate: an update. Pediatrics. 2016;137(2):e20154271.

Anand KJS, Phil D, Hickey PR. Pain and its effects in the human neonate and fetus. N Engl J Med. 1987;317(2):1321-29.

Anand KJS, Hall RW. Controversies in neonatal pain: an introduction. Semin Perinatol. 2007;30(5):273-274.

Araújo GC, Miranda JOF, Santos DV, Camargo CL, Sobrinho CLN, Santa Rosa DO. Dor em recém-nascidos: identificação, avaliação e intervenções. Rev. baiana enferm. . 2015;29(3):261-70.

Associação Brasileira de Normas Técnicas. ISO/IEC 9126-1. Engenharia de software

- Qualidade de produto. Parte 1: Modelo de qualidade. 2003.

Associação Brasileira de Normas Técnicas. ISO/IEC 14598-6. Engenharia de software - Avaliação do produto. Parte 6: Documentação de módulos de avaliação. 2004. 
Aymar CLG, Lima LS, Santos CMR, Moreno EAC, Coutinho SB. Pain assessment and management in the NICU: analysis of and educational intervention for health professionals. J Pediatr. 2014;90(3):308-15.

Balda RDCX, Almeida MFB, Peres CDA, Guinsburg R. Fatores que interferem no reconhecimento por adultos da expressão facial de dor no recém-nascido. Rev Paul Pediatr. 2009;27(2):160-67.

Bembich S, Brovedani P, Cont G, Travan L, Grassi V, Demarini S. Pain activates a defined area of the somatosensory and motor cortex in newborn infants. Acta Paediatr. 2015;104:e530-e533.

Benoit B, Martin-Misener R, Newman A, Latimer M, Campbell-Yeo M. Neurophysiological assessment of acute pain in infants: a scoping review of research methods. Acta Paediatr. 2017. doi:10.1111/apa.13839.

Bueno M, Kimura AF, Castral TC, Holsti L. Translation and adaptation of the Behavioral Indicators of Infant Pain (BIIP) into Portuguese (Brazil). In: Abstracts do 9th International Forum on Pediatric Pain; 2013 out3-6; White Point, CA. White Point: The Centre for Pediatric Pain Research, 2013.

Bueno M, Duarte ED, Marques RL, Freire LM, Castral TC. Neonatal pain assessment program II: an innovative strategy to increase knowledge translation. Case Report. Rev. Dor. 2014;15(2):152-55.

Bueno M, Forni E, Costa T, Kimura AF. Adaptação Transcultural e Validação do Premature Infant Pain Profile - Revised para o português (Brasil). In: Anais do 67ª Congresso Brasileiro de Enfermagem. 2015 out. 27-30; São Paulo. ABEn- Seção -SP; 2015.

Buxton EC, De Muth JE. Pharmacists' perceptions of a live continuing education program comparing distance learning versus local learning. Res Social Adm Pharm. 2013;9(2):230-235.

Camacho ACLF. Análise das publicações nacionais sobre educação à distância na enfermagem. Rev Bras Enferm. 2009;62(4):588-93.

Caetano EA, Lemos NRF, Cordeiro SM, Pereira FMV, Moreira DDS, Buchhorn SMM. O recém-nascido com dor: atuação da equipe de enfermagem. Esc. Anna Nery Rev. Enferm. 2013;17(3):439-45. 
Campos GHB, Martins I, Nunes BP. Instrumento para a avaliação da qualidade de objetos de aprendizagem. Coordenação Central de Educação A Distância PUC-Rio. 2008; p.8.

Capellini VK, Daré MF, Castral TC, Christoffel MM, Leite AM, Scochi CGS. Conhecimento e atitudes de profissionais de saúde sobre avaliação e manejo da dor neonatal. Rev. Eletr. Enf. 2014;16(2):361-9.

Carbajal R, Paupe A, Hoenn E, Lenclen R, Olivier-Martin M. DAN: une échelle comportementale d'èvaluation de la douleur aiguë du nouveau-né. Arch Pediatr. 1997;4(7):623-28.

Carbajal R, Rousset A, Danan C, Coquery S, Nolent P, Ducrocq S, et al. Epidemiology and treatment of painful procedures in neonates in intensive care units. JAMA. 2008;300(1):60-70.

Carr ECJ, Briggs EV, Briggs M, Allcock N, Black P, Jones D. Understanding factors that facilitate the inclusion of pain education in undergraduate curricula: Per10.spectives from a UK survey. Br J Pain. 2016;10(2):100-107.

Carvalho Neto S. Dimensões de qualidade em ambientes virtuais de aprendizagem [tese]. São Paulo. Faculdade de Economia, Administração e Contabilidade da Universidade de São Paulo. 2009.

Castro FSF, Dias DMV, Higarashi IH, Scochi CGS, Fonseca LMM. Avaliação da interação estudante-tecnologia educacional digital em enfermagem neonatal. Rev Esc Enferm USP. 2015;49(1):114-121.

Cignacco E, Mueller R, Hamers JPH, Gessler P. Pain assessment in the neonate using the Bernese Pain Scale for Neonates. Early Hum Dev. 2004;78(2):124-31.

Cong X, McGrath JM, Cusson RM, Zhang D. Pain assessment and measurement in neonates. Adv Neonatal Care. 2013;13(6):379-395.

Cook DA, Garside S, Levinson AJ, Dupras DM, Montori VM. What do we mean by web-based learning? A systematic review of the variability of interventions. Med Educ. 2010;44:765-774.

Cornelissen L, Fabrizi L, Patten D, Worley A, Meek J, Boyd S, et al. Postnatal temporal, spatial and modality tuning of nociceptive cutaneous flexion reflexes in human infants. PLoS ONE. 2013;8(10):e76470. 
Crescêndio EP, Zanelato S, Leventhan LC. Avaliação e alívio da dor no recémnascido. Rev. eletrônica enferm. 2009;11(1):64-69.

Cruz MD, Fernandes AM, Oliveira CR. Epidemiology of painful procedures performed in neonates: a systematic review of observational studies. Eur J Pain. 2016;20(4):489_ 498.

Debillon T, Zupan V, Ravault N, Magny JF, Dehan M. Development and initial validation of the edin scale, a new tool for assessing prolonged pain in preterm infants. Arch Dis Child Fetal Neonatal Ed. 2001;85(1):36-41.

Dias FSB, Marba STM. Avaliação da dor prolongada no recém-nascido: the evaluation of prolonged pain in the newborn: adaptation of the EDIN scale for brazilian culture. Texto Contexto Enferm. 2014;23(4):964-70.

Dittz E, Malloy-Diniz LF. Neonatal pain and neuropsychological development. REME. 2006;10(3):266-70.

Du S, Liu Z, Liu S, Yin H, Xu G, Zhang H, et al. Web-based distance learning for nurse education: a systematic review. Int Nurs Rev. 2013;60(2):167-77.

Duhn LJ, Medves JM. A systematic integrative review of infant pain assessment tools. Adv Neonatal Care. 2004;4(3):126-140.

Dy SM, Hughes M, Weiss C, Sisson S. Evaluation of a web-based palliative care pain management module for housestaff. J Pain Symptom Manage. 2008;36(6):596-603.

Efe E, Dikmen S, Atlas N, Boneval C. Turkish pediatric surgical nurses' knowledge and attitudes regarding pain assessment and nonpharmacological and environmental methods in newborns' pain relief. Pain Manag Nurs. 2013;14(4):343-350.

Laboratório de Utilizabilidade da Informática. Ergolist [Internet]. Florianópolis: Universidade Federal de Santa Catarina; [atualizado em 2011; citado em 2017 jun. 03]. Disponível em: http://www.labiutil.inf.ufsc.br/ergolist/.

Filatro A. Design instrucional contextualizado: educação e tecnologia. $3^{a}$ ed. São Paulo: Editora Senac; 2003. 215p.

Finer N, Leone T. oxygen saturation monitoring for the preterm infant: the evidence basis for current practice. Pediatr Res. 2009;65(4):375-80.

Fitzgerald M, Walker SM. Infant pain management: a developmental neurobiological approach. Nat Clin Pract Neurol. 2009;5(1):35-50. 
Fonseca LMM. Semiotécnica e semiologia do recém-nascido pré-termo: desenvolvimento e validação de um software educacional [tese]. Ribeirão Preto: Escola de Enfermagem de Ribeirão Preto, Universidade de São Paulo; 2007. Fonseca LMM, Leite AM, Mello DF, Dalri MCB, Scochi CGS. Semiotécnica e semiologia do recém-nascido pré-termo: avaliação de um software educacional. Acta Paul Enferm. 2008; 21(4):543-8.

Fonseca LMM, Leite AM, Mello DF, Silva MAI, Lima RAG, Scochi CGS. Tecnologia educacional em saúde: contribuições para a enfermagem pediátrica e neonatal. Esc. Anna Nery Rev. Enferm. 2011;15(1):190-196.

Fonseca LMM, Del'angelo N, Góes FSN, Castro FSF, Ponce De Leon CGSM, Scochi CGS. Avaliação clínica do prematuro: opinião dos estudantes de enfermagem acerca de um software educacional. Cienc. Enferm. 2012;18(2): 83-91.

Fonseca LMM, Aredes NDA, Leite AM, Santos CB, Lima RAG, Scochi CGS. Avaliação de uma tecnologia educacional para a avaliação clínica de recém-nascidos prematuros. Rev. Latino-Am. Enfermagem. 2013;21(1):1-8.

Freire LM, Paula MA, Duarte ED, Bueno M. Educação a distância no cenário da enfermagem neonatal: revisão sistemática. Rev Esc Enferm USP. 2015;49(3):515521.

Frutuoso JT, Moraes R. Relato verbal na avaliação psicológica da dor verbal. Aval. Psicol. 2004;3(2):107-14.

Gava TBS, Nobre IAM, Sondermann DVC. O modelo ADDIE na construção colaborativa de disciplinas a distância. Inform. educ. 2014;17(1):11-124.

Gibbins S, Maddalena P, Yamada J, Stevens B. Testing the satisfaction and feasibility of a computer-based teaching module in the neonatal intensive care unit. Adv Neonatal Care. 2007;7(1):43-49.

Gibbins S, Stevens BJ, Yamada J, Dionne K, Campbell-Yeo M, Lee G, et al. Validation of premature infant pain profile - revised (PIPP-R). Early Hum. Dev. 2014;90(4):18993.

Gil AC. Como elaborar projetos de pesquisa. 4. ed. São Paulo: Atlas; 2008.

Góes FSN, Fonseca LMM, Furtado MCC, Leite AM, Scochi CGS. Avaliação do objeto virtual de aprendizagem "Raciocínio diagnóstico em enfermagem aplicado ao prematuro". Rev. Latino-Am. Enfermagem. 2011;19(4):1-8. 
Gonçalves GR, Peres HHC, Rodrigues RDC, Tronchin DMR, Pereira IM. Proposta educacional virtual sobre atendimento da ressureição cardiopulmonar no recémnascido. Rev Esc Enferm USP. 2010;44(2):413-20.

Granito RAN. Educação a distância e estilos de aprendizagem: elaboração de um protocolo de qualidade para ambientes virtuais de ensino [dissertação]. Ribeirão Preto. Faculdade de Economia, Administração e Contabilidade de Ribeirão Preto da Universidade de São Paulo. 2008.

Grunau RE, Craig KD. Pain expression in neonates: facial action and cry. Pain. 1987;28(0):395-410.

Grunau RE, Oberlander T, Holsti L, Whitfield MF. Bedside application of the neonatal facial coding system in pain assessment of premature neonates. Pain. 1998;76(3):27786.

Grunau RE, Holsti L, Peters JWB. Long-term consequences of pain in human neonates. Semin Fetal Neonatal Med. 2006;11(1):268-75.

Grunau RE, Fitzgerald CE, Ellwood AL, Craig KD. Early human experience unit: Neonatal Facial Coding System Training manual. 2007.

Guinsburg R, Arias MCC. A linguagem da dor no recém-nascido. Documento Científico do Departamento de Neonatologia, Sociedade Brasileira de Pediatria. 2010. Disponível em: http://www.sbp.com.br/pdfs/doc linguagem-da-Dor-out2010.pdf Habich M, Letizia M. Pediatric pain assessment in the emergency department: a nursing evidence-based practice protocol. Paediatr Nurs. 2015;41(4):198-202.

Hall RW, Anand KJS. Pain management in newborns. Clin Perinatol. 2014;41(4):895924.

Harrison D, Bueno M, Reszel J. Prevention and management of pain and stress in the neonate. Res Rep Neonatol. 2015;5:9-16.

Hatfield LA, Meyers MA, Messing TM. A systematic review of the effects of repeated painful procedures in infants: Is there a potential to mitigate future pain responsivity? J Nurs Educ Pract. 2013;3(8):99-112.

Heimann C. Capacitação pedagógica de docentes de enfermagem: desenvolvimento e avaliação de um curso à distância [dissertação]. São Paulo: Escola de Enfermagem, Universidade de São Paulo; 2012.

Holsti L, Grunau RE. Initial validation of the behavioral indicators of infant pain (BIIP). Pain. 2007;132(3):264-72. 
Huckstadt A, Hayes K. Evaluation of Interactive Online Courses for Advanced Practice Nurses. J Am Acad Nurse Pract. 2008;17(3):85-89.

Hudson-Barr D, Capper-michel B, Lambert S, Palermo TM, Morbeto K, Lombardo S. Validation of the pain assessment in neonates (PAIN) scale with the neonatal infant pain scale (NIPS). Neonatal Netw. 2002;21(1):15-21.

Hulley SB, Cummings SR, Browner WS, Grady DG, Newman TB. Delineando a pesquisa clínica. 4를 ed. Porto Alegre: Artmed; 2015.

Hummel P, Puchalski M, Creech SD, Weiss MG. Clinical reliability and validity of the N-PASS: neonatal pain, agitation and sedation scale with prolonged pain. J Perinatol. 2007;28(1):55-60.

Humphrey T. Some correlations between the appearance of human fetal reflexes and the development of the nervous system. Prog. Brain Res. 1964;4(1):93-135.

Krechel SW, Bildner J. CRIES: a new neonatal postoperative pain measurement score. Initial testing of validity and reliability. Paediatr Anaesth. 1995;5(1):53-61.

Krishnan L. Pain relief in neonates. J Neonat Surg. 2013;2(2):19.

Lahti M, Hatonen H, Valimaki M. Impact of e-learning on nurses' and student nurses knowledge, skills, and satisfaction: a systematic review and meta-analysis. Int. j. nurs. stud. 2014;51(1):136-149.

Lawrence J, Alcook D, McGrath P, Kay J, MacMurray SB, Dulberg C. The development of a tool to assess neonatal pain. Neonatal Netw. 1993;12(6):59-66.

Liu SH, Liao HL, Pratt JA. Impact of media richness and flow on e-learning technology acceptance. Comput Educ. 2009;52:599-607.

Maldonado AE, Reichert J. A interatividade na educação a distância: o papel central da interatividade nos processos de ensino-aprendizagem na EAD. Comunicação \& Educação. 2010;15(3):117-124.

Martin F. Effects of practice in a linear and non-linear web-based learning environment. J Educ Techno Soc. 2008;11(4):81-93.

Martins SW, Dias FS, Enumo SRF, Paula KMP. Avaliação e controle da dor por enfermeiras de uma unidade de terapia intensiva neonatal. Rev Dor. 2013;14(1):21-6. Maxwell LG, Malavolta CP, Fraga MV. Assessment of pain in the neonate. Clin Perinatol. 2013;40:457-469. 
Melo GMD, Lélis ALPDA, Moura AFD, Cardoso MVLML, Silva VMD. Escalas de avaliação da dor em recém-nascidos: revisão integrativa. Rev Paul Pediatr. 2014;32(4):395-402.

Merskey H, Bogduk N. IASP task force on taxonomy part III: pain terms, a current list with definitions and notes on usage. IASP Task Force on Taxonomy. 1994. Disponível em:

http://www.iasp-

pain.org/Content/NavigationMenu/GeneralResourcesLinks/PainDefinitions/default.ht m\#Pain

Molenda M. In search of the elusive ADDIE model. International Society for Performance Improvement. 2003. Disponível em: http://www.comp.dit.ie/dgordon/Courses/ILT/ILT0004/InSearchofElusiveADDIE.pdf Moore JL, Dickson-Deane C, Galyen K. e-Learning, online learning, and distance learning environments: are they the same? Internet High Educ. 2011;14:129-135.

Motta GDCP, Shardosim JM, Cunha MLC. Neonatal Infant Pain Scale: cross- cultural adaption and validation in Brazil. J Pain Symptom Manage. 2015;50(3):394-401.

Naumann J, Salmerón L. Does navigation always predict performance? Effects of navigation on digital reading are moderated by comprehension skills. IRRODL. 2016;17(1):42-59.

Oliveira RM, Siebra e Silva AV, Chaves EMC, Sales NC. Avaliação comportamental e fisiológica da dor em recém-nascidos por profissionais de enfermagem. REME. 2010;14(1):19-24.

Oliveira SR, Machado ACCP, Miranda DM, Campos FS, Ribeiro CO, Magalhães LC, et al. Espectroscopia de luz próxima ao infravermelho como ferramenta auxiliar no estudo do desenvolvimento infantil. Rev. paul. pediatr. 2015;33(2):230-240.

Padalino Y, Peres HHC. E-learning: estudo comparativo da apreensão do conhecimento entre enfermeiros. Rev Latino-am Enfermagem. 2007;15(3):1-8.

Pereira ALST, Guinsburg R, Almeida MFB, Monteiro MC, Santos AMN, Kopelman BI. Validity of behavioral and physiologic parameters for acute pain assessment of term newborn infants. Sao Paulo Med J. 1999;117(2):72-80.

Prado C, Vaz DR, Almeida DM. Teoria da aprendizagem significativa: elaboração e avaliação de aula virtual na plataforma Moodle. Rev Bras Enferm. 2011;64(6):111421. 
Prado C, Santiago LC, Silva JAM, Pereira IM, Leonello VM, Otrenti E, et al. Ambiente virtual de aprendizagem no ensino de enfermagem : relato de experiência. Rev Bras Enferm. 2012;65(5):862-66.

Presbytero R, Vaz da Costa ML, Santos RCL. Os enfermeiros da unidade neonatal frente ao recém-nascido com dor. Revista RENE. 2010;11(1):125-32.

Puljak L, Sapunar D. Web-based elective courses for medical students: an example in pain. Pain Med. 2011;12:854-63.

Rangel EML. Avaliação do ambiente virtual de aprendizagem no ensino de fisiologia em um curso de licenciatura em enfermagem [tese]. Ribeirão Preto. Escola de Enfermagem de Ribeirão Preto da Universidade de São Paulo. 2009.

Reissland N, Francis B, Mason J. Can healthy fetuses show facial expressions of "pain" or "distress"? PLoS ONE. 2013;8(6):e65530.

Rochman DL, Sheehan MJ, Kulich RJ. Evaluation of a pain curriculum for occupational therapists: experiences from a master's-level graduate program over six years. Disabil Rehabil, 2013;35(22):1933-1940.

Rodrigues RCV. Ambiente virtual de aprendizagem em reanimação cardioresporatória em neonatologia [dissertação]. São Paulo: Escola de Enfermagem, Universidade de São Paulo; 2008.

Rodrigues RCV, Peres HHC. Panorama brasileiro do ensino de enfermagem online. Rev Esc Enferm USP. 2008;42(2):298-304.

Rodrigues AC, Guinsburg R. Pain evaluation after a non-nociceptive stimulus in preterm infants during the first 28 days of life. Early Hum Dev. 2013;89(1):75-79.

Romiszowski HP. Avaliação no design instrucional e qualidade da educação a distância: qual a relação? RBAAD. 2004. Disponível em: http://www.abed.org.br/revistacientifica/Revista_PDF_Doc/2004_Avaliacao_Design_I nstrucional_Qualidade_Educacao_Hermelina_Romiszowski.pdf Roque GOB, Silva LM. metodologia para avaliação e acompanhamento de cursos a distância: em busca da qualidade. 2011. Disponível em: www.abed.org.br/congresso2011/cd/155.pdf

Santos LMD, Ribeiro IS, Santana RCBD. Identificação e tratamento da dor no recémnascido prematuro na unidade de terapia intensiva. Rev Bras Enferm. 2012;65(2):26975. 
Scochi CGS, Carletti M, Nunes R, Furtado MCDC, Leite AM. A dor na unidade neonatal sob a perspectiva dos profissionais de enfermagem de um hospital de Ribeirão Preto-SP. Rev Bras Enferm. 2006;59(2):188-94.

Sellam G, Cignacco EL, Craig KD, Engberg S. Contextual factors influencing pain response to heelstick procedures in preterm infants: what do we know? A systematic review. Eur J Pain. 2011;15(7):1-15.

Silva FFF, Gave NC, Costa T, Bueno M. Estratégias de educação a distância sobre dor neonatal e pediátrica para profissionais da saúde. In: Anais do III Encontro de Enfermagem Neonatológica; 2016 nov. 23-24; São Paulo. São Paulo: Universidade Federal de São Paulo. p. 30.

Simons SHP, Van Dijk M, Ananda KS, Roofthooft D, Van Lingen RA, Tibboel D. Do we still hurt newborn babies? Arch Pediatr Adolesc Med. 2003;157:1058-1064.Stevens BJ, Johnston CC, Petryshen P, Taddio A. Premature Infant Pain Profile: development and initial validation. Clin J Pain. 1996;12(1):13-22.

Stevens BJ, McGrath P, Gibbins S, Beyene J, Breau L, Camfield C, et al. Determining behavioural and physiological responses to pain in infants at risk for neurological impairment. Pain. 2007;127(1-2):94-102.

Stevens BJ, Gibbins S, Yamada J, Dionne K, Lee G, Johnston C, et al. The premature infant profile-revised (PIPP-R): initial validation and feasibility. Clin $J$ Pain. 2014;30(3):238-43.

TaddioA, Shah V, Atenafu E, Katz J. Influence of repeated painful procedures and sucrose analgesia on the development of hyperalgesia in newborn infants. Pain. 2009;144(1):43-48.

Tobase L. Desenvolvimento e avaliação do curso online sobre Suporte Básico de Vida nas manobras de reanimação cardiopulmonar do adulto [tese]. São Paulo. Escola de Enfermagem da Universidade de São Paulo. 2016.

Valeri BO, Holsti L, Linhares MBM. Neonatal pain and developmental outcomes in children born preterm: a systematic review. Clin J Pain. 2015;31(4):355-362.

Van Dijk M, Tibboel D. Updated on pain assessment in sick neonates and infants. Pediatr. Clin. North Am. 2012;59(5): 1167-81.

Vincent CVH, Wilkie DJ, Wang E. Pediatric nurses' beliefs and pain management practices: an intervention pilot. West J Nurs Res. 2011;33(6):825-45. 
Xelegati R, Évora YDM. Desenvolvimento de ambiente virtual de aprendizagem em eventos adversos, em enfermagem. Rev. Latino-Am. Enfermagem. 2011;19(5):1-8. 
113

Apêndices 


\section{APÊNDICE A - Carta Convite aos Especialistas em Dor Neonatal}

Prezado (a) Senhor (a),

São Paulo, agosto de 2016.

Meu nome é Fernanda, sou enfermeira, estudante de Mestrado em Ciências da Saúde pelo Programa de Pós-Graduação em Enfermagem (PPGE) da Escola de Enfermagem da Universidade de São Paulo. Convido-o (a) a participar como Juiz (a) na avaliação de uma proposta educacional online, denominada Programa de Avaliação da Dor Neonatal - PADNeo, que visa qualificar profissionais e alunos da área da saúde a realizar a avaliação adequada da dor neonatal à beira leito. Esta pesquisa faz parte de um projeto coordenado pela Professora Doutora Mariana Bueno, docente da Escola de Enfermagem da Universidade de São Paulo, para desenvolvimento e implementação da plataforma educacional online, financiado pelo Conselho Nacional de Desenvolvimento Científico e Tecnológico (CNPq) e pela International Association for the Study of Pain (IASP).

Sua indicação deve-se ao fato de possuir título de Doutor com projetos de pesquisa e/ou orientações de Mestrado ou Doutorado na área da dor neonatal.

Solicitamos sua avaliação da proposta educacional com ênfase em itens como: navegação livre, clareza das informações, facilidade de localização das informações, pertinência, contextualização, correção do conteúdo, múltiplas janelas, facilidade de aprendizagem na interação, eficiência na utilização, facilidade de retorno, ergonomia, estética, uso de marcas especiais, utilização de recursos audiovisuais, referências, interatividade, gestão de erros, ajuda aos usuários, qualidade da informação e portabilidade.

Na possibilidade de participação, enviaremos informações para o acesso ao ambiente virtual, bem como o instrumento de avaliação, via e-mail, para a sua apreciação e preenchimento.

Comprometemo-nos a the fornecer todas as informações e esclarecimentos que o (a) $\mathrm{Sr}$ (a) desejar sobre a pesquisa e resultados durante ou após participação. Para tanto, forneço meu e-mail e telefone para contato: fernanda.felipe.silva@usp.br, (11) 999639325 e do Comitê de Ética em Pesquisa da Escola de Enfermagem da Universidade de São Paulo, telefone: (11) 30618855 e e-mail: cepee@usp.br.

$\mathrm{Na}$ expectativa de contarmos com a sua valiosa colaboração, aguardamos a sua manifestação e colocamo-nos à disposição para os esclarecimentos necessários.

Atenciosamente, 


\section{APÊNDICE B - Carta Convite aos Especialistas em Neonatologia}

Prezado (a) Senhor (a),

São Paulo, agosto de 2016.

Meu nome é Fernanda, sou enfermeira, estudante de Mestrado em Ciências da Saúde pelo Programa de Pós-Graduação em Enfermagem (PPGE) da Escola de Enfermagem da Universidade de São Paulo. Convido-o (a) a participar como Juiz (a) na avaliação de uma proposta educacional online, denominada Programa de Avaliação da Dor Neonatal - PADNeo, que visa qualificar profissionais e alunos da área da saúde a realizar a avaliação adequada da dor neonatal à beira leito. Esta pesquisa faz parte de um projeto coordenado pela Professora Doutora Mariana Bueno, docente da Escola de Enfermagem da Universidade de São Paulo, para desenvolvimento e implementação da plataforma educacional online, financiado pelo Conselho Nacional de Desenvolvimento Científico e Tecnológico (CNPq) e pela International Association for the Study of Pain (IASP).

Sua indicação deve-se ao fato de ser um (a) profissional na área da saúde com tempo mínimo de três anos na assistência neonatal e/ou possuir título de Mestre ou Doutor na área específica.

Solicitamos sua avaliação da proposta educacional com ênfase em itens como: navegação livre, clareza das informações, facilidade de localização das informações, pertinência, contextualização, correção do conteúdo, múltiplas janelas, facilidade de aprendizagem na interação, eficiência na utilização, facilidade de retorno, ergonomia, estética, uso de marcas especiais, utilização de recursos audiovisuais, referências, interatividade, gestão de erros, ajuda aos usuários, qualidade da informação e portabilidade.

Na possibilidade de participação, enviaremos informações para o acesso ao ambiente virtual, bem como o instrumento de avaliação, via e-mail, para a sua apreciação e preenchimento.

Comprometemo-nos a Ihe fornecer todas as informações e esclarecimentos que o (a) $\mathrm{Sr}$ (a) desejar sobre a pesquisa e resultados durante ou após participação. Para tanto, forneço meu e-mail e telefone para contato: fernanda.felipe.silva@usp.br, (11) 999639325 e do Comitê de Ética em Pesquisa da Escola de Enfermagem da Universidade de São Paulo, telefone: (11) 30618855 e e-mail: cepee@usp.br.

$\mathrm{Na}$ expectativa de contarmos com a sua valiosa colaboração, aguardamos a sua manifestação e colocamo-nos à disposição para os esclarecimentos necessários.

Atenciosamente,

Fernanda Felipe Ferreira da Silva

Pesquisadora 


\title{
APÊNDICE C - Carta Convite aos Especialistas em Educação a Distância
}

\author{
Prezado (a) Senhor (a),
}

São Paulo, agosto de 2016.

Meu nome é Fernanda, sou enfermeira, estudante de Mestrado em Ciências da Saúde pelo Programa de Pós-Graduação em Enfermagem (PPGE) da Escola de Enfermagem da Universidade de São Paulo. Convido-o (a) a participar como Juiz (a) na avaliação de uma proposta educacional online, denominada Programa de Avaliação da Dor Neonatal - PADNeo, que visa qualificar profissionais e alunos da área da saúde a realizar a avaliação adequada da dor neonatal à beira leito. Esta pesquisa faz parte de um projeto coordenado pela Professora Doutora Mariana Bueno, docente da Escola de Enfermagem da Universidade de São Paulo, para desenvolvimento e implementação da plataforma educacional online, financiado pelo Conselho Nacional de Desenvolvimento Científico e Tecnológico (CNPq) e pela International Association for the Study of Pain (IASP).

Sua indicação deve-se ao fato de possuir formação de nível superior na área de educação a distância ou título de Doutor com projetos de pesquisa e/ou orientações de Mestrado ou Doutorado na área específica.

Solicitamos sua avaliação da proposta educacional com ênfase em itens como: navegação livre, clareza das informações, facilidade de localização das informações, pertinência, contextualização, correção do conteúdo, múltiplas janelas, facilidade de aprendizagem na interação, eficiência na utilização, facilidade de retorno, ergonomia, estética, uso de marcas especiais, utilização de recursos audiovisuais, referências, interatividade, gestão de erros, ajuda aos usuários, qualidade da informação e portabilidade.

Na possibilidade de participação, enviaremos informações para o acesso ao ambiente virtual, bem como o instrumento de avaliação, via e-mail, para a sua apreciação e preenchimento.

Comprometemo-nos a Ihe fornecer todas as informações e esclarecimentos que o (a) $\mathrm{Sr}$ (a) desejar sobre a pesquisa e resultados durante ou após participação. Para tanto, forneço meu e-mail e telefone para contato: fernanda.felipe.silva@usp.br, (11) 999639325 e do Comitê de Ética em Pesquisa da Escola de Enfermagem da Universidade de São Paulo, telefone: (11) 30618855 e e-mail: cepee@usp.br.

$\mathrm{Na}$ expectativa de contarmos com a sua valiosa colaboração, aguardamos a sua manifestação e colocamo-nos à disposição para os esclarecimentos necessários.

Atenciosamente, 


\section{APÊNDICE D - Formulário de Avaliação do Programa de Avaliação da Dor Neonatal (PAD-Neo) por Especialistas}

Prezado(a) Senhor(a),

Eu, Fernanda Felipe Ferreira da Silva, sou responsável pela pesquisa "Programa de Avaliação da Dor Neonatal (PAD-Neo): Validação de conteúdo e de aparência de curso online", desenvolvida como aluna de Mestrado em Ciências da Saúde pelo Programa de Pós-Graduação em Enfermagem (PPGE) da Escola de Enfermagem da Universidade de São Paulo, sob orientação da Profa. Dra. Mariana Bueno.

O curso online será distribuído em dez módulos e é destinado a estudantes e profissionais da saúde como enfermeiros, médicos, fisioterapeutas, que estejam envolvidos nos cuidados com o recém-nascido. O curso está hospedado na plataforma Moodle $\AA^{\circledR}$ - Cursos de Extensão - STOA USP. Os objetivos educacionais são: aprimorar o conhecimento relacionado à dor e sua mensuração e avaliação no recém-nascido, aprimorar as habilidades do usuário no reconhecimento da dor no recém-nascido, capacitar o usuário na escolha e utilização de instrumentos de avaliação da dor neonatal de acordo com a idade gestacional e quadro clínico do recém-nascido, e possibilitar que o usuário avalie a dor no recém-nascido utilizando os diferentes instrumentos.

Nesta etapa solicitamos a sua participação para avaliação do curso, por meio do instrumento ora apresentado, baseado no proposto pela Coordenação Central de Educação a Distância - CCEAD - PUCRIO (Campos, Martins, Nunes, 2008) e adaptado por Tobase (2016). Para avaliar é necessário atender a um dos critérios estabelecidos:

- Título de Doutor e possuir projetos de pesquisa e/ou orientações de Mestrado ou Doutorado na área da dor neonatal;

- Profissionais de saúde atuantes na assistência neonatal por tempo mínimo de três anos, ou possuir título de Mestre ou Doutor na área específica;

- Formação de nível superior na área de educação a distância ou possuir título de Doutor e possuir projetos de pesquisa e/ou orientações de Mestrado ou Doutorado na área específica. 
Este instrumento é composto por 2 (duas) partes: caracterização de perfil e critérios de avaliação do curso.

Por favor, preencha os seus dados e responda às questões propostas.

No campo "Observações", escreva suas sugestões e comentários.

Salientamos que sua participação é muito importante e desde já agradecemos sua valiosa contribuição.

Comprometemo-nos a the fornecer todas as informações e esclarecimentos que o (a) Sr (a) desejar sobre a pesquisa e resultados durante ou após sua participação. Para tanto, forneço meu e-mail e telefone para contato fernanda.felipe.silva@usp.br, (11) 999639325 e do Comitê de Ética em Pesquisa da Escola de Enfermagem da Universidade de São Paulo, telefone: (11) 30618855 e e-mail: cepee@usp.br.

Fernanda Felipe Ferreira da Silva

Profa. Dra. Mariana Bueno

Escola de Enfermagem da Universidade de São Paulo

\section{Perfil do Avaliador}

Sexo: $\square$ Feminino $\square$ Masculino

Idade: _ anos

Formação Profissional:

Descreva resumidamente sua experiência profissional

Área, cargo/função e tempo de atuação:

Local de trabalho atual:

Cargo/Função atual: 


\section{Instrumento de Avaliação}

Instruções para avaliação: Em cada página, segue a descrição do aspecto a ser avaliado no curso, a escala de avaliação e uma caixa de comentários. Para o preenchimento, analise cada critério e indique um dos itens da escala (imagem abaixo):

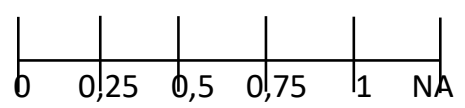

- Os valores variam entre $0-0,25-0,5-0,75-1$, onde 0 representa a avaliação mais negativa do critério e 1 a mais positiva;

- Assinale na escala, o valor que the parece melhor representar o grau com que o critério foi atingido;

- Ao considerar que o item não se aplica ao critério avaliado, assinale NA.

- Utilize o campo Comentários para expressar suas impressões e sugestões.

- Caso assinale valores: 0 ou 0,25 ou 0,5 por favor justifique em Comentários.

\section{Navegação Livre}

Permite a navegação livre, isto é, permite o controle da sequência de uso durante a utilização do software. Favorece a autonomia do usuário no uso dos comandos.

Avaliação: $\square 0,0 \square 0,25 \square 0,5 \square 0,75 \square$ 1,0 $\square$ NA

Comentários: 


\section{Clareza das Informações}

Enfoca apenas um conceito básico. É interessante que cada conceito seja abordado de maneira clara e, de preferência, em uma única janela, facilitando o entendimento das informações.

Avaliação: $\square 0,0 \square 0,25 \square 0,5 \square 0,75 \square 1,0 \square$ NA

Comentários:

\section{Facilidade de Localização das Informações}

Possui mecanismos que facilitam a localização da informação. É importante que o usuário tenha informação sobre o que existe no curso e como ele está organizado. Para isto é preciso que existam mecanismos que apresentem formas de localização tais como mapas globais, rota de aprendizagem, menu, glossário e outras guias.

Avaliação: $\square 0,0 \square 0,25 \square 0,5 \square 0,75 \square 1,0 \square$ NA

Comentários:

\section{Pertinência}

O conteúdo é apresentado de forma lógica. As formas de interação e navegação são rapidamente compreendidas.

Avaliação: $\square 0,0 \square 0,25 \square 0,5 \square 0,75 \square 1,0 \square$ NA

Comentários:

\section{Contextualização}

O conteúdo está adequado e coerente com a área e o nível de ensinos propostos.

Avaliação: $\square 0,0 \square 0,25 \square 0,5 \square 0,75 \square 1,0 \square$ NA

Comentários: 


\section{Correção de Conteúdo}

Avalia o rigor cientifico dos conhecimentos transmitidos.

Avaliação: $\square 0,0 \square 0,25 \square 0,5 \square 0,75 \square 1,0 \square$ NA

Comentários:

\section{Múltiplas Janelas}

Abre várias janelas simultaneamente, se necessário. Isto não é uma regra, pois a abertura de múltiplas janelas sobrepostas também pode confundir o leitor. Contudo, em certas situações torna-se interessante apresentar informações parcialmente sobrepostas.

Avaliação: $\square 0,0 \square 0,25 \square 0,5 \square 0,75 \square 1,0 \square$ NA

Comentários:

\section{Facilidade de Aprendizagem na Interação}

Permite compreender rapidamente a interação no software. A estrutura, o software e sua navegação devem ser de fácil entendimento pelo usuário.
Avaliação:
$0,0 \square$
0,25
0,5
0,75
$1,0 \square$
NA

Comentários:

\section{Eficiência de Utilização}

A navegação é simples, isto é, todas as informações e comandos apresentados são necessários para a utilização no curso.
Avaliação:
0,0
0,25
0,5
0,75
1,0
NA

Comentários: 


\section{Facilidade de Retorno}

Retorno fácil a localizações anteriores. Muitas vezes, durante a navegação pode ocorrer o caso em que o leitor decide seguir ligações que o conduzam a informações inesperadas e/ou indesejadas. Neste caso, o software deve possibilitar o retorno fácil. Avaliação: $\square 0,0 \square 0,25 \square 0,5 \square 0,75 \square 1,0 \square$ NA

Comentários:

\section{Ergonomia}

Manutenção da interação e da apresentação de forma uniforme em todas as telas. A uniformidade dos recursos utilizados na navegação (ex.: botões e ícones localizados sempre na mesma posição) permite ao usuário uma familiarização de forma mais eficiente.

Avaliação: $\square 0,0 \square 0,25 \square 0,5 \square 0,75 \square 1,0 \square$ NA

Comentários:

\section{Estética}

O objeto possui padrões de interface adequados ao conteúdo.

Avaliação: $\square 0,0 \square 0,25 \square 0,5 \square 0,75 \square 1,0 \square$ NA

Comentários: 


\section{Uso de Marcas Especiais}

Utilização de marcas especiais como cores, molduras e outras para facilitar o reconhecimento do contexto em que se encontra. É interessante que, ao mudar de contexto durante a navegação pelo curso, o leitor receba indicações visuais a respeito do ponto em que se encontra, facilitando a sua orientação.

Avaliação: $\square 0,0 \square 0,25 \square 0,5 \square 0,75 \square 1,0 \square$ NA

Comentários:

\section{Utilização de Recursos Audiovisuais}

Apresenta recursos audiovisuais de forma adequada.

Avaliação: $\square 0,0 \square 0,25 \square 0,5 \square 0,75 \square 1,0 \square$ NA

Comentários:

\section{Referências}

Apresentação das fontes de seu conteúdo e das informações de seu autor.

Avaliação: $\square 0,0 \square 0,25 \square 0,5 \square 0,75 \square 1,0 \square$ NA

Comentários:

\section{Interatividade}

Interação com o software. Há evidências de que o aluno aprende mais quando participa ativamente do processo de aprendizado, e não fica apenas passivamente recebendo informações.

Avaliação: $\square 0,0 \square 0,25 \square 0,5 \square 0,75 \square 1,0 \square$ NA

Comentários: 


\section{Gestão de Erros}

Avalia os mecanismos que permitem evitar ou reduzir a ocorrência de erros, e quando eles ocorrem, estes mecanismos devem favorecer a sua correção. Inclui proteção contra erros, qualidade das mensagens de erro e correção dos erros e reversão fácil das ações.

Avaliação: $\square \quad 0,0 \square 0,25 \square 0,5 \square \quad 0,75 \square \quad 1,0 \square$ NA

Comentários:

\section{Ajuda aos Usuários}

Avalia a disponibilidade de auxílio. Há recursos de auxílio ao usuário.

Avaliação: $\square \quad 0,0 \square 0,25 \square 0,5 \square 0,75 \square \quad \square \quad \square \quad \square$ NA

Comentários:

\section{Qualidade da Informação}

Avalia conteúdos corretos, fontes fidedignas, vocabulário adequado ao público, carga informacional (quantidade de informação) compatível.

Avaliação: $\square \quad 0,0 \square 0,25 \square 0,5 \square 0,75 \square \quad 1,0 \square$ NA

Comentários:

\section{Portabilidade}

Funcionamento adequado em diferentes browsers.
Avaliação:
0,0
0,25
$0,5 \square$
0,75
1,0
NA

Comentários: 
Acrexas 


\section{Anexo 1}

\section{Parecer Consubstanciado do Conselho de Ética em Pesquisa}

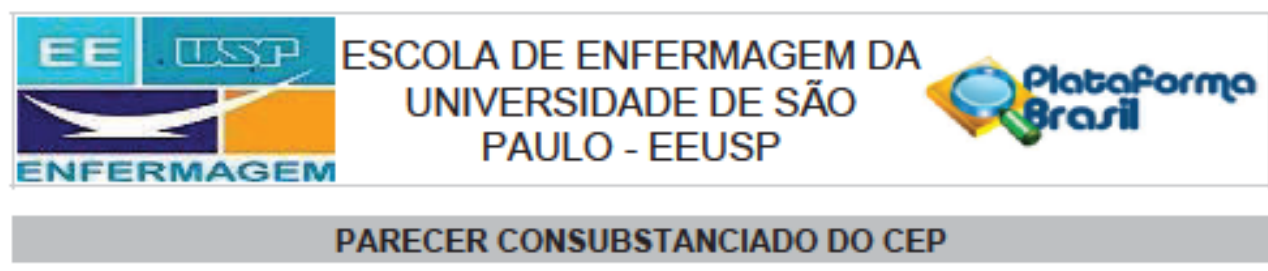

\section{DADOS DA EMENDA}

Título da Pesquisa: Programa de Avaliação da Dor Neonatal II: desenvolvimento e avaliaçäo de proposta educacional online sob a perspectiva de especialistas e de usuários.

Pesquisador: MARIANA BUENO

Área Temática:

Versäo: 3

CAAE: 41048915.8 .0000 .5392

Instituição Proponente: Escola de Enfermagem da Universidade de São Paulo - EEUSP

Patrocinador Principal: CNPQ

\section{DADOS DO PARECER}

Número do Parecer: 1.596.346

Apresentação do Projeto:

Está pesquisa pretende desenvolver o PAD-Neo II e conduzir avaliação da proposta educacional online por especialistas em tecnologia da informação, enfermagem neonatal/pediátrica e educaçäo em enfermagem e conduzir avaliaçäo do curso por usuários, estes graduandos em enfermagem e profissionais residentes de um programa multiprofissional em neonatologia. A equipe de pesquisa é composta por docentes de diferentes instituiçöes nacionais de ensino superior e pesquisa (Escola de Enfermagem da Universidade Federal de Minas Gerais, Escola de Enfermagem da Universidade de Säo Paulo, Faculdade de Enfermagem da Universidade Federal de Goiás, Hospital Sofia Feldman) e os integrantes possuem conhecimento consolidado nas temáticas assistência neonatal, dor no recém-nascido e educação em enfermagem. As pesquisadoras canadenses (University of Toronto e University of Ottawa) que compöem a equipe säo amplamente experientes na temática dor em recém-nascidos e crianças e em transferència do conhecimento, e contribuirão nos aspectos teóricos e na organização geral da proposta educacional.

Objetivo da Pesquisa:

Elaborar uma proposta educacional online sobre avaliação da dor no recém-nascido, denominada Programa de Avaliação da Dor Neonatal II (PADNeo II)

Endereço: Av. Dr Eneas de Carvalho Agular, 419

Bairro: Cerquelra Cesar

CEP: $05.403-000$

Telefone: (11)3061-8858

E-mall: cepeegusp.br 


\section{EE DSTP
ENFERMAGEM DE ENFERMAGEM DA
UNIVRSIDADE DE SÄO
PAULO - EEUSP}

Continuaçbo do Parecer: 1.596346

\section{Avaliação dos Riscos e Benefícios:}

Para a pesquisadora, os riscos envolvem possíveis desconfortos que os especialistas e/ou usuários possam apresentar mediante os videos e fotos de recém-nascidos submetidos a procedimentos dolorosos.

Os Benefícios apontados pela pesquisadora são de oferecer cuidado humanizado, atraumático e favorecedor do desenvolvimento é essencial ao recém-nascido. Dessa forma, o adequado controle da dor deve ser uma premissa no cuidado neonatal. E aponta como um recurso de extrema importância em um país de vasta extensão territorial. E que futuramente, usuários de diversas localidades poderão se beneficiar do curso.

\section{Comentários e Consideraçőes sobre a Pesquisa:}

Foi realizada a apreciação da carta convite aos especialistas e do novo formulário, ambos solicitados e apresentados pela pesquisadora, assim como as modificaçöes realizadas no corpo projeto de pesquisa. Todos os documentos apresentados encontram-se dentro dos padröes exigidos de clareza, e de acordo com os objetivos propostos para o projeto.

Consideraçöes sobre os Termos de apresentação obrigatória:

Todos os termos de apresentação obrigatória foram devidamente apresentados.

Recomendaçöes:

Não há.

Conclusőes ou Pendências e Lista de Inadequaçöes:

Não há.

Consideraçöes Finais a critério do CEP:

- Este CEP informa a necessidade de registro dos resultados parciais e finais na Plataforma Brasil;

- Esta aprovação näo substitui a autorização da instituição coparticipante, antes do início da coleta de dados.

Este parecer foi elaborado baseado nos documentos abaixo relacionados:

\begin{tabular}{|l|c|c|c|c|}
\hline \multicolumn{1}{|c|}{ Tipo Documento } & Arquivo & Postagem & Autor & Situação \\
\hline $\begin{array}{l}\text { Informações Básicas } \\
\text { do Projeto }\end{array}$ & $\begin{array}{c}\text { PB_INFORMAÇŌES_BÁSICAS_716685 } \\
\text { E2_pdf }\end{array}$ & $\begin{array}{c}30 / 05 / 2016 \\
22: 15: 53\end{array}$ & & Aceito \\
\hline
\end{tabular}

Endereço: Av. Dr Eneas de Carvalho Agular, 419

Bairro: Cerquelra Cesar
UF: SP $\quad$ Municlplo: SAO PAULO CEP: $05.403-000$

Telefone: (11)3051-8859

E-mall: cepeegusp.br 


\section{EE ESTP
ENFERA DE ENFERMAGEM DA
UNIVERSIDADE DE SÄO
PAULO - EEUSP}

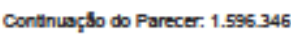

\begin{tabular}{|l|l|c|l|c|}
\hline TCLE / Termos de & CartaConvite_FormulariodeAvaliacao.do & $\begin{array}{c}30 / 05 / 2016 \\
22: 11: 13\end{array}$ & MARIANA BUENO & Aceito \\
$\begin{array}{l}\text { Assentimento / } \\
\text { Justificativa de } \\
\text { Ausência }\end{array}$ & cx & & & \\
\hline Projeto Detalhado $/$ & $\begin{array}{l}\text { Emenda3_Universal_2014_MBueno_Pro } \\
\text { jetodePesquisa.doc }\end{array}$ & $\begin{array}{c}24 / 05 / 2016 \\
11: 21: 30\end{array}$ & MARIANA BUENO & Aceito \\
lnvestigador & Folha de Rosto.pdf & $16 / 01 / 2015$ & & Aceito \\
\hline Folha de Rosto & & $17: 01: 29$ & & \\
\hline
\end{tabular}

Situação do Parecer:

Aprovado

Necessita Apreciaçäo da CONEP:

Näo

SAO PAULO, 16 de Junho de 2016

Assinado por:

Lisabelle Mariano Rossato

(Coordenador)

Endereço: Av. Dr Eneas de Carvalho Agular, 419 